\title{
Parent and sibling relationship influences on late adolescent social anxiety and other adjustment outcomes
}

\author{
Catherine Joan Massey \\ West Virginia University
}

Follow this and additional works at: https://researchrepository.wvu.edu/etd

\section{Recommended Citation}

Massey, Catherine Joan, "Parent and sibling relationship influences on late adolescent social anxiety and other adjustment outcomes" (2000). Graduate Theses, Dissertations, and Problem Reports. 1182.

https://researchrepository.wvu.edu/etd/1182

This Dissertation is protected by copyright and/or related rights. It has been brought to you by the The Research Repository @ WVU with permission from the rights-holder(s). You are free to use this Dissertation in any way that is permitted by the copyright and related rights legislation that applies to your use. For other uses you must obtain permission from the rights-holder(s) directly, unless additional rights are indicated by a Creative Commons license in the record and/ or on the work itself. This Dissertation has been accepted for inclusion in WVU Graduate Theses, Dissertations, and Problem Reports collection by an authorized administrator of The Research Repository @ WVU.

For more information, please contact researchrepository@mail.wvu.edu. 
Parent and Sibling Relationship Influences

on Late Adolescent Social Anxiety and Other Adjustment Outcomes

Catherine J. Massey

Dissertation Submitted to

The Eberly College of Arts and Sciences

at West Virginia University

in partial fulfillment of the requirements

for the degree of

Doctor of Philosophy

in

Life-Span Developmental Psychology

Tracy L. Morris, Ph.D., Chair

Martin L. Boone, Ph.D.

Stanley H. Cohen, Ph.D.

Daniel W. McNeil, Ph.D.

JoNell Strough, Ph.D.

Department of Psychology

Morgantown, West Virginia

2000

Keywords: Parenting, Siblings, Social Anxiety, Developmental Psychopatholoy Copyright 2000, Catherine J. Massey 


\begin{abstract}
Parent and Sibling Relationship Influences

on Late Adolescent Social Anxiety and Other Adjustment Outcomes
\end{abstract}

Catherine J. Massey

The primary objective of the present study was to examine associations among several family relationships and adolescent social anxiety utilizing a family systems perspective. The second objective was to investigate specific family relationships and their association with adolescent adjustment outcomes such as depression, general anxiety, global self-worth, and social acceptance self-worth. Social anxiety levels of only children and children with siblings also were compared. Five-hundred and fifteen (337 females, 178 males) participants in late adolescence completed a questionnaire packet according to whether or not they had siblings. The questionnaire packets contained all or most of the following measures depending on number of siblings: (1) a demographic questionnaire; (2) the Parental Bonding Instrument (Parker, Tupling, \& Brown, 1979); (3) the Network of Relationships Inventory (Furman \& Buhrmester, 1985); (4) the Inventory of Family Experiences (Barrett Singer \& Weinstein, 1986); (5) the Beck Anxiety Inventory (Beck, Epstein, Brown, \& Steer, 1988); (6) the Beck Depression Inventory - II (Beck, Steer, \& Brown, 1996); (7) the Social Phobia and Anxiety Inventory (Turner, Beidel, Dancu, \& Stanley, 1989); and (8) the Self-Perception Profile for College Students (Neeman \& Harter, 1986). Results showed that perceived optimal maternal parenting (high care/low control) and perceived optimal parenting by both parents were related to low levels of social anxiety, depression, and general anxiety and high levels of global and social acceptance self-worth. Perceptions of positive sibling relationships (high social support/low negativity) were associated with low levels of social anxiety and depression and high levels of global and social acceptance self-worth. Furthermore, better adjustment outcomes were reported by adolescents who reported no parental favoritism than for adolescents who reported that they were favored by one parent and unfavored by the other parent or that they were unfavored by both. In addition, favored adolescents reported better adjustment outcomes than unfavored adolescents No differences were found in social anxiety levels between only children and children with siblings. Furthermore, no gender differences were found in relation to family relationships and late adolescent adjustment. 


\section{ACKNOWLEDGEMENTS}

I would like to extend my appreciation to my chairperson, Tracy Morris, for her excellent guidance and support. I also would like to thank my committee members, Marty Boone, Stan Cohen, Dan McNeil, and JoNell Stough, for their helpful comments and suggestions. I could not have had a better dissertation committee.

I also would like to thank my friends, especially Debra McKee and Robin Bartlett, for their encouraging words and support. Lastly, I send my sincerest thanks to my husband, Ron, my Mother, Father, and siblings. They provide me with so much love and support that I could not have accomplished what I have without these wonderful people in my life. 


\section{TABLE OF CONTENTS}

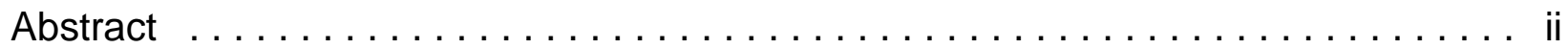

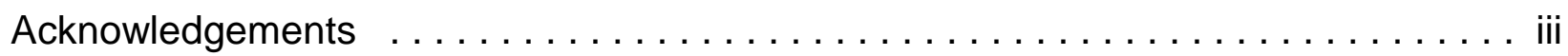

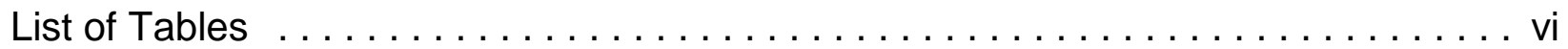

List of Figures $\ldots \ldots \ldots \ldots \ldots \ldots \ldots \ldots \ldots \ldots \ldots \ldots \ldots \ldots \ldots \ldots \ldots \ldots \ldots \ldots$

Introduction and Literature review $\ldots \ldots \ldots \ldots \ldots \ldots \ldots \ldots \ldots \ldots \ldots \ldots \ldots \ldots \ldots$

Definition of social anxiety and its characteristics $\ldots \ldots \ldots \ldots \ldots \ldots$

Etiology of social anxiety $\ldots \ldots \ldots \ldots \ldots \ldots \ldots \ldots \ldots \ldots \ldots \ldots \ldots \ldots \ldots$

Correlates of social anxiety $\ldots \ldots \ldots \ldots \ldots \ldots \ldots \ldots \ldots \ldots \ldots$

What is adolescent adjustment? $\ldots \ldots \ldots \ldots \ldots \ldots \ldots \ldots \ldots \ldots \ldots 8$

Influence of the parent-adolescent relationship on adolescent adjustment and social anxiety $\ldots \ldots \ldots \ldots \ldots \ldots \ldots \ldots \ldots \ldots \ldots \ldots$

Influence of the parent-sibling relationship on adolescent adjustment $\ldots \ldots 11$

Influence of the sibling-adolescent relationship on adolescent adjustment

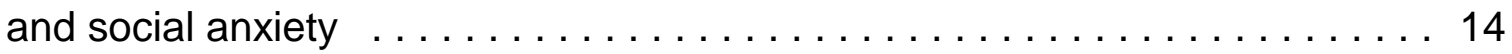

Gender differences, family relationships, and adolescent adjustment . . . . 16

Child resiliency and protective factors $\ldots \ldots \ldots \ldots \ldots \ldots \ldots \ldots \ldots$

Issues of retrospective research $\ldots \ldots \ldots \ldots \ldots \ldots \ldots \ldots \ldots \ldots$

Statement of the problem and hypotheses $\ldots \ldots \ldots \ldots \ldots \ldots \ldots \ldots \ldots \ldots$

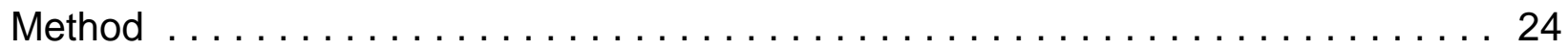

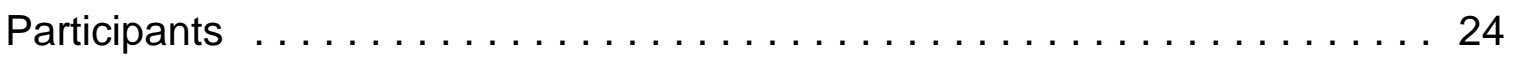

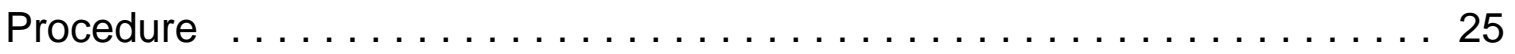




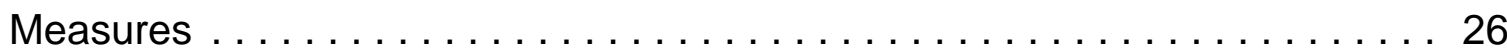

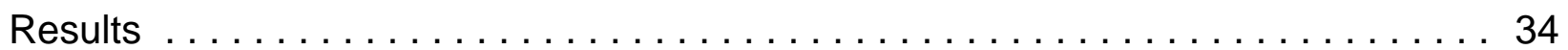

Intercorrelations of the measured variables for only children $\ldots \ldots \ldots \ldots 35$

Intercorrelations of the measured variables for adolescents with siblings . . . 35

Gender differences for outcome variables . . . . . . . . . . . . . . 39

Adolescent adjustment outcomes and family relationships $\ldots \ldots \ldots \ldots .40$

Social anxiety in only children and children with siblings $\ldots \ldots \ldots \ldots \ldots 50$

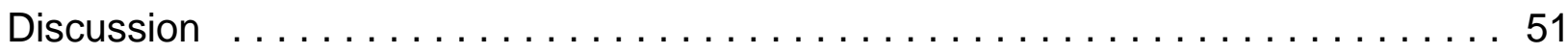

Adolescent adjustment outcomes and family relationships $\ldots \ldots \ldots \ldots 51$

Social anxiety in only children and children with siblings $\ldots \ldots \ldots \ldots \ldots 59$

General conclusions $\ldots \ldots \ldots \ldots \ldots \ldots \ldots \ldots \ldots \ldots \ldots \ldots$

Theoretical implications ..................... 59

Limitations of the present study $\ldots \ldots \ldots \ldots \ldots \ldots \ldots \ldots$

Suggestions for future research $\ldots \ldots \ldots \ldots \ldots \ldots \ldots \ldots$

Conclusion $\ldots \ldots \ldots \ldots \ldots \ldots \ldots \ldots \ldots \ldots \ldots \ldots \ldots \ldots \ldots \ldots \ldots \ldots$

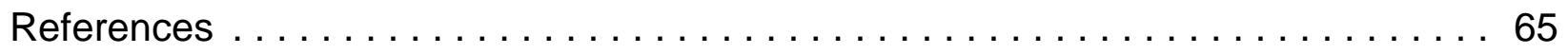

Appendix ................................... 119

Demographic questionnaire . . . . . . . . . . . . . . . . . 119 


\section{LIST OF TABLES}

Table

1. Descriptive statistics for additional demographic variables $\ldots \ldots \ldots \ldots \ldots \ldots 79$

2. Descriptive statistics for measured variables $\ldots \ldots \ldots \ldots \ldots \ldots \ldots \ldots \ldots$

3. Descriptive statistics for the categorical variables $\ldots \ldots \ldots \ldots \ldots$. $\ldots$.

4. Intercorrelations for the measured variables for only children . . . . . . . . . 102

5. Intercorrelations for the measured variables for adolescents with sibling(s) . . 105

6. Means and standard deviations for late adolescent adjustment outcomes

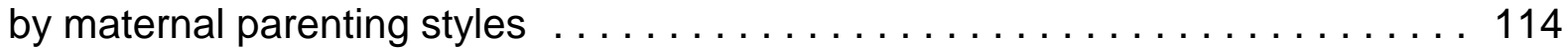

7. Means and standard deviations for late adolescent adjustment outcomes

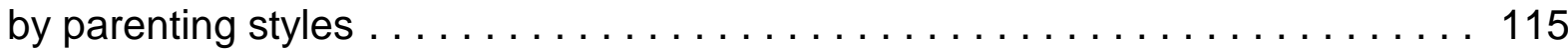

8. Means and standard deviations for late adolescent adjustment outcomes

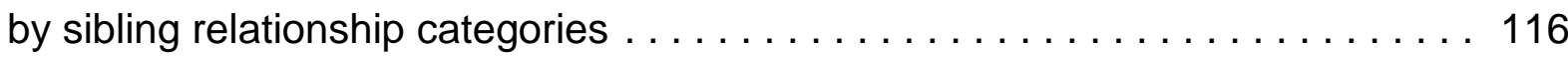

9. Means and standard deviations for late adolescent adjustment outcomes by parental favoritism categories $\ldots \ldots \ldots \ldots \ldots \ldots \ldots \ldots \ldots \ldots \ldots \ldots \ldots$

10. Means and standard deviations for late adolescent adjustment outcomes by family relationship variables 


\section{LIST OF FIGURES}

Figure

1. Interrelationships within the family system $\ldots \ldots \ldots \ldots \ldots \ldots \ldots \ldots$

vii 


\section{Parent and Sibling Relationship Influences}

on Late Adolescent Social Anxiety and Other Adjustment Outcomes

The main focus of the present study was to examine several family relationships and their association to social anxiety. Sullivan (1953) asserted that positive family relationships are vital to healthy social and personality development. A psychologically healthy family provides the love and support needed by its members to promote optimal functioning (Schuster \& Ashburn, 1992). Each relationship subsystem (e.g., parental, parent-child, sibling) within the family affects and reflects the entire system (Sroufe \& Fleeson, 1988). A dysfunctional relationship in one subsystem can negatively affect other family subsystems. This perspective follows the family systems model (see Figure 1). Minuchin (1985) asserts that "if an individual is part of an organized family system, he or she is never truly independent and can only be understood in context" ( $p$. 290). Each member is part of an interdependent network in which the behavior of one member influences other individuals within the family.

Family relationship subsystems have been shown to be associated with adolescent adjustment. Massey (1999) found associations between reported social support from several family relationships (i.e., parent-adolescent, parent-sibling, and sibling) and adolescent internalizing behaviors (e.g., withdrawal, anxiety) and selfconcept. Other studies have shown that the quality of the parent-adolescent relationship has been associated with adolescent self-esteem (Rice, 1990), depression (Seelig \& Brandon, 1997), antisocial behavior (Sim \& Vuchinich, 1996), and late adolescent social anxiety (Anhalt, 1999; Warren, Huston, Egeland, \& Sroufe, 1997) . 
Similar to Massey's (1999) findings, previous research has shown that the quality of the sibling relationship is related to preadolescent depression and anxiety (Epkins, Whitehead, Bounds, \& Frey, 1997), and young adult self-esteem and social competence (Caya \& Liem, 1998). Furthermore, perceived parental favoritism has been linked to negative sibling relationships (Boer, Goedhart, \& Treffers, 1992; Kowal \& Kramer, 1997) which, in turn, may affect adjustment outcomes. For instance, O'Connor, Hetherington, and Reiss (1998) reported that parental favoritism was positively related to depression and antisocial behavior for the unfavored adolescent. In their sample, the sibling relationship also was rated as negative by the adolescents. Another study found that parental favoritism was not only correlated with adolescent adjustment such as internalizing and externalizing (e.g., acting out, fighting) behaviors and self-concept, but also was negatively associated with perceived social support from the parent and sibling (Massey, 1999). Therefore, parental favoritism may affect adjustment outcomes directly by making the unfavored adolescent feel unwanted or, if favored, anxious to please the parent. Parental favoritism also may influence the adolescent indirectly by reducing the number of social support resources available.

In summary, the quality of the parent-adolescent relationship has been linked to social anxiety, but parental favoritism and the sibling relationship have been relatively overlooked in the social anxiety literature. Examining these family relationships is especially important given that adolescence is the most anxious period of development because of new social roles and situations (e.g., dating, impending adulthood; Leary \& Kowalski, 1995). Therefore, in the proposed study, social anxiety and other adjustment outcomes (i.e., depression, general anxiety, global and social acceptance self-worth) 
are examined in relation to the parent-adolescent, parent-sibling, and sibling relationships.

\section{Definition of Social Anxiety and Its Characteristics}

Social anxiety is defined as a fear of interpersonal evaluation in social situations (Schlenker \& Leary, 1982). That is, social anxiety tends to occur when an individual is concerned about what other persons think of him or her. The social event that causes anxiety can be presently occurring or an imagined social interaction that may or may not arise. Social anxiety influences psychological processes including the affective, behavioral, cognitive, and somatic domains (Leary \& Kowalski, 1995). Individuals who experience social anxiety may have feelings of nervousness, depression, and hopelessness and may escape these feelings by avoiding or withdrawing from anxiety provoking situations. Their cognitive processes in social situations tend to be negative. For instance, they may think that they will say something stupid in a social encounter. These individuals, when faced with an anxiety provoking social situation, also may experience somatic symptoms such as increased heart rate, perspiration, and nausea.

There are a variety of social situations that may provoke social anxiety. Holt, Heimberg, Hope, and Liebowitz (1992) assert that there are four situational domains of social anxiety. First, and probably the most anxiety provoking, is formal speaking and interaction. These social situations may include giving a speech in front of an audience, acting, and small group membership. The second situational domain is informal speaking and interaction. This domain may include going to a party and calling or speaking to someone you do not know very well. Assertive interaction is the third situational domain. Speaking to authority figures and expressing disagreement are 
included in assertive interaction. The last situational domain is behavior observation, which may consist of social anxiety provoked by working, writing, or eating while being watched. Fear of negative evaluation is one common feature of these four situational domains of social anxiety (Holt et al., 1992).

There are basically two types of social anxiety, anticipatory and reactive (Leary \& Kowalski, 1995). Anxiety that precedes a social event is known as anticipatory. Thinking about interacting with people at an upcoming party may invoke feelings of anxiety. On the other hand, reactive social anxiety occurs when a social event has already taken place. A speaker who makes a mistake while giving his or her speech may react with feelings of anxiety. Reactive social anxiety is often referred to as embarrassment. Anticipatory is the most common form of social anxiety (Leary \& Kowalski, 1995).

Social anxiety differs in both frequency and intensity across individuals (Leary \& Kowalski, 1995). Some individuals are relatively unaffected by social encounters and experience little or no anxiety, whereas others may have life-impeding social anxiety or social phobia. Most individuals, however, fall between the two extremes.

Both self-presentational concerns and the context of the situation (Gilbert \& Trower, 1990; Schlenker \& Leary, 1982) contribute to individual differences in social anxiety. First, people differ on the importance placed on positive evaluations from others and whether they feel they will succeed in attaining those favorable evaluations. Those who stress the importance of a positive evaluation and are unsure whether they can attain a favorable one tend to experience high levels of social anxiety. Conversely, those individuals who are confident that they will attain a positive evaluation or have 
little or no concern about what others think of them will experience little or no anxiety (Goldfried \& Sobocinski, 1975). Secondly, the context in which the social situation occurs tends to influence the level of social anxiety (Gilbert \& Trower, 1990). An individual ordinarily comfortable talking with his or her supervisor may experience social anxiety when talking to the same supervisor during job evaluations. In another example, an individual may not have feelings of social anxiety when they interact with the same sex, but experience anxiety in the presence of the opposite sex. This anxiety may be even more heightened when dating concerns are present. Leary and Kowalski (1995) assert that males may be less socially anxious than females when it comes to interacting with members of the opposite sex. However, the data have been inconsistent when it comes to gender differences in social anxiety. Some studies have found gender differences in social anxiety or shyness (Leary \& Dobbins, 1983; Pilkonis, 1977), whereas others have not (Anhalt, 1999; Hansford \& Hattie, 1982).

According to Buss (1980), socially anxious behaviors do not appear until a child has sufficient ability to take another's perspective in viewing the self. Infants may show anxiety in certain social situations (e.g., strangers present), but this behavior does not constitute social anxiety. These early reactions in social situations tend to be an innate reaction. However, these innate reactions or biological dispositions may have a tendency to carry-over into childhood and adolescence (Kagan, Reznick, \& Snidman, 1988), thus influencing sociability. It is not until age four or five when true socially anxious behaviors are manifested (Buss, 1980). Social anxiety then tends to increase with age with adolescence being the most anxious period of development (Leary \& Kowalski, 1995). Adolescents encounter rapid physical growth and new social roles 
and situations (e.g., dating, impending adulthood) that can increase self-consciousness and anxiety levels. In fact, the average age of onset for social anxiety disorder is middle adolescence (Beidel, 1998).

\section{Etiology of Social Anxiety}

Behavioral, biological, and family factors have been implicated in the development of social anxiety (Beidel, 1998; Morris, in press). Behavioral antecedents of social anxiety include direct conditioning, observational learning, and information transfer. Fifty-percent of individuals diagnosed with social anxiety disorder developed it by direct conditioning (Beidel, 1998; Stemberger, Turner, Beidel, \& Calhoun, 1995). That is, they experienced a traumatic event in which they were humiliated or embarrassed in the presence of other people. Social anxiety may also develop through observational learning or by witnessing a socially traumatic event.

Information transfer is related to family factors associated with social anxiety disorder. Information transfer includes consistent criticism by others (e.g., parents) that your behavior is unacceptable (Beidel \& Turner, 1998). In fact, Morris and Huffman (1998) contend that family processes such as the interaction between the parent and child may indirectly influence the level of social anxiety by affecting the child's social skills and performance inhibitions. Several studies have linked the quality of the parentchild relationship to child social anxiety levels (for review see Masia \& Morris, 1998). Another family factor that may influence a person's level of social anxiety is the level of parental social anxiety. Parental social anxiety may inhibit the child's exposure to social interactions thus reducing the opportunities to develop social skills (Beidel \& Turner, 1998; Daniels \& Plomin, 1985a; Masia \& Morris, 1998). 
Lastly, there is evidence to suggest a biological component of social anxiety. An interesting study conducted by Fyer, Manuzza, Chapman, Liebowitz and Klein (1993) found that individuals who had a relative diagnosed with social anxiety disorder were three times more likely to develop social anxiety disorder than normal controls. Thus, evidence suggests that there may be a predisposition or genetic component to the development of social anxiety. It is important to mention, however, that the environment and biological make up of an individual interact in such a way that having a predisposition for social anxiety does not infer that he or she will develop social anxiety disorder. An individual's environment may foster sociability and thus reduce the risk of social anxiety (Fyer et al., 1993).

Correlates of Social Anxiety

Social anxiety often is related to other adjustment outcomes such as general anxiety, depression, loneliness, and self-esteem. Individuals who are socially anxious are more likely to have low self-esteem and to experience depression, loneliness, and general anxiety than those who are low in social anxiety (Inderbitzen-Pisaruk, Clark, \& Solano, 1992; Leary, 1990; Moore \& Schultz, 1983; Rubin, 1993; Schmidt \& Fox, 1995). These adjustment outcomes often are labeled as internalizing behaviors and have been linked to the quality of various family relationships such as the parent-child and sibling relationships (Massey, 1999). In fact, researchers assert that the quality of the parentchild, peer, and sibling relationships may be possible causes of social anxiety or shyness (Asendorpf, 1986; Conger, Conger, \& Scaramella, 1997; Morris \& Huffman, 1998; Warren et al., 1997). Parent-adolescent, parent-sibling, and sibling relationships are the focus of the proposed study. 


\section{What is Adolescent Adjustment?}

Adjustment is a multifaceted term used to characterize healthy psychological functioning. Adolescents who are well adjusted are able to function effectively in their environment, whereas adolescents with adjustment problems often exhibit maladaptive behaviors such as aggression, antisocial behavior, anxiety, and depression. Adolescent adjustment may be influenced by many family subsystems such as the parent-adolescent relationship, parent-sibling relationship, and the sibling relationship. Influence of the Parent-Adolescent Relationship on

\section{Adolescent Adjustment and Social Anxiety}

A positive parent-adolescent relationship is essential for healthy adolescent adjustment (Sullivan, 1953). Attachment is a good example of the importance of parent-child relationships. In a longitudinal study by Warren et al. (1997), children who were anxiously attached to their mother at 12 months of age were more likely to develop child and late adolescent anxiety disorders than avoidant or securely attached children. An association between attachment and self-esteem also has been found. Rice (1990) reported that securely attached adolescents tended to have higher selfesteem than insecurely attached adolescents. In addition, early attachment relationships tend to carry-over and affect intimate relationships in adulthood (Hazan \& Shaver, 1987; Kamptner, Wang, \& Cusick, 1997).

A positive parent-adolescent relationship provides the much-needed support during the difficult developmental period of adolescence (Schuster \& Ashburn, 1992). In fact, Sim and Vuchinich (1996) suggest that family stressors are most influential during adolescence. In their longitudinal study investigating parent-child relationships in 
association to antisocial behavior spanning from childhood to adulthood, they found that disengaged parent-adolescent relationships led to higher levels of antisocial behavior than disengaged parent-child or parent-adult relationships.

Studies have shown that developmental outcomes such as depression, selfesteem, and social anxiety are related to the quality of the parent-child relationship. Stocker (1994) reported that maternal warmth was negatively associated with loneliness in second-grade children. Similar results were found in studies examining parentadolescent relationships. Perceived parental social support was inversely related to adolescent internalizing behaviors (Massey, 1999) and depression (Seelig \& Brandon, 1997), and positively associated with parental hostility (Harold \& Conger, 1997). Anhalt (1999) reported that late adolescent depression was lower for individuals who perceived high parental care and low control, and higher for individuals who perceived low parental care and high control. Similar results were found by Morris and Huffman (1998). Specifically, adolescents who perceived that their parents were high in care and low in control reported lower levels of depression than adolescents who perceived that their parents were low in care and high in control. The negative effects of poor parenting during childhood and adolescence continue into young adulthood. Young adults tended to report depressive symptoms when they perceived their parents as showing inconsistent warmth and affection (Schwartz \& Zuroff, 1979). In addition, Parker (1983a) found that depressives reported both parents as more controlling and less warm than participants in a control group.

Self-esteem also has been investigated in relation to parent-adolescent relationships. Adolescence is the developmental period in which an individual's self- 
esteem is fragile and his or her identity takes shape (Erikson, 1968). It is during this period that social support from loved ones is most crucial. In fact, adolescents tended to link their sense of self to how they perceived behaviors directed toward them from friends and loved ones (Harter, 1987; Rosenberg, 1979). Massey (1999) reported that perceived parental social support was positively associated with adolescent selfconcept. Parental intrusiveness and warmth also have been shown to be related to adolescent and young adult self-esteem. Conger et al. (1997) found that early adolescent self-esteem was likely to be lower when parents were perceived as controlling. On the other hand, self-esteem in young adulthood tended to be higher when parents were perceived as warm and affectionate (Parish \& McCluskey, 1994).

Another component of adjustment that is influenced by the parent-adolescent relationship is social anxiety. It appears that parental support may be related to their childrens' level of social anxiety (Bruch \& Cheek, 1995; Parker \& Gladstone, 1996). Warren et al. (1997) reported that children who were anxiously attached to their mother at 12 months of age tended to develop child or late adolescent anxiety disorders with social phobia being the most prevalent. Studies that have examined parent-child relationships in late adolescence found that adolescents who perceived their parents as high in care and low in control were low in social anxiety (Anhalt, 1999; Morris \& Huffman, 1998). Anhalt also found similar differences between these parenting characteristics and general anxiety. Lastly, a study that examined family relationships and social competence in late adolescence found that social competence was predicted by parental relationships but varied by gender (Bell, Avery, Jenkins, Feld, \& Schoenrock, 1985). Males and females were more socially competent when they were 
close to their father, but female social competence also was predicted by low parental intrusiveness and contentment at home. This trend continues into young adulthood. In a retrospective study by Parker (1979a), adults with social phobia reported less parental warmth and more parental overprotection than the control group. Similar results were found in a college sample where high and low socially anxious groups were compared (Klonsky, Dutton, Liebel, 1990). These findings would indicate that parents who are responsive and supportive to their children tend to promote child sociability; whereas, rejecting and unsupportive parents may foster socially anxious children. Influence of the Parent-Sibling Relationship on Adolescent Adjustment

In general, children are extremely sensitive to and aware of how they are treated relative to their siblings (Dunn, 1988). Parental differential treatment is very distressing to children, particularly when it involves maternal behavior. The more the mother differentially treats her children the more conflict is likely to occur between siblings (Furman, 1995). Research examining early sibling relationships reveals that positive maternal behaviors (e.g., close, playful, affectionate behaviors) shown toward the second-born child tend to foster negative behaviors (e.g., hitting) from the first-born toward the younger sibling (Dunn, 1988). These negative behaviors were especially prevalent if the mother and first-born were close before the second child's birth. It is important to note that the more dissimilar the parent's treatment of the siblings, the more negative the sibling relationship tends to be (Boer et al., 1992).

There is disagreement between parents' perceptions of equality in parenting their children and adolescents' perceptions of their parents impartiality (Boer et al., 1992). Parents tend to feel they are fair in how they parent one child relative to another, 
whereas some adolescents' perceive that their parents have a favorite child. In fact, studies that examined parental favoritism revealed that 50 to 68 percent of the participants' perceived that favoritism exists in their families (Harris \& Howard, 1985; Kiracofe \& Kiracofe, 1990). Furthermore, those who perceived themselves as being the favored child tended to identify the opposite-sex parent as the partisan. This finding occurred regardless of birth order except for the oldest children. Both males and females who were oldest children tended to perceive that they were favored by their father (Kiracofe \& Kiracofe, 1990).

Perceived parental favoritism influences child adjustment in various ways. McHale, Crouter, McGuire, and Updegraff (1995) found that school-age children who were favored by both parents tended to have higher self-esteem and lower anxiety levels than children who were treated equally with respect to their siblings. Externalizing behaviors also were found to be related to parental favoritism. Schoolage children who were favored by both parents had fewer externalizing behaviors than unfavored children (Stocker, 1995). Parental differential treatment also may negatively affect the quality of the sibling relationship. Kowal and Kramer (1997) reported less sibling relationship warmth when maternal and paternal differential treatment were present in a sample of preadolescents.

The association between perceived parental favoritism and adjustment outcomes endures into adolescence. One study showed that social self-esteem was higher in late adolescence for those who reported no parental favoritism than for those who perceived they were favored (Zervas \& Sherman, 1994). Jodl, Bridges, Kim, Mitchell, and Chan (1999) reported higher levels of depressive symptoms and 
externalizing behaviors when parental differential treatment was present. Similarly, Massey (1999) found that the more parental favoritism in the home as reported by the adolescents, the poorer their self-concepts and the higher their levels of internalizing and externalizing behaviors. Other researchers reported adjustment differences between favored and unfavored children. Daniels, Dunn, Furstenburg, and Plomin (1985) found that adolescents who reported less parental warmth as compared to their siblings tended to have poorer adjustment outcomes and less sibling friendliness as reported by parents and teachers. Harris and Howard (1985) reported that parental favoritism was positively related to depression, anger, and identity confusion for the unfavored adolescent. Similarly, O'Connor and his colleagues (1998) showed that when the parent-adolescent relationship was negative and the parent-sibling relationship was positive, the adolescent tended to have high levels of depression and antisocial behavior. In addition, the sibling relationship was rated as negative by the adolescents. Thus, it appears that parental favoritism not only may affect adjustment outcomes, but also may negatively influence the parent-adolescent and sibling relationships. In fact, Massey (1999) found that adolescents reported low levels of social support from their parents and siblings when parental favoritism was perceived, and Bedford (1992) reported that individuals who felt they were the unfavored child tended to have less affection and more conflict with their parents in adulthood.

Differential treatment may appear more in remarried families. Remarried families may include step-children and biological children in the same household. Mekos, Hetherington, and Reiss (1996) found that parents were less involved with their step-children than with their biological children. Specifically, parents tended to show 
less support and more negativity to their step-children than to their biological children. Problem behaviors (e.g., alcohol and marijuana use) also were more prevalent in remarried homes than in intact homes. Influence of the Sibling-Adolescent Relationship on

\section{Adolescent Adjustment and Social Anxiety}

Sibling relationships can provide love and support or may be conflict ridden and hostile. Siblings spend a great deal of time together in childhood, and the quality of their relationship may have profound positive or negative effects on personality and social development (Furman \& Lanthier, 1996; Hartup \& van Lieshout, 1995). Sibling relations also may be the first opportunity for peer interactions, thus helping the child develop important social skills for future relationships (Bedford, 1989). Studies have shown associations between sibling relationship quality and adjustment outcomes such as depression, anxiety, and self-esteem.

Stocker (1994) conducted an interesting study that examined the quality of relationships with friends and siblings and their link to adjustment in school-age children. Stocker found that level of sibling conflict was negatively associated with selfworth and positively related to loneliness and depression. These correlations were nonsignificant for level of conflict in friendships. On the other hand, sibling relationship warmth was positively related to self-worth and negatively associated with loneliness. Similar findings were reported for friendship warmth. A study that examined sibling relationships and adjustment outcomes in late childhood and preadolescence found that sibling relationship satisfaction was negatively related to depression and anxiety 
(Epkins et al., 1997), whereas sibling hostility was positively related to depression and anxiety.

Relatively few studies have examined sibling relationship influences on adolescent and young adult adjustment. In these studies, social competence, selfesteem, depression, and internalizing and externalizing behaviors have been linked to sibling relationship quality. Conger et al. (1997) found in early adolescence that participants who reported that their siblings were controlling tended to have higher levels of depression and externalizing behaviors and lower levels of self-confidence than participants who reported less sibling control. Another study found that adolescents tended to have positive self-concepts and low levels of internalizing behaviors if they perceived high sibling social support (Massey, 1999). Similarly, in a retrospective study, Caya and Liem (1998) reported that young adults who rated their childhood sibling relationships as supportive had higher self-esteem, self-worth, and social competence than those who reported low sibling support. In addition, sibling support also buffered them from the negative effects of high conflict homes. Young adults in high conflict homes with high sibling support reported higher levels of selfesteem and social competence than only children and young adults with low sibling support. This study demonstrated that the sibling relationship may be an important factor in the development of social anxiety or social competence. Oldest and only children are often expected to be more socially anxious (Asendorpf, 1986) and to have higher self-esteem than laterborn children (Coopersmith, 1981). However, self-esteem is generally inversely related to social anxiety. Therefore, other family relationship 
factors such as the quality of the sibling relationship may be more important to the development of social anxiety and self-esteem than ordinal position.

Similar adjustment outcomes have been found when studying young adults and sibling relationships. Loneliness was inversely correlated with sibling closeness and rivalry and positively associated with sibling conflict (Ponzetti \& James, 1997). Sibling abuse also is a potential danger to healthy psychological adjustment. Gelles and Straus (1988) reported that sibling abuse is the most common form of abuse in the family. It is more frequent than spousal or parental child abuse. Graham-Bermann, Cutler, Litzenberger, \& Schwartz (1994) investigated sibling violence and adjustment outcomes in a retrospective study using college students. They found that females who were emotionally aggressed upon or experienced mild violence from their sibling had high anxiety levels. Thus, evidence supports the notion that sibling relationships are important to healthy psychological adjustment. Further examination into the sibling relationship and its potential link to adjustment outcomes is warranted.

\section{Gender Differences, Family Relationships, and Adolescent Adjustment}

Reported gender differences in studies examining family relationships and adolescent adjustment have been inconsistent. Klonsky and colleagues (1990) found that female social anxiety was predicted by paternal rejection and neglect, whereas male social anxiety was predicted by paternal overprotection and birth order, with oldest males being the most anxious. Another study found that maternal and paternal control were negatively related to middle adolescent self-confidence for both males and females (Conger et al., 1997). Interestingly, only adolescent female self-confidence was related to sibling control. Furthermore, for females, maternal and paternal control 
were positively associated with middle adolescent externalizing behaviors, but only maternal control was related to internalizing behaviors (Conger et al., 1997). For boys, maternal, paternal, and sibling control were positively associated with middle adolescent externalizing behaviors, but males internalizing behaviors were only predicted by maternal and sibling control. In contrast, Seelig and Brandon (1997) reported that only maternal control was related to adolescent female internalizing behaviors, and neither maternal or paternal control were related to adolescent male internalizing behaviors. Similar results were reported for parental care. Adolescent females reported high levels of internalizing behaviors when their mother and father were low in care, however, no relation was found for males (Seelig \& Brandon, 1997). Gender differences in parental differential treatment also have been equivocal. Kiracofe and Kiracofe (1990) reported that the favored child tended to identify the opposite-sex parent as the partisan. This finding occurred regardless of birth order except for the oldest children. Both males and females who were oldest children tended to perceive that they were favored by their father (Kiracofe \& Kiracofe, 1990). However, Daniels et al. (1985) contend that age and gender of the siblings only account for $1 \%-2 \%$ of the variance in perceived differential experience within the family. Furthermore, other studies examining family relationships have found no differences for age and gender of the siblings (Daniels \& Plomin, 1985b; Stocker, 1994; 1995).

Some gender differences in sibling relationship characteristics have been reported. Preadolescent sibling relationships were higher in warmth when the siblings were close in age and of the same gender than when the siblings were close in age but of the opposite gender (Furman \& Buhrmester, 1985). In addition, opposite-gender 
siblings who were close in age were higher in conflict than opposite-gender siblings who were widely spaced in age. In a study investigating sibling relationships in young adulthood, Stocker, Lanthier, and Furman (1997) reported that opposite-gender siblings reported less conflict than same-gender siblings. However, Burhmester and Furman (1990) reported that females rated same-gender sibling relationships as more positive than opposite-gender siblings in a study spanning from middle childhood to late adolescence (Buhrmester \& Furman, 1990). This finding was nonsignifjcant for males.

In summary, gender differences in family relationships and adolescent adjustment are difficult to predict. Some studies report gender differences in the parent-adolescent, parent-sibling, and sibling relationships, whereas other studies do not find any differences. Other factors such as the characteristics of each family member and family relationship subsystems (e.g., parent-adolescent, sibling) appear to be more important than family constellation variables like gender, birth order, or age. Child Resiliency and Protective Factors

Although most research examines the influence of negative family relationships on child maladjustment, it is important to mention that many children from dysfunctional families develop into well-adjusted productive members of society. Rutter (1987) asserted that resilience can only be understood by examining the interaction between an individual's environment and his or her developmental outcomes. Protective factors such as a positive parent-child relationship, sibling relationship, or peer relationship may help diminish the risk of maladjustment in a high-risk home. A factor would be considered protective if it is present in a high-risk home and the child's level of maladjustment was lower compared to another child who did not have the protective 
factor but also was from a high-risk home. Moreover, that same protective factor would not have any effect on child adjustment if he or she came from a low-risk home.

Studies have shown that having a good relationship with one parent protected preadolescents from the negative effects of marital distress (Neighbors, Forehand, \& McVicar, 1993; Jenkins \& Smith, 1990). Jenkins and Smith also reported lower levels of maladjustment when the pre-adolescent had a good relationship with a sibling, friend, or adult outside the household. However, these relationships did not have any effect on adjustment outcomes for preadolescents from homes low in marital discord, which supports Rutter's (1987) view on resilience. It also has been asserted that variables such as high intelligence, high self-esteem, and an internal locus of control are important individual characteristics that help protect adolescents from high risk environments (Fergusson \& Lynskey, 1996; Neighbors et al., 1993; Springer \& Gastfriend, 1995).

\section{Issues of Retrospective Research}

It has been speculated that retrospective research is problematic because individuals base their answers on recollections of past experiences. Individuals may base their answers on (1) actual experiences that took place during childhood and adolescence; (2) their mood states; (3) inaccurate memories of experiences; or (4) social desirability (Gerlsma, Arrindell, \& Emmelkamp, 1991). Social desirability may occur when any self-report measure is used (Kazdin, 1992). Individuals have a tendency to present themselves in a positive light even when it contradicts their true behavior. In a review article that examined the reliability and validity of retrospective studies, Brewin, Andrews, and Gotlib (1993) reported that individuals' mood states 
appear to affect their recollections of how they were parented depending on the type of questions asked. Questions that were directed at specific behaviors tended to be more reliable and valid, retrospectively, than questions that focused on global behaviors. Henry, Moffitt, Caspi, Langley, and Silva (1994) reported very low agreement between retrospective and prospective measures for subjective psychological states and family processes. It is important to mention, however, that many of the retrospective questions Henry et al. (1994) used in their study to assess psychological states and family processes involved global behaviors. For instance, when the participants were in early to middle adolescence they completed a scale to measure attachment to their parents. The attachment scale included specific behaviors about how the parents treated the adolescent. When the adolescents were 18 years of age, however, they were asked a global question about their relationship with their parents when they were 13 to 15 years of age. More specifically, they were asked about how close they felt to their parents. Retrospective studies must be interpreted with caution, but evidence suggests that retrospective studies may give fairly accurate accounts of perceived social experiences in childhood and adolescence if questions regarding specific behaviors are utilized (Brewin et al., 1993). Thus retrospective studies may provide useful information regarding family antecedents of psychosocial development. Statement of the Problem and Hypotheses

The main focus of the present study was to examine associations among several family relationships and adolescent social anxiety. Most studies examining social anxiety have looked at one family relationship such as the parent-child relationship. Family systems theory maintains that in order to understand the development and 
psychosocial functioning of an individual, multiple family relationship subsystems must be explored such as the parent-child and sibling relationships (Sroufe \& Fleeson, 1988). Previous research has shown that the parent-adolescent relationship is related to social anxiety (Anhalt, 1999; Morris \& Huffman, 1998; Warren et al., 1997), but no studies have looked at perceived parental favoritism and the sibling relationship as potential influences on socially anxious behaviors. It is probable that parental favoritism and the sibling relationship are related to social anxiety given that they have been linked to depression, general anxiety (Epkins et al., 1997; Harris \& Howard, 1985; McHale et al., 1995), social competence (Caya \& Liem, 1998), and internalizing behaviors (Massey, 1999). In addition, if parental favoritism is present in the household, other family relationships such as the parent-adolescent and sibling relationships would likely be negatively affected (Massey, 1999). This notion is supported by family systems theory. That is, each family relationship subsystem within the family affects and reflects the whole system (Sroufe \& Fleeson, 1988). A dysfunctional relationship in one subsystem can negatively affect other family subsystems. For instance, the psychosocial development of the unfavored adolescent may not only be affected by parental rejection, but their resources (e.g., parent, sibling) for social support also are diminished. Thus, examining several family relationships concurrently is vital in identifying family factors that may affect adolescent adjustment.

The secondary objective was to investigate specific family relationships and their association with adolescent adjustment outcomes such as depression, general anxiety, global self-worth, and social acceptance self-worth. Previous studies have shown that several family relationship subsystems (e.g., parent-adolescent, sibling) are related to 
adolescent adjustment (Massey, 1999; O'Connor et al., 1998). The present study further explored these associations by examining specific relationship characteristics of the parent-adolescent, parent-sibling, and sibling relationships with regard to late adolescent adjustment.

The last objective was to compare social anxiety levels between only children and children with siblings. It has been asserted that only children and oldest children tend to be more socially anxious than laterborn children (Asendorpf, 1986). However, focusing on ordinal position excludes the important roles that the sibling relationship and perceived parental favoritism may play on social anxiety. Gender differences also were explored for parent and sibling relationships and their association with adjustment outcomes. No predictions regarding gender were made because prior research has been equivocal in finding gender differences in relation to family relationships and adjustment outcomes.

The hypotheses of the proposed study are as follows:

\section{$\underline{\text { Adolescent Social Anxiety and Family Relationships }}$}

1. Adolescents whose parents are high in care and low in control will be less socially anxious than adolescents whose parents are low in care and high in control.

2. Adolescents who have sibling relationships that are high in social support and low in negativity will be less socially anxious than adolescents who have sibling relationships that are low in social support and high in negativity. 
3. Adolescents who perceive that they are the favored child or that no parental favoritism is present will be less socially anxious than adolescents who perceive they are the unfavored child.

4. Adolescents who have (1) parents who are high in care and low in control;

(2) sibling relationships that are high in social support and low in negativity; and (3) perceive that there is no parental favoritism will be less socially anxious than adolescents who have two, one, or none of the above family relationship variables present.

Social Anxiety in Only Children and Children With Siblings

5. Adolescents with siblings will be less socially anxious than only children regardless of birth order if (1) they have parents high in care and low in control; (2) they have sibling relationships high in social support and low in negativity; and (3) they perceive there is no parental favoritism.

Adolescent Adjustment (i.e., depression, general anxiety, self-worth) and Family Relationships

6. Adolescents whose parents are high in care and low in control will have better adjustment outcomes than adolescents whose parents are low in care and high in control.

7. Adolescents who have sibling relationships that are high in social support and low in negativity will have better adjustment outcomes than adolescents who have sibling relationships that are low in social support and high in negativity. 
8. Adolescents who perceive that they are the favored child or that no parental favoritism is present will have better adjustment outcomes than adolescents who perceive they are the unfavored child.

9. Adolescents who have (1) parents who are high in care and low in control;

(2) sibling relationships that are high in social support and low in negativity; and (3) perceive that there is no parental favoritism will have better adjustment outcomes than adolescents who have two, one, or none of the above family relationship variables present.

\section{Method}

\section{$\underline{\text { Participants }}$}

Participants were 515 (337 females, 178 males) undergraduate students from West Virginia University who were recruited from various psychology courses. The participants' ages ranged from 18-20 years old $(\underline{M}=18.75, \underline{S D}=.72)$ and, in accordance with the Journal of Late Adolescence, are developmentally considered to be in late adolescence. In addition, the participants are college students and most have not yet entered into the expected responsibilities of adulthood (e.g., full-time employment). Only children and participants with siblings, half-siblings, or step-siblings were included in the study. Sixty-three (12.2\%) participants were only children, 227 (44.1\%) had one sibling, and 225 (43.7\%) had two or more siblings. In addition, participants who grew-up in intact, divorced, or remarried homes took part in the study. Thirteen $(2.5 \%)$ of the participants reported that their biological parents were never married; $360(70.3 \%)$ reported that they were currently married; $130(25.4 \%)$ reported that they were divorced; and $9(1.8 \%)$ reported that their parents were married but one 
parent is deceased. Fourteen percent of the participants reported living with a stepparent. A majority of the participants were single (93.8\%) and caucasian (91.8\%). Table 1 displays descriptive statistics for additional demographic variables.

\section{Procedure}

Each participant completed a questionnaire packet according to whether he or she was an only child, had one sibling, or had two or more siblings. The questionnaires were presented in the same order for all participants. Participants were asked to fill out questionnaires on their sibling(s) and parents, step-parent, or guardian (if applicable). Participants from remarried homes were asked to fill out parent-related questionnaires on their biological parents unless they had lived with a step-parent for a longer period of time. In this case, the participants were asked to complete the parent-related questionnaires on a parent and step-parent. In addition, if a step-sibling or half-sibling lived in the same household as the participant for two or more years, sibling related questionnaires could be completed on that step-sibling or half-sibling. Detailed instructions were included in the questionnaire packets, and a researcher was present to answer any questions that arose. Each questionnaire packet was reviewed by the researcher to check for unanswered questions. The participants were queried by the researcher as to whether or not they meant to miss the question. If the question was missed accidently, the participant was asked to answer the missed question. It took the participants approximately 35-60 minutes to complete the questionnaires depending on whether or not the participant had sibling(s). The participants completed the questionnaires in groups of 20 or less to allow for privacy, and received course extra credit for taking part in the study. 


\section{Measures}

Demographic questionnaire. Questions regarding the participants' age and ethnic group were included. Also, the age and sex of siblings, along with questions that concerned years residing with sibling(s), parent(s), step-parent(s) or guardian(s) were included. Furthermore, questions regarding age of parent(s), and the adolescents' perception of whether or not their parent(s) expressed any concerns about their mental health also were included on the demographic questionnaire. Each mental health concern (i.e., depression, anxiety, shyness, low self-esteem), as perceived by the adolescent, was coded as " 1 " if it was not present and " 2 " if it was present. The demographic questionnaire is displayed in the appendix.

Beck Anxiety Inventory (Beck, Epstein, Brown, \& Steer, 1988). The Beck Anxiety Inventory (BAI) is a self-report measure developed to assess the level of overt behavioral, physiological, and cognitive symptoms of anxiety in an individual. The BAI was designed to measure anxiety independent of depressive symptoms. The scale is comprised of 21 items that are rated on a 4 -point scale $(0=$ not at all to $3=$ severely, I could barely stand it). The 21 items are summed to get a total score that ranges from 0 to 63 . The higher the total score, the more anxiety experienced by the individual in the past week. The BAI has been utilized with college student samples (Anhalt, 1999) and has been shown to be a valid instrument with this population (Osman, Kopper, Barrios, Osman, \& Wade, 1997). The internal consistency of the BAI was .92 and the one-week test-retest reliability was reported as $\underline{r}=.75$ (Beck et al., 1988).

Content, concurrent, construct, and discriminant validity were calculated using data from 160 participants who were diagnosed with anxiety and mood disorders and 
receiving outpatient therapy (Beck et al., 1988). Content validity was determined by including items related to symptoms of anxiety disorders as described by the Diagnostic and Statistical Manual of Mental Disorders, Third Edition (DSM-III; American Psychiatric Association, 1980). Regarding concurrent validity, the BAI was correlated with other self-report anxiety measures. The BAI was significantly correlated with the Cognition Checklist-Anxiety subscale $(\underline{r}=.51$; Beck, Brown, Steer, Eidelson, \& Riskind, 1987) and the Hamilton Anxiety Rating Scale - Revised ( $\underline{r}=.51$; Riskind, Beck, Brown, \& Steer, 1987).

Construct validity was assessed by correlating the BAI with other anxiety and depression self-report measures such as the Beck Depression Inventory (BDI; Beck \& Steer, 1987). The BAI was significantly correlated with the BDI $(\underline{r}=.25)$, but was lower than previous studies examining other anxiety measures (Beck et al., 1988). Lastly, discriminant validity was determined by comparing an anxious group, mood disordered group, and control group. Twenty-five percent of the participants diagnosed with a primary anxiety disorder scored higher than participants diagnosed with a mood disorder, which indicates some overlap. However, those who were in the anxious group scored significantly higher on the BAI than those in the depressed or control group.

Beck Depression Inventory - II (Beck, Steer, \& Brown, 1996). The Beck Depression Inventory - II (BDI-II) was designed to measure a person's level of depressive symptoms in the past two weeks. The scale is comprised of 21 items that are rated on a 4-point scale (0 to 3$)$. Cognitive-affective and somatic components are included in the BDI-II. The cognitive-affective factor includes statements related to sadness, pessimism, self-criticalness, suicidal thoughts, crying, loss of interest, 
indecisiveness, past failure, self-dislike, worthlessness, irritability, and loss of interest in sex. The somatic component includes statements related to agitation, loss of interest, loss of energy, changes in sleeping pattern, changes in appetite, concentration, and fatigue or tiredness. The 21 items are summed to get a total score that ranges from 0 to 63 . The higher the total score, the more depression experienced by the individual in the past two weeks. The BDI - II has been utilized with college student samples (Anhalt, 1999) and has been shown to be a valid instrument with this population (Steer \& Clark, 1997). The internal consistency of the BDI-II was .92 and the one-week testretest reliability was reported as .93 (Beck et al., 1996).

Content, construct and discriminant validity were calculated using data from 500 participants who were receiving outpatient psychiatric treatment (Beck et al., 1996). Items for the BDI-II were developed using the criteria for depressive disorders according to the Diagnostic and Statistical Manual of Mental Disorders, Fourth Edition (DSM-IV: American Psychiatric Association, 1994). Construct validity of the BDI-II was determined by correlating the measure with a previous version, the amended Beck Depression Inventory (BAI-IA; Beck, Rush, Shaw, \& Emery, 1979). The BDI-II was strongly correlated with the BAI-IA $(\underline{r}=.93)$.

Discriminant validity was determined by comparing BDI-II scores for clinical and non-clinical groups (Beck et al., 1996). Specifically, the clinical group scored twice as high on the BDI-II as the non-clinical group. In addition, the BDI-II adequately discriminated mood disorders from anxiety and adjustment disorders.

Social Phobia and Anxiety Inventory (Turner, Beidel, Dancu, \& Stanley, 1989). The Social Phobia and Anxiety Inventory (SPAI) was developed to measure an 
individual's level of social anxiety. The inventory consists of 45 items that are rated on a 7 -point scale $(1=$ never to 7 = always $)$. The SPAI includes a social phobia total score and agoraphobia and social anxiety subscales. The social anxiety subscale score is derived by subtracting the agoraphobia subscale score (range is 0 to 78 ) from the social phobia total score (range is 0 to 192). The social anxiety subscale score distinguishes individuals who experience anxiety in social situations because of a fear of negative evaluation from those who are anxious in social situations for fear of having a panic attack (agoraphobia). The higher the social anxiety subscale score, the more social anxiety experienced by the individual. The SPAI has good psychometric properties that have been calculated using samples of college students and clinical patients. The internal consistencies for the agoraphobia and social anxiety subscales are .85 and .96 , respectively, and the two-week test-retest reliability was .86 (Turner et al., 1989).

Discriminant validity of the SPAI was calculated from a sample of socially $(\mathrm{N}=$ 59) and non-socially anxious ( $\mathrm{N}=123)$ college students (Turner et al., 1989). Participants who were identified as socially anxious scored significantly higher than those who were identified as non-socially anxious. In a clinical sample with patients diagnosed with social phobia, panic disorder or panic disorder with agoraphobia, and obsessive-compulsive disorder, socially phobic patients scored significantly higher on the SPAI than the patients from the other two groups.

Self-Perception Profile for College Students (Neeman \& Harter, 1986). The SelfPerception Profile for College Students was developed to assess self-worth in college students. The scale is comprised of five domains that measure competencies and abilities, seven domains that tap into social relationships, and a global self-worth 
subscale. Creativity, intellectual ability, scholastic competence, job competence, and athletic competence make up the competency and ability domains. The social relationship domains include appearance, romantic relationships, social acceptance, close friendships, parent relationships, humor, and morality. Each domain has four items except for global self-worth which has six items. The scale consists of 54 total items. For each item, the student is asked which kind of student he or she is most like, then the student decides whether that description is "sort of true" or "really true" for him or her. Each item is scored according to a 4 -point scale $(1=$ low competence to $4=$ high competence). The higher the score, the higher the self-worth. For the purposes of this study, global self-worth and social acceptance subscales will be included in the study. The internal consistencies of the subscales ranged from .76 to .92 (Neeman \& Harter, 1986).

Parental Bonding Instrument (Parker et al., 1979). The Parental Bonding Instrument (PBI) was developed to assess an individual's retrospective account of his or her parents child-rearing behaviors (e.g., care or affection, control or overprotection). The inventory consists of 25 items that are rated on a 4 -point scale $(0=$ very like to $3=$ very unlike). The PBI includes control (13 items) and care (12 items) subscales that are scored separately. The control subscale has a range of 0 to 39 , and the care subscale has a range of 0 to 36; the higher the score, the higher the parental control and care. There are four categories of parenting that can be measured with the PBI using cutoff scores. These cutoff scores are based on sample median splits for parental care and control. Any scores above the cutoffs are considered high, and any scores below the cutoffs are considered low. The median splits for the present sample were of the 
following: (a) 32 for maternal care; (b) 29 for paternal care; (c) 12 for maternal control, and (d) 11 for paternal control, which are similar to the sample used in developing the measure (Parker et al., 1979). The four categories of parenting include the following: 1) "optimal parenting" includes high care and low control scores; (2) "affectionate constraint" consists of high care and high control scores; (3) "affectionless control" contains low care and high control scores; and (4) "neglectful parenting" involves low care and low control scores. The participants were asked to complete the PBI on their male and female parent, step-parent, or guardian. The internal consistencies of the care and control subscales are .88 and .74 , respectively, and the three-week test-retest reliability was .76 for the care subscale and .63 for the control subscale (Parker et al., 1979).

The PBI has been shown to possess adequate concurrent validity. In one study, mothers who scored high on the control scale, and were later interviewed about their parenting practices by an interviewer blind to the PBI scores, were judged to have been controlling parents (Parker, 1983b). Moderate correlations $\underline{r}=.62$ for care, $\underline{r}=.47$ for control) also were reported for participant and sibling reports.

Network of Relationships Inventory (Furman \& Buhrmester, 1985). The Network of Relationships Inventory (NRI) was designed to assess a person's perception of his or her personal relationships. The inventory consists of 36 items that are rated on a 5point scale $(1=$ little or none to $5=$ the most $)$. The components of companionship, instrumental aid, intimacy, nurturance, affection, admiration, satisfaction, and reliable alliance make up the social support factor. The negative relationship factor includes the components of conflict, antagonism, and punishment. The other component of relative 
power is not included in the social support or negative factors, but is a factor itself. The higher the average score for each respective factor, the more social support, negativity, and relative power in the relationship. For the purposes of this study, only the social support and negative factors were included. Participants with one sibling completed the scale on their sibling, and participants with two or more siblings completed the scale on their most liked and least liked sibling. Median splits were calculated on the social support and negative sibling relationship scores to get high and low groups for each factor. Connolly and Konarski (1992) reported the internal consistencies of the social support and negative relationship subscales as $>.90$ (as cited in Furman, 1996).

Concurrent validity between siblings for the social support factor of the NRI for the mother, father, and sibling relationships were reported as $.58, .32$, and .46, respectively (Massey, 1999).

Inventory of Family Experiences (SIDE-R; Barrett Singer \& Weinstein, 1996). The Sibling Inventory of Differential Experience (SIDE; Daniels \& Plomin, 1985b) was designed to assess an individual's perception of parental favoritism. The items on the original SIDE were of a direct comparison format. The individual completing the scale would compare how their parents treated them relative to their sibling. An indirect comparison is used for the SIDE-R which has been shown to provide a more sensitive and predictive measure of parental favoritism. The SIDE-R is a 9-item scale in which individuals rate on a 4 -point scale $(1=$ almost never to $4=$ almost always $)$ how they were treated by their parents or guardian (if applicable). Then they rate how they perceive their sibling was treated by their parents. Thus, the participants rate perceived mother and father differential treatment toward themselves and their siblings on 
independent scales. The SIDE-R contains subscales that measure parental differential affection ( 5 items) and control (4 items). The subscales are scored by subtracting the participants' reports of each parent's treatment of their sibling from the participants' reports of each parent's treatment of them (Barrett Singer \& Weinstein, 1996). The items are then added for each subscale, and the subscale score is divided by the number of items to get maternal and paternal differential affection and control scores. A score of "0" for parental (both mother and father) affection and control scores indicates there is no favoritism. A negative score for parental affection and a positive score for parental control signifies that the adolescent is unfavored. A positive score for parental affection and a negative score for parental control implies that the adolescent is favored. The higher the score, the more parental favoritism. For this study, adolescents also were categorized as favored if they had a positive score for parental affection and a "0" for parental control. Similarly, they were categorized as unfavored if they had a negative score for affection and a "0" for control. This scoring technique was used because the affection subscale contains an item that directly assesses whether the adolescent or sibling is favored (e.g., "My mother has tended to favor me."), and gives a broader assessment of perceived parental favoritism. Internal consistencies for the affection and control subscales of the SIDE-R are .79 and .76 , respectively (Barrett Singer, 1996), and the two-week test-retest reliability for the SIDE subscales ranged from .77 to .93 (Daniels \& Plomin, 1984).

Concurrent validity was assessed by comparing participant and sibling scores for the SIDE (Daniels \& Plomin, 1984). There was low to moderate agreement between 
the participant and sibling reports ( $r s=-.25$ to -.49 ). In addition, Barrett Singer (1996) reported moderate correlations between the SIDE-R and SIDE (.49 to .82).

\section{Results}

The data for one-hundred and three participants were randomly selected and checked for accuracy of data entry. The data check yielded a $98.8 \%$ accuracy rate.

Missing data for any item on the SPAI was input as a "1" (never), which is the lowest possible score for any item. One participant refused to answer approximately $20 \%$ of the questions on the SPAI and was counted as missing data. No missing data was present for the BAI and BDI-II. Missing data for the other measures (i.e., NRI, PBI, Self-Perception Scale, and SIDE-R) were left as missing because multiple items on the respective scales were missed.

Descriptive statistics for the measured variables are listed in Table 2.

Descriptive statistics for the categorical variables are listed in Table 3. The mean scores for the PBI, BAI, BDI-II, and the social anxiety score of the SPAI were consistent with similar studies conducted at West Virginia University (Anhalt, 1999; Morris \& Huffman, 1998). Global self-worth and social acceptance mean scores also were similar to the college student population used in the development of the scale (Neeman \& Harter, 1986). Lastly, the NRI social support and negativity scores were consistent with a study that examined college student sibling relationships (Furman \& Buhrmester, 1992). Mean scores were unavailable for the SIDE-R.

Adolescents reported whether or not their female and male parent expressed concerns about depression, shyness, anxiety, or low self-esteem. Twenty percent of the adolescents reported that their female parent expressed concerns about 
depression, $6.6 \%$ about shyness, 33\% about anxiety, and $16.3 \%$ about low self-

esteem. For the male parent, $11.8 \%$ of the adolescents reported that their male parent expressed concerns about depression, $6.3 \%$ about shyness, $19.3 \%$ about anxiety, and $6.7 \%$ about low self-esteem.

Intercorrelations of the Measured Variables for Only Children

Intercorrelation coefficients for the measured variables for only children are displayed in Table 4. Only childrens' level of general anxiety and perceived paternal anxiety were correlated. If paternal anxiety was perceived as present, only childrens' level of general anxiety tended to be low. Furthermore, a relationship was found for perceived paternal self-esteem and only childrens' level of global self-worth and social acceptance self-worth. If the adolescents' perceived that their father had low selfesteem, the adolescents also tended to report low levels of general self-worth and social acceptance self-worth. Several significant correlations were found for only childrens' adjustment outcomes and perceived parental control. Only children who reported low maternal and paternal control tended to have low levels of social anxiety and depression and high levels of global and social acceptance self-worth. Lastly gender of the only child was associated with perceived parental control. Specifically, males tended to perceive lower levels of maternal and paternal control than females. Intercorrelations of the Measured Variables for Adolescents With Siblings Intercorrelation coefficients for the measured variables for adolescents with siblings are displayed in Table 5. Perceived maternal depression was correlated with adolescents' reported levels of depression. If maternal depression was perceived as present, adolescents tended to have high levels of depression. Similar results were 
found for adolescent adjustment outcomes and perceived maternal shyness, anxiety, and self-esteem. If maternal shyness, anxiety, and low self-esteem were perceived as present, adolescents tended to have high levels of social anxiety and general anxiety and low levels of general and social acceptance self-worth. Only perceived paternal anxiety and self-esteem were significantly correlated with adolescent adjustment outcomes. Specifically, if paternal anxiety and low self-esteem were perceived as present, adolescents tended to report high levels of general anxiety and low levels of social acceptance self-worth.

Several family relationship characteristics were found to be associated with adolescent adjustment outcomes. Perceived maternal and paternal care were negatively correlated with late adolescent social anxiety, depression, and general anxiety, and positively associated with global and social acceptance self-worth. Specifically, adolescents who perceived high levels of maternal and paternal care tended to report low levels of social anxiety, depression, and general anxiety and high levels of global and social acceptance self-worth. In addition, adolescents who reported low levels of maternal and paternal control tended to have low levels of agoraphobia, social anxiety, depression, and general anxiety, and high levels of global and social acceptance self-worth.

Perceived sibling social support and negativity also were related to adolescent adjustment outcomes. Adolescents who perceived high levels of social support from their sibling(s) tended to have low levels of social anxiety and depression and a high level of global self-worth. Interestingly, perceived sibling negativity was correlated with more developmental outcomes than sibling social support. Adolescents who perceived 
low levels of negativity from their sibling(s) tended to have low levels of social anxiety, agoraphobia, depression, and general anxiety, and high levels of global and social acceptance self-worth.

Significant correlations also were found for parental differential treatment or favoritism. Specifically, maternal differential control was related to adjustment outcomes for adolescents with one sibling but not for adolescents who reported on two siblings. Adolescents with one sibling tended to have low levels of agoraphobia, depression, and general anxiety if they perceived low levels of maternal differential control. Regarding paternal differential affection, adolescents with one sibling tended to have low levels of depression and high levels of global and social acceptance self-worth if they perceived low levels of paternal differential affection. Adolescents who reported on two siblings had fewer significant correlations regarding developmental outcomes and parental differential treatment than adolescents with one sibling. Adolescents who reported low levels of maternal differential affection tended to have low social anxiety (most liked sibling) and high global and social acceptance self-worth (least liked sibling). For paternal differential control, adolescents tended to have low levels of general anxiety (most and least liked sibling) and agoraphobia (most liked sibling) and high levels of global self-worth (most liked sibling) if they reported low levels of paternal differential control. Lastly, paternal differential affection was related to global self-worth (most and least liked sibling) and depression (most liked sibling). Specifically, adolescents who reported low levels of paternal differential affection had high global self-worth and low levels of depression. 
Constellation variables such as gender and age of the adolescent and sibling(s) and their association with the measured variables also were examined. For adolescents with one sibling, age difference between the adolescent and sibling was correlated with adjustment outcomes. More specifically, adolescents who were older than their sibling tended to report low levels of social anxiety, agoraphobia, depression, and general anxiety, and high levels of global self-worth. Only paternal control was related to adolescent and sibling gender. A high level of paternal control tended to be perceived by adolescents if they were the opposite-gender from their sibling.

For adolescents with two siblings, age differences between the adolescent and most liked sibling was associated with paternal control, maternal differential control, and maternal and paternal differential affection. Adolescents who were older than their most liked sibling tended to report high levels of paternal control and maternal differential control. Not surprisingly, adolescents who were older also reported low levels of maternal and paternal differential affection. Gender of the adolescent and most liked sibling was only related to general anxiety and maternal control. Specifically, adolescents who were the opposite-gender from their most liked sibling tended to be high in general anxiety and reported low levels of maternal differential control. Age difference between the adolescent and least liked sibling was related to paternal differential affection and control. Adolescents who perceived that their father was high in differential control and low in differential affection tended to be older than their least liked sibling. Gender of the adolescent and least liked sibling was found to be related to agoraphobia, social acceptance, and maternal differential control. Specifically, adolescents who were the opposite-gender from their least liked sibling tended to be 
low in social acceptance self-worth and high in agoraphobia. In addition, perceived maternal differential control also was rated as low for the opposite-gender adolescent.

Finally, age and gender of the adolescent were examined in relation to the measured variables. Age of the adolescent was only related to maternal and paternal care and paternal differential control (least liked sibling). Adolescents who were older tended to perceive low levels of maternal and paternal care and high levels of paternal differential control (least liked sibling). The only correlations significant for gender of the adolescent were agoraphobia, paternal care, paternal differential control (one sibling), and maternal differential affection (most liked sibling). Adolescent males tended to report lower levels of agoraphobia and paternal care than females. In addition, adolescent males reported higher paternal differential control (one sibling) and maternal differential affection (most liked sibling) than females.

Given that the bivariate correlations did not show any consistent patterns among the variables of interest and the constellation variables (e.g., age and gender of sibling), age and gender of the adolescent relative to the sibling(s) were excluded from the following analyses. In addition, agoraphobia was included in the analyses as an outcome variable even though it was not included in the hypotheses. Gender Differences for Outcome Variables

A one-way between-subjects multvariate analysis of variance was performed with gender of the participant as the independent variable and the outcome variables (i.e., social anxiety, agoraphobia, general anxiety, depression, global self-worth, and social acceptance self-worth) as the dependent variables. Using Wilks' Criterion, the combined dependent variables were significantly affected by gender of the participant, 
$\underline{F}(7,504)=2.93, \underline{p}<.01$. Tests of between-subjects effects revealed that males $(\underline{M}=$ 17.03, $\underline{S D}=9.97)$ were significantly lower in agoraphobia than females $(\underline{M}=20.76, \underline{S D}$ $=11.97), \underline{\mathrm{p}}<.01$. No other significant differences were found.

Adolescent Adjustment Outcomes and Family Relationships

Hypotheses 1 and 6: Adolescents whose parents are high in care and low in control will be less socially anxious and have better adjustment outcomes than adolescents whose parents are low in care and high in control. Mothers and fathers were placed into four parenting categories (optimal, affectionate constraint, affectionless control, and neglectful) based on the median splits of the PBI for maternal and paternal care and control. A $4 \times 4 \times 2$ between-subjects multivariate analysis of variance was performed with maternal and paternal parenting styles and gender of the participant as the independent variables and the adjustment outcomes (i.e., social anxiety, agoraphobia, general anxiety, depression, global self-worth, and social acceptance self-worth) as the dependent variables. The majority of the participants completed the maternal PBI on their biological/adoptive mother (98.1\%) and biological/adoptive father (89.9\%). The cell sizes for maternal parenting styles and gender were: 1) optimal (154; 56 males and 98 females); 2) affectionate constraint (120; 29 males and 91 females); 3) affectionless control (154; 58 males and 96 females); and 4) neglectful (70; 26 males and 44 females). The cell sizes for paternal parenting styles were: 1) optimal (144; 46 males and 98 females); 2) affectionate constraint (115; 27 males and 88 females); 3) affectionless control (156; 50 males and 106 females); and 4) neglectful (83; 46 males and 37 females). The cell sizes across maternal and paternal parenting styles were: 1) optimal (106; 33 males and 73 
females); 2) affectionate constraint (73; 12 males and 61 females); 3) affectionless control (104; 36 males and 68 females); and 4) neglectful (37; 18 males and 19 females)

Using Wilks' Criterion, the combined dependent variables were significantly affected by type of maternal parenting style, $\underline{F}(21,1321.42)=2.51$, $\underline{p}<.05$. The multivariate tests for paternal parenting style and the interactions were nonsignificant. Tests of between-subjects effects revealed that maternal parenting styles were significant for social anxiety, $\underline{F}(3,466)=9.53, \underline{p}<.01$, general anxiety, $\underline{F}(3,466)=3.13$, $\underline{\mathrm{p}}<.05$, depression, $\underline{\mathrm{F}}(3,466)=7.68, \underline{\mathrm{p}}<.01$, global self-worth, $\underline{\mathrm{F}}(3,466)=9.06$, $\underline{\mathrm{p}}<$ .01 , and social acceptance self-worth, $\underline{F}(3,466)=3.74, \underline{p}<.01$. The results of the subsequent Tukey tests are shown in Table 6. Adolescents who reported optimal maternal parenting had lower social anxiety and depression levels and higher social acceptance self-worth than those who reported affectionate constraint or affectionless control maternal parenting. For general anxiety, adolescents who reported optimal maternal parenting had lower general anxiety levels than those who reported affectionless control maternal parenting. Regarding global self-worth, adolescents who reported optimal maternal parenting had higher global self-worth than those who reported affectionate constraint, affectionless control, or neglectful maternal parenting.

The relationship between adolescent adjustment outcomes and parental parenting styles also was examined. Parents were placed into four parenting categories (optimal, affectionate constraint, affectionless control, and neglectful) based on the median splits of the PBI for maternal and paternal care and control. That is, only mothers and fathers who both had optimal parenting styles were included in the optimal 
parenting category. The same grouping procedure was used for the affectionate constraint, affectionless control, and neglectful parenting styles. Participants reporting that their parents did not have the same parenting style were excluded from the analysis. A $4 \times 2$ between-subjects mutivariate analysis of variance was performed with parenting styles and gender of the participant as the independent variables and the adjustment outcomes (i.e., social anxiety, agoraphobia, general anxiety, depression, global self-worth, and social acceptance self-worth) as the dependent variables. The majority of the participants completed the maternal PBI on their biological/adoptive mother (98.9\%) and biological/adoptive father (92.5\%). The cell sizes for parenting styles and gender were: 1) optimal (106; 33 males and 73 females); 2) affectionate constraint (73; 12 males and 61 females); 3 ) affectionless control (104; 36 males and 68 females); and 4) neglectful (37; 18 males and 19 females).

Using Wilks' Criterion, the combined dependent variables were significantly affected by the parenting style categories, $\underline{F}(21,879.22)=4.25, \underline{p}<.01$. The gender $x$ parenting style interaction was nonsignificant. Tests of between-subjects effects revealed that parenting style was significant for agoraphobia, $\underline{F}(3,312)=3.82, \underline{p}<.05$, social anxiety, $\underline{F}(3,312)=11.18$, general anxiety, $\underline{F}(3,312)=5.57$, depression, $\underline{F}(3$, $312)=14.83$, global self-worth, $\underline{F}(3,312)=24.92$, and social acceptance self-worth, $\underline{F}(3,312)=16.90, \underline{p s}<.01$. The results of the subsequent Tukey tests are shown in Table 7. Adolescents who reported optimal parenting had lower agoraphobia, social anxiety, and general anxiety levels than those who reported affectionless control parenting. Furthermore, adolescents had lower depression levels and higher social acceptance self-worth when they reported optimal parenting than those who reported 
affectionate constraint or affectionless control parenting. Lastly, adolescents who reported optimal parenting had higher global self-worth than those who reported affectionate constraint, affectionless control, or neglectful parenting.

In summary, adolescents who perceived that their mother had an optimal parenting style were better adjusted than adolescents who reported less than an optimal maternal parenting. Similar results were reported for parental (both mother and father combined) parenting styles. Adolescents who reported optimal parenting from both parents were better adjusted than adolescents who reported less than optimal parenting.

Hypotheses 2 and 7: Adolescents who have sibling relationships that are high in social support and low in negativity will be less socially anxious and have better adjustment outcomes than adolescents who have sibling relationships that are low in social support and high in negativity. Participants who had siblings (one, two or more) were combined into four sibling categories based on the median splits for the sibling social support and negativity subscale scores of the NRI. The sibling social support and negativity scores were averaged across siblings for participants who reported on two siblings (most liked and least liked). A $4 \times 2$ between-subjects multivariate analysis of variance was performed with sibling relationship categories (high social support/low negativity, high support/high negativity, low support/high negativity, and low support/low negativity) and gender of the participant as the independent variables and the adjustment outcomes (i.e., social anxiety, agoraphobia, general anxiety, depression, global self-worth, and social acceptance self-worth) as the dependent variables. The majority of the participants with sibling(s) completed the NRI on their biological sibling 
(89\%). The NRI was completed by the participants on an equal number of male (50\%) and female (50\%) siblings. The cell sizes for the sibling categories and gender were: 1 ) high support/low negativity (132; 33 males and 99 females); 2) high support/high negativity (86; 27 males and 59 females); 3) low support/high negativity (138; 54 males and 84 females); and 4) low support/low negativity (88; 35 males and 53 females).

Using Wilks' Criterion, the combined dependent variables were significantly affected by sibling category, $\underline{F}(21,1235.28)=2.13, \underline{p}<.01$. The sibling categories $x$ gender interaction was nonsignificant. Tests of between-subjects effects revealed that sibling category was significant for agoraphobia, $\underline{F}(3,436)=3.14$, social anxiety, $\underline{E}(3$, $436)=3.04$, general anxiety, $\underline{F}(3,436)=2.84$, depression, $\underline{E}(3,436)=4.97$, global selfworth, $\underline{F}(3,436)=3.17$, and social acceptance self-worth, $\underline{F}(3,436)=5.10$, $\underline{p} s<.05$. The results of subsequent Tukey tests are depicted in Table 8. Adolescents who reported sibling relationships high in social support and low in negativity had lower levels of social anxiety and higher social acceptance self-worth than those who reported sibling relationships low in social support and high in negativity or sibling relationships low in social support and low in negativity. For agoraphobia, adolescents who reported sibling relationships high in social support and low in negativity had lower levels of agoraphobia than those who reported sibling relationships high in social support and high in negativity. Furthermore, adolescents who reported sibling relationships low in social support and low in negativity had lower levels of general anxiety than those who reported sibling relationships low in social support and high in negativity.

Regarding depression, adolescents who reported sibling relationships high in social support and low in negativity had lower levels of depression and higher global 
self-worth than those who reported sibling relationships low in social support and high in negativity or sibling relationships high in social support and high in negativity.

In summary, adolescents who reported sibling relationships high in social support and low in negativity were better adjusted than adolescents who reported the following three sibling relationships: (1) high social support/low negativity; (2) low social support/high negativity; (3) low social support/low negativity.

Hypotheses 3 and 8: Adolescents who perceive that they are the favored child or that no parental favoritism is present will be less socially anxious and have better adjustment outcomes than adolescents who perceive they are the unfavored child. Participants who had siblings (one, two or more) were combined into three maternal and paternal differential treatment categories (no favoritism, favored, unfavored) based on their scores on the maternal and paternal differential affection and control scores of SIDE-R. Participants who reported on two siblings (most liked and least liked) were placed in the differential treatment categories based on their scores in relation to both siblings for maternal and paternal differential treatment (e.g., favored over both siblings). A $3 \times 3 \times 2$ between-subjects multivariate analysis of variance was performed with maternal and paternal differential treatment categories and gender of the participant as the independent variables, and the adjustment outcomes (i.e., social anxiety, agoraphobia, general anxiety, depression, global self-worth, and social acceptance self-worth) as the dependent variables. The majority of participants completed the SIDE-R on their biological/adoptive mother (99.3\%) and biological/adoptive father (90.6\%). The majority of participants also completed the SIDE-R on their biological sibling (89.8\%). The SIDE-R was completed by the 
participants on male (43.3\%) and female (56.7\%) siblings. The cell sizes for maternal differential treatment and gender were: 1 ) no favoritism (32; 12 males and 20 females); 2) favored (50; 14 males and 36 females); 3) unfavored (56; 17 males and 39 females). The cell sizes for paternal differential treatment and gender were: 1$)$ no favoritism (35; 8 males and 27 females); 2) favored (56; 12 males and 44 females); and 3) unfavored (47; 23 males and 24 females). The cell sizes for parental differential treatment across mother and father were: 1) no favoritism (17; 4 males and 13 females); 2 ) favored (30; 5 males and 25 females); and 3) unfavored (27; 11 males and 16 females).

Using Wilks' Criterion, the combined dependent variables were nonsignificantly affected by either maternal or paternal differential treatment, ำ $>.05$. The interactions also were nonsignificant, ps $>.05$.

The relationship between adolescent adjustment outcomes and parental differential treatment also were examined. Participants were placed into four parental differential treatment categories (no favoritism, favored, unfavored, favored by one parent/unfavored by other parent) based on the maternal and paternal differential affection and control scores of the SIDE-R. That is, only participants who perceived that they were favored by both their mother and father were included in the favored category. The same grouping procedure was used for the no favoritism, unfavored, and favored by one parent/unfavored by other parent groups. Similar grouping procedures have been used in previous studies examining parental favoritism (Harris \& Howard, 1985; Kiracofe \& Kiracofe, 1990). Participants who did not meet the criteria for inclusion into the parental differential treatment categories were excluded from the analysis. A $4 \times 2$ between-subjects mutivariate analysis of variance was performed with 
parental differential treatment categories and gender of the participant as the independent variables, and the adjustment outcomes (i.e., social anxiety, agoraphobia, general anxiety, depression, global self-worth, and social acceptance self-worth) as the dependent variables. The majority of participants completed the SIDE-R on their biological/adoptive mother (99.1\%) and biological/adoptive father (89.6\%). The majority of participants also completed the SIDE-R on their biological sibling (88.3\%). The SIDE-R was completed by the participants on male (43.1\%) and female $(56.9 \%)$ siblings. The cell sizes for parental differential treatment and gender were: 1) no favoritism (17; 4 males and 13 females); 2) favored (30; 5 males and 25 females); 3 ) unfavored (27; 11 males and 16 females); and 4) favored by one parent/unfavored by one parent ( $31 ; 11$ males and 20 females).

Using Wilks' Criterion, the combined dependent variables were significantly affected by parental differential treatment, $\underline{F}(18,260.70)=1.79, \underline{p}<.05$. The gender $x$ parental differential treatment interaction was nonsignificant. Tests of between-subjects effects revealed that parental differential treatment was significant for depression, $\underline{F}(3$, $97)=6.99$, global self-worth, $\underline{F}(3,97)=7.65$, and social acceptance self-worth, $\underline{F}(3$, $97)=4.58, \underline{p} s<.01$. The results of subsequent Tukey tests are depicted in Table 9. Adolescents who reported no parental favoritism had lower levels of depression and higher global self-worth than those who reported that they were favored by one parent and unfavored by the other parent or that they were unfavored by both parents. The favored adolescent also reported a lower level of depression and higher global selfworth than the unfavored adolescent. Finally, adolescents who reported no parental favoritism had higher levels of social acceptance self-worth than those who reported 
that they were favored by one parent and unfavored by the other parent or that they were unfavored by both parents. Although there were no significant differences between groups for agoraphobia, social anxiety, or general anxiety, it is important to note that the no favoritism group had much lower levels of agoraphobia, social anxiety, and general anxiety than the favored, unfavored, or favored by one parent and unfavored by the other parent groups.

In summary, adolescents who reported that there was no favoritism from either parent were better adjusted than adolescents who reported that they were favored by one parent and unfavored by the other parent or that they were unfavored by both parents. In addition, adolescents who perceived they were favored by both parents tended to be better adjusted than adolescents who perceived that they were unfavored by both parents. Overall, however, adolescents tended to be better adjusted when they reported that no favoritism was present.

Hypotheses 4 and 9: Adolescents who have at least one of the following three family relationship variables: (1) parents who are high in care and low in control; (2) sibling relationships that are high in social support and low in negativity; and (3) perceive that there is no parental favoritism, will be less socially anxious and have better adjustment outcomes than adolescents who have none of the above family relationship variables present. The hypotheses examining the importance of combined family relationship variables were revised because of the small cell sizes for two and three of the family variables present. A $2 \times 2$ between-subjects mutivariate analysis of variance was performed with family relationship variables (at least one present and none present) and gender of the participant as the independent variables and the 
adjustment outcomes (i.e., social anxiety, agoraphobia, general anxiety, depression, global self-worth, and social acceptance self-worth) as the dependent variables. All of the participants completed the PBI and SIDE-R on their biological/adoptive mother (100\%) and the majority of the participants completed them on their biological/adoptive father (94.7\%). The majority of participants also completed the SIDE-R and NRI on their biological sibling (96.8\%). The SIDE-R was completed by the participants on male (48.6\%) and female (51.4\%) siblings. The cell sizes of the family variables were: 1 ) at least one present (32; 5 males and 27 females); and 2) none present (25; 9 males and 16 females).

Using Wilks' Criterion, the combined dependent variables were significantly affected by the family relationship variables, $\underline{F}(6,48)=3.77$, $\underline{p}<.01$. The gender $x$ family relationship variables interaction was nonsignificant. Tests of between-subjects effects revealed that the family relationship variables were significant for social anxiety, $\underline{F}(1,53)=11.07$, depression, $\underline{F}(1,53)=7.46$, global self-worth, $\underline{F}(1,53)=16.96$, and social acceptance self-worth, $\underline{F}(1,53)=17.26, \underline{p} s<.01$. The means and standard deviations of the two groups are presented in Table 10. Adolescents who reported at least one of the family relationship variables present in their home had lower social anxiety and depression levels and higher global and social acceptance self-worth than adolescents who reported none of the family relationship variables in their home. Thus, adolescents who reported at least one positive family relationship (of interest) were better adjusted than adolescents who reported no positive family relationships. 
Social Anxiety in Only Children and Children With Siblings

Hypothesis 5: For adolescents who report less than optimal parents, those with siblings will be less socially anxious than only children regardless of birth order if they have sibling relationships high in social support and low in negativity. The hypothesis examining the social anxiety levels in only children and children with siblings was revised because of the small cell sizes for three of the family variables present. A $2 \times 2$ between-subjects mutivariate analysis of variance was performed with child status/family variables (only children with less than optimal parents and adolescents with less than optimal parents but optimal [high support/low negativity] sibling[s]) and gender of the participant as the independent variables and social anxiety and agoraphobia as the dependent variables. A majority of the participants completed the PBI on their biological/adoptive mother (98.7\%) and their biological/adoptive father (88.6\%). The majority of participants with sibling(s) completed the NRI on their biological sibling (93\%). The SIDE-R was completed by the participants on male (40\%) and female siblings (60\%). The cell sizes of the child status/family variables were: 1 ) only children with less than optimal parents (33; 10 male and 23 females); and 2) adolescents with less than optimal parents but optimal siblings (46; 10 males and 36 females).

Using Wilks' Criterion, the combined dependent variables were nonsignificantly affected by child status/family variables, $\underline{p}>.05$. The gender $x$ child status/family variables interaction also was nonsignificant, $\underline{p}>.05$. 


\section{Discussion}

The main focus of the present study was to examine associations among several family relationships and late adolescent social anxiety. The parent-adolescent, parentsibling, and sibling relationships were examined as important factors that may influence social anxiety. The second objective was to investigate these same family relationships and their association with late adolescent adjustment outcomes such as depression, general anxiety, global self-worth, and social acceptance self-worth. Lastly, comparisons were made between adolescents with siblings and only children to investigate family relationship influences on social anxiety.

The predictions regarding the first two objectives were largely supported. The quality of the parent-adolescent and sibling relationships were related to late adolescent social anxiety. In addition, these same family relationships and the parent-sibling relationship were associated with other adjustment outcomes such as depression and self-worth. The hypothesis regarding social anxiety levels in only children and children with siblings was not supported. The specific findings related to the three objectives of the study are addressed and discussed.

\section{$\underline{\text { Adolescent Adjustment Outcomes and Family Relationships }}$}

One objective of this study was to examine specific parenting styles and their association with late adolescent social anxiety and other adjustment outcomes such as depression, general anxiety, global self-worth, and social acceptance self-worth. The parenting styles included: 1) optimal (high care/low control), 2) affectionate constraint

(high care/high control), 3) affectionless control (low care/high control), and 4) neglectful (low care/low control). It was postulated that adolescents who perceived optimal 
parenting from their mother and father would have lower levels of social anxiety and better adjustment outcomes than adolescents who perceived affectionless control maternal and paternal parenting. These predictions were supported for mother but not for father. Adolescents who perceived optimal maternal parenting reported lower levels of social anxiety, general anxiety and depression and higher global and social acceptance self-worth than adolescents who perceived affectionless control maternal parenting. Previous studies found similar results regarding optimal parenting for social anxiety (Anhalt, 1999; Morris \& Huffman, 1998; Parker, 1979a), general anxiety (Anhalt, 1999), depression (Anhalt, 1999; Morris \& Huffman, 1998; Parker, 1983a), and selfesteem (Conger, 1997; Rice, 1990). It is interesting, however, that the present study found differences for maternal parenting styles but no differences for paternal parenting styles. Anhalt (1999) found in a similar study that late adolescents' had high social anxiety when their father was perceived as having the affectionate constraint parenting style. Anhalt also reported that adolescents were high in depression and general anxiety when they perceived their fathers as having an affectionless control parenting style. These findings were not replicated in the present study. The results were consistent with previous studies showing no differences for paternal parenting styles (Parker, 1979b; 1986).

Late adolescent social anxiety, depression, and self-worth also were related to other maternal parenting styles. Adolescents who perceived optimal maternal parenting reported lower levels of social anxiety and depression and higher global and social acceptance self-worth than adolescents who reported affectionate constraint maternal parenting. In addition, global self-worth was higher for adolescents who reported 
optimal maternal parenting than for adolescents who reported neglectful maternal parenting. Thus, evidence suggests that a perceived optimal maternal parenting style tends to promote healthy psychosocial functioning in late adolescence, whereas less than optimal maternal parenting tends to hinder healthy psychosocial functioning.

Further analysis of the data revealed that adolescents who perceived optimal parenting (for both parents) had lower levels of social anxiety, general anxiety, depression, and higher global and social acceptance self-worth than adolescents who perceived affectionless control parenting. Significant results also were found between optimal parenting and the neglectful and affectionate constraint parenting styles. Specifically, adolescents who perceived optimal parenting had higher global self-worth than adolescents who perceived neglectful parenting. In addition, adolescents who reported optimal parenting had lower levels of depression and higher global and social acceptance self-worth than adolescents who reported affectionate constraint parenting.

The present study provides support that both parents are vital to adolescent psychological functioning. The perceived level of care and control by both parents, when coupled with other adolescent stressors such as new social roles and identity development, appear to be important to late adolescent psychosocial functioning. Evidence suggests that a good relationship with both parents may be important to adolescent well-being. In a study examining marital conflict and adolescent adjustment, Massey (1999) found that adolescents who reported a good relationship with one parent did not have better adjustment outcomes than adolescents who reported a poor relationship with both parents. Adolescents who reported a good relationship with both parents, however, tended to have higher self-concepts and lower levels of internalizing 
behaviors than adolescents who reported a good relationship with one parent or a poor relationship with both parents.

Regarding the sibling relationship, it was predicted that adolescents who perceived that their sibling relationships were high in social support and low in negativity would be less socially anxious and have better adjustment outcomes than adolescents who perceived that their sibling relationships were low in social support and high in negativity. This prediction was largely supported. Adolescents who reported sibling relationships high in social support and low in negativity had lower levels of social anxiety and depression and higher global and social acceptance self-worth than adolescents who reported sibling relationships low in social support and high in negativity. Differences also were found between sibling relationships high in social support and low in negativity and the remaining two sibling categories (high social support/high negativity and low social support/low negativity). Adolescents who perceived that their sibling relationships were high in social support and low in negativity had lower levels of social anxiety and higher social acceptance self-worth than adolescents who perceived that their sibling relationships were low in social support and low in negativity. Furthermore, adolescents who reported sibling relationships high in social support and low in negativity had lower levels of depression and higher levels of global self-worth than adolescents who reported sibling relationships high in social support and high in negativity. Interestingly, the hypothesis regarding general anxiety was not supported. Adolescents who reported sibling relationships low in social support and low in negativity, however, were lower in general anxiety than adolescents who reported sibling relationships low in social support and high in negativity. 
These results suggest that social support from the sibling relationship may be more important than sibling negativity in relation to social anxiety and social acceptance self-worth, whereas, perceived sibling negativity may be more important in general anxiety, depression, and feelings of global self-worth. Previous research has shown that sibling conflict is negatively related to self-worth and positively associated with depression in school-age children (Stocker, 1994). Similarly, Epkins et al. (1997) reported that preadolescent depression and anxiety were positively related to sibling hostility. Graham-Bermann et al. (1994) found similar results for sibling abuse and anxiety in young adulthood. Perceived sibling social support, on the other hand, has been found to be related to adolescent self-concept (Massey, 1999) and young adult self-esteem, self-worth, and social competence (Caya \& Liem, 1998). However, Massey also found a negative association between perceived sibling social support and internalizing behaviors, which include socially anxious behaviors. Further research is needed to explore the sibling relationship categories in the present study and their link to adolescent psychosocial functioning.

The present study broadens the sibling relationship literature by revealing that positive sibling relationships, namely those high in social support and low in negativity, are important to late adolescent sociability and healthy psychosocial functioning. Evidence suggests that perceptions of positive sibling relationships may provide adolescents with ample levels of support to promote late adolescent well-being and positive feelings of self-worth and social acceptance.

Parental favoritism also has been related to adolescent adjustment outcomes (Daniels et al., 1985; Massey, 1999; O'Connor et al., 1998; Jodl et al., 1999). However, 
no research has examined how parental favoritism is related to late adolescent social anxiety. The prediction that adolescents who perceive that they are the favored child or that no parental favoritism is present would be less socially anxious and have better adjustment outcomes than adolescents who perceive that they are the unfavored child was partially supported. No significant differences were found when parental favoritism was examined separately for mother and father. However, when perceived parental favoritism was investigated for both parents combined (e.g., favored by mother and father), significant differences were found. Adolescents who reported no parental favoritism had lower levels of depression and higher global self-worth and social acceptance self-worth than adolescents who reported that they were unfavored by both parents or favored by one parent and unfavored by the other parent. The favored adolescent also reported lower levels of depression and higher global self-worth than the unfavored adolescent. Although there were no significant differences between groups for social anxiety or general anxiety, it is important to note that the no favoritism group had much lower levels of social anxiety and general anxiety than the favored, unfavored, or favored by one parent and unfavored by the other parent groups. Statistical power (.46 and .38, respectively) was low for social and general anxiety because of the small cell sizes. Further research is needed with a larger sample size and a more inclusive parental favoritism measure to assess specific characteristics of parental favoritism (e.g., child abilities, personality) and its influence on adolescent adjustment.

The implications of these findings are noteworthy. Parental favoritism may affect adolescent adjustment directly by making the unfavored child feel inadequate and 
unworthy (Daniels et al., 1985; Harris \& Howard, 1985) and the favored child pressured to please the parents (Zervas \& Sherman, 1994). Interestingly, adolescents who perceived that they were favored by one parent and unfavored by the other parent reported similar levels of maladjustment than adolescents who perceived that they were unfavored by both parents. This finding suggests that being favored by one parent does not compensate for being unfavored by the other parent.

Parental favoritism also may influence adolescent adjustment indirectly by disrupting the parent-adolescent and sibling relationships. In fact, Massey (1999) found that adolescents' perceptions of maternal and paternal favoritism not only were related to externalizing and internalizing behaviors and self-worth, but also were negatively related to perceived social support from the sibling and respective parent. Parentadolescent relationships need to be supportive during the difficult developmental period of adolescence (Schuster \& Ashburn, 1992). It is especially critical during adolescence because an individual's self-esteem is fragile and his or her identity starts to take shape (Erikson, 1968). Negative parent-adolescent relationships may foster psychological maladjustment, whereas positive parent-adolescent relationships can promote healthy psychological functioning (Harold \& Conger, 1997; Seelig \& Brandon, 1997; Sim \& Vuchinich, 1996). Research also has shown that positive sibling relationships can provide support and be a favorable influence on adjustment outcomes (Caya \& Liem, 1998; Jenkins \& Smith, 1990). Thus, parental favoritism may leave the unfavored adolescent vulnerable to psychological maladjustment because of strained family relationships and feelings of low self-worth (Daniels et al., 1985; Massey, 1999). 
The final prediction that was associated with adolescent adjustment and family relationships combines the characteristics of several relationships to assess the importance of positive family relationships to late adolescent well-being. It was hypothesized that adolescents who have at least one of the following three family relationship variables: (1) parents high in care and low in control; (2) sibling relationships high in social support and low in negativity; and (3) perceive that there is no parental favoritism, would be less socially anxious and have better adjustment outcomes than adolescents who have none of the above family relationships present. This postulation was largely supported. Adolescents who reported at least one of the family relationship variables present in their home had lower levels of social anxiety and depression and higher global and social acceptance self-worth than adolescents who reported none of the family relationship variables present in the home. These findings may provide evidence for protective factors within the home that can buffer children from the negative effect of a poor family relationship (Rutter, 1987). For instance, positive sibling relationships may help protect adolescents from maladjustment even if the parent-adolescent relationship is negative. The present study found that adolescents who reported parental favoritism and less than optimal parenting and sibling relationships had poorer adjustment outcomes than adolescents who reported at least one positive family relationship. Jenkins and Smith (1990) reported low levels of maladjustment in pre-adolescents when they had a good relationship with a sibling, friend, or adult outside the household even though the parent-child relationships were strained. Massey (1999), however, did not find evidence to support Jenkins and 
Smith's findings. Further research is needed to explore protective factors within and outside the family system.

Social Anxiety in Only Children and Children with Siblings

The hypothesis that examined social anxiety levels in only children and children with siblings was not supported. It was hypothesized that for adolescents who reported less than optimal parenting, children with siblings would have lower levels of social anxiety than only children if children with siblings had an optimal (high social support/low negativity) relationship with their siblings. The present study found that children with siblings did not have significantly lower levels of social anxiety than only children. However, the effect (.03) and sample size (46 children with siblings, 33 only children) were low. Previous research has reported that oldest and only children are more socially anxious (Asendorpf, 1986) and to have higher self-esteem than laterborn children (Coopersmith, 1981). However, self-esteem is generally inversely related to social anxiety suggesting that other factors such as parental favoritism or sibling relationships may be related to social anxiety levels. Further research is needed to study social anxiety differences within the family system for only children and children with siblings.

\section{General Conclusions}

Theoretical Implications. The theoretical implications of the present study are noteworthy. First, the present study clarifies the significance of examining adolescent adjustment within the family context. This study provides sound evidence for family systems theory (Minuchin, 1985). That is, examining several family relationship subsystems concurrently are needed to get a better assessment of how these 
relationships influence adolescent adjustment. For example, the results showed that perceived parenting, the sibling relationship, and perceived parental favoritism were all related to adolescent adjustment.

Second, the present study identified specific characteristics of the parentadolescent, parent-sibling, and sibling relationships that may affect adolescent psychological functioning. More specifically, the present study found that perceptions of optimal parenting (high care/low control), positive sibling relationships (high social support/low negativity), and no parental favoritism were associated with positive developmental outcomes such as low levels of depression and strong feelings of selfworth.

Limitations of the Present Study. One limitation of the present study is that it is a correlational design. Causation cannot be inferred from the results. It is unknown what the direction of effects are or whether some other factor that was not measured influenced the adjustment outcomes. For example, the present study cannot decipher if positive family relationships cause healthy psychological adjustment or if healthy psychological adjustment cause positive relationships, or is there an unmeasured factor like temperament that affects adolescent adjustment and how family members interact? Future research is needed to examine the causal pathways of social (e.g., family and peers) and biological (e.g., temperament) factors on adolescent adjustment.

Another limitation of the present study was that the results were based solely on nonindependent raters. Adolescents reported on their own family relationships and adjustment outcomes, and thus the variables of interest may be correlated due to shared method variance even if they are distinct constructs. Future research should 
include multiple raters such as family members and peers to measure adjustment outcomes, and observational methods to assess family relationship characteristics.

A third limitation was that there was little ethnic diversity in the sample; the majority of participants were caucasian. Thus, the findings of the present study may not generalize to other ethnic groups. An interesting avenue of research would be to investigate parent and sibling relationship influences on adolescent adjustment in African American and Hispanic families.

The fourth limitation to the present study was that the ratio of females to males included in the sample was 2 to 1 . The participants recruited were students enrolled in lower-level psychology courses at West Virginia University where females tend to be the majority. In addition, of the students recruited, males tended to have a higher noshow rate for their research appointment than females. Thus, the sample was largely female which may account for the lack of gender differences found. Future research should include a more equal sample of males and females to explore gender differences in relation to family relationships and adolescent adjustment.

The last limitation is that it is a retrospective study. The relationships among family subsystems and the adjustment outcomes may be inaccurate because the ratings were based on recollections of past experiences. However, studies have shown that retrospective studies may give a fairly accurate account of an individual's experiences in childhood and adolescence if the questions encompass specific behaviors (Brewin et al., 1993; Plantes et al., 1988). Further studies would need to explore prospective accounts of parent and sibling relationships and their influence on adolescent adjustment outcomes. 
Suggestions for Future Research. The results and conclusions of the present study provide many directions for future research on family relationships and adolescent adjustment. First, many studies are needed to study the complexity of family relationship subsystems that work within the family system. Triadic family relationships (Davis, Hops, Alpert, \& Sheeber, 1998) such as the interaction among mother, father, and adolescent would be useful to understand further how family relationships influence adolescent adjustment outcomes. Furthermore, examining relationships with extended family members (e.g., grandparents, aunts, uncles), peers, and friends as both exacerbations of risk for maladjustment and protective factors from unhealthy psychosocial development are necessary.

Another important area for future research in adolescent adjustment is family structure. It is common in today's society for children to grow up in divorced or remarried families. Recently, studies investigating relationships with step-parents, halfsiblings, and step-siblings and their influence on adolescent adjustment have become of interest (Hetherington \& Clingempeel, 1994; Hetherington, Henderson, \& Reiss, 1999). The present study included adolescents from intact, divorced, and remarried homes, but most of the participants in the present sample (70.3\%) were from intact families. Further research is needed to explore the complexities of non-intact families and their affect on adolescent adjustment.

Third, longitudinal studies are particularly needed to study how family relationships change from early to late adolescence, and how these changes are related to internalizing and externalizing behaviors such as anxiety, depression, drug use, and aggression. Given that the average age of onset for social anxiety disorder is 
middle adolescence (Beidel, 1998), longitudinal studies using a family systems perspective would be especially useful in identifying family characteristics that hinder or facilitate child sociability. It also would be interesting to examine family relationships and how they relate to late adolescent and young adult relationship development and characteristics (e.g., intimacy, jealousy).

Fourth, family relationships are complex subsystems that may be influenced by many factors such as temperament and gender of the adolescent and other family members. Future studies on adolescent adjustment need to explore temperamental and personality differences among family members and how these factors may affect adolescent psychosocial functioning and relationship interactions within the family.

Lastly, future research is needed to develop a more comprehensive measure to assess parental favoritism. The measure (SIDE-R) used in the present study includes statements that assess global behaviors directed from the parent to the child. For instance, "Mom has tended to favor me," is one of the statements included on the SIDE-R. Developing a measure to include specific behaviors, abilities, or characteristics in which the child was favored or unfavored would give a better assessment of parental favoritism than a global assessment of whether he or she was favored.

Conclusion. The findings of the present study deliver significant contributions to the literature examining the link between family systems and adolescent adjustment. The results showed that several family relationships were related to social anxiety, depression, general anxiety, and global and social acceptance self-worth. In addition, the concurrent measurement of several family relationship subsystems was 
instrumental in identifying potential influences on adolescent adjustment. This study identified specific characteristics of the parent-adolescent, parent-sibling, and sibling relationships that may be influential to healthy adolescent psychosocial functioning. The results revealed that adolescents had the best adjustment outcomes when they reported optimal parenting (high care/low control), positive sibling relationships (high social support/low negativity), and no parental favoritism. The present study illuminates the need for studies to explore further the complexities of the family system and its influence on adolescent adjustment. 


\section{References}

American Psychiatric Association (1980). Diagnostic and statistical manual of mental disorders ( $3^{\text {rd }}$ ed.). Washington, D.C.: Author.

American Psychiatric Association (1987). Diagnostic and statistical manual of mental disorders ( $3^{\text {rd }}$ ed., rev.). Washington, D.C.: Author.

American Psychiatric Association (1994). Diagnostic and statistical manual of mental disorders (4th ed.). Washington, D.C.: Author.

Anhalt, K. (1999). The relation between parenting factors and social anxiety: A retrospective study. Unpublished doctoral dissertation, West Virginia University, Morgantown, West Virginia.

Asendorpf, J. (1986). Shyness in middle and late childhood. In W. H. Jones, J. M. Cheek, \& S. R. Briggs (Eds.), Shyness (pp. 91-103). New York: Plenum.

Barrett Singer, A. T. (1996). Different lives within the family revisited: Perceived differential parental treatment as predictive of self-perceptions and achievement in college. Unpublished master's thesis, University of California at Berkeley.

Barrett Singer, A. T., \& Weinstein, R. S. (1996, July). Indirect comparisons provide a more sensitive measure of differential parental treatment. Poster presented at the annual meeting of the American Psychological Association, San Francisco, CA.

Beck, A. T., Brown, G., Steer, R. A., Eidelson, J. I., \& Riskind, J. H. (1987). Differentiating anxiety from depression: A test of the cognitive content-specificity hypothesis. Journal of Abnormal Psychology, 96, 179-183. 
Beck, A. T., Epstein, N., Brown, G., \& Steer, R. A. (1988). An inventory for measuring clinical anxiety: Psychometric properties. Journal of Consulting and Clinical Psychology, 56, 893-897.

Beck, A. T., Rush, A. J., Shaw, B. F., \& Emery, G., (1979). Cognitive therapy of depression. New York: Guilford Press.

Beck, A. T., \& Steer, R. A. (1987). Manual for the Beck Depression Inventory, San Antonio, TX: The Psychological Corporation.

Beck, A. T., Steer, R. A., \& Brown, G. K. (1996). Manual for Beck Depression Inventory - II. San Antonio, TX: Psychological Corporation.

Bedford, V. H. (1989). Sibling research in historical perspective. American Behavioral Scientist, 33, 6-18.

Bedford, V. H. (1992). Memories of parental favoritism and the quality of parent-child ties in adulthood. Journal of Gerontology, 47, S149-S155.

Beidel, D. C. (1998). Social anxiety disorder: Etiology and early clinical presentation. Journal of Clinical Psychiatry, 59(17), 27-31.

Beidel, D. C., \& Turner, S. M. (1998). Shy children: Phobic adults. Washington, D.C.: American Psychological Association.

Bell, N. J., Avery, A. W., Jenkins, D., Feld, J., \& Schoenrock, C. J. (1985). Family relationships and social competence during late adolescence. Journal of Youth and Adolescence, 14, 109-119. 
Boer, F., Goedhart, A. W., \& Treffers, P. D. A. (1992). Siblings and their parents. In F. Boer \& J. Dunn (Eds.), Children's sibling relationships: Developmental and clinical issues (pp. 41-54). Hillsdale, NJ: Lawrence Erlbaum.

Brewin, C. R., Andrews, B., \& Gotlib, J. H. (1993). Psychopathology and early experience: A reappraisal of retrospective reports. Psychological Bulletin, 113, 82-98.

Bruch, M. A., \& Cheek, J. M. (1995). Developmental factors in childhood and adolescent shyness. In R. G. Heimberg, M. R. Liebowitz, D. A. Hope, \& F. R. Schneier (Eds.), Social phobia (pp. 163-182). New York: Guilford.

Buhrmester, D., \& Furman, W. (1990). Perceptions of sibling relationships during middle childhood and adolescence. Child Development, 61, 1387-1398.

Buss, A. H. (1980). Self-consciousness and social anxiety. San Francisco: Freeman.

Caya, M. L., \& Liem, J. H. (1998). The role of sibling support in high-conflict families. American Journal of Orthopsychiatry, 68, 327-333.

Conger, K. J., Conger, R. D., \& Scaramella, L. V. (1997). Parents, siblings, psychological control, and adolescent adjustment. $\underline{\text { Journal of Adolescent }}$ Research, 12, 113-138.

Coopersmith, S. (1981). The antecedents of self-esteem. Palo Alto, CA: Consulting Psychologists.

Daniels, D., Dunn, J., Furstenberg, F. F., Jr., \& Plomin, R. (1985). Environmental differences within the family and adjustment differences within pairs of adolescent siblings. Child Development, 56, 764-774. 
Daniels, D., \& Plomin, R. (1984). Sibling Inventory of Differential Experience (SIDE). Boulder, CO: University of Colorado.

Daniels, D., \& Plomin, R. (1985a). Origins of individual differences in infant shyness. Developmental Psychology, 21, 118-121.

Daniels, D., \& Plomin, R. (1985b). Differential experience of siblings in the same family. Developmental Psychology, 21, 747-760.

Davis, B. T., Hops, H., Alpert, A., \& Sheeber, L. (1998). Child responses to parental conflict and their effect on adjustment: A study of triadic relations. Journal of Family Psychology, 12, 163-177.

Dunn, J. (1988). Connections between relationships: Implications of research on mothers and siblings. In R. Hinde \& J. Stevenson-Hinde (Eds.), Relationships within families (pp. 168-180). Oxford, Great Britain: Oxford University Press.

Epkins, C. C., Whitehead, R. A., Bounds, J. K., \& Frey, E. D. (1997, April). Child report on sibling behavior: Differences with parents and sibling due to self-report, parents symptoms, and sibling relations. Poster presented at the biennial meeting of the Society for Research in Child Development, Washington, D.C.

Erikson, E. H. (1968). Identity, youth, and crises. New York: Norton.

Fergusson, D. M., \& Lynskey, M. T. (1996). Adolescent resiliency to family adversity. Journal of Child Psychology and Psychiatry, 37, 281-292.

Furman, W. (1995). Parenting siblings. In M. H. Bornstein (Ed.), Vol. 1 Handbook of parenting: Children and parenting (pp. 143-162). Hillsdale, NJ: Lawrence Erlbaum. 
Furman, W. (1996). The measurement of friendship perceptions: Conceptual and methodological issues. In W. M. Bukowski, A. F. Newcomb, \& W. W. Hartup (Eds), The company they keep: Friendship in childhood and adolescence (pp. 41-65). New York: Cambridge University Press.

Furman, W., \& Buhrmester, D. (1985). Children's perceptions of the personal relationships in their social networks. Developmental Psychology, 21, 10161024.

Furman, W., \& Buhrmester, D. (1992). Age and sex differences in perceptions of networks of personal relationships. Child Development, 63, 103-115.

Furman, W., \& Lanthier, R. P. (1996). Personality and sibling relationships. In G. H. Brody (Ed.), Sibling relationships: Their causes and consequences (pp.127-146). Norwood, NJ: Ablex.

Fyer, A. J., Mannuzza, S., Chapman, T. F., Liebowitz, M. R., \& Klein, D. F. (1993) A direct interview family study of social phobia. Archives of General Psychiatry, 50, 286-293.

Gelles, R. J., \& Straus, M. A. (1988). Intimate violence. New York: Simon \& Schuster. Gerlsma, C., Arrindell, W. A., \& Emmelkamp, P. M. G. (1991). Mood and memories of early parenting: Connotation of two parental rearing style questionnaires. Personality and Individual Differences, 12, 551-555.

Gilbert, P., \& Trower, P. (1990). The evolution and manifestation of social anxiety. In W. R. Crozier (Ed.), Shyness and embarrassment (pp. 119-143). New York: Cambridge University Press. 
Goldfried, M. R., \& Sobocinski, D. (1975). Effect of irrational beliefs on emotional arousal. Journal of Consulting and Clinical Psychology, 43, 504-510.

Graham-Bermann, S. A, Cutler, S. E., Litzenberger, B. W., \& Schwartz, W. E. (1994). Perceived conflict and violence in childhood sibling relationships and later emotional adjustment. Journal of Family Psychology, 8, 85-97.

Hansford, B. C., \& Hattie, J. A. (1982). Communication apprehension: An assessment of Australian and United States data. Applied Psychological Measurement, 6, 225-233.

Harold, G. T., \& Conger, R. D. (1997). Marital conflict and adolescent distress: The role of adolescent awareness. Child Development, 68, 333-350.

Harris, I. D., \& Howard, K. I. (1985). Correlates of perceived parental favoritism. The Journal of Genetic Psychology, 146, 45-56.

Harter, S. (1987). The determinants and mediational role of global self-worth in children. In N. Eisenberg (Ed.), Contemporary issues in developmental psychology (pp. 219-242). New York: Wiley.

Hartup, W. W., \& van Lieshout, C. F. M. (1992). Personality development in social context. Annual Review of Psychology, 46, 655-687.

Hazan, C., \& Shaver, P. (1987). Romantic love conceptualized as an attachment process. Journal of Personality and Social Psychology, 52, 511-524.

Henry, B., Moffitt, T. E., Caspi, A., Langley, J., \& Silva, P. A. (1994). On the "remembrance of things past:" A longitudinal evaluation of the retrospective method. Psychological Assessment, 6, 92-101. 
Hetherington, E. M., \& Clingempeel, W. G. (1992). Coping with marital transitions: A family systems perspective. Monographs of the Society for Research in Child Development, 57 (2-3, Serial No. 227).

Hetherington, E. M., Henderson, S. H., \& Reiss, D. (1999). Adolescent siblings in stepfamilies: Family functioning and adolescent adjustment. Monographs of the Society for Research in Child Development, 64 (4, Serial No. 231).

Holt, C. S., Heimberg, R. G., Hope, D. A., \& Liebowitz, M. R. (1992). Situational domains of social phobia. Journal of Anxiety Disorders, 6, 63-77.

Inderbitzen-Pisaruk, H., Clark, M. L., \& Solano, C. H. (1992). Correlates of loneliness in midadolescence. Journal of Youth and Adolescence, 21, 151-167.

Jenkins, J. M., \& Smith, M. A. (1990). Factors protecting children living in disharmonious homes: Maternal reports. Journal of the American Academy of Child and Adolescent Psychiatry, 29, 60-69.

Jodl, K. M., Bridges, M., Kim, J. E., Mitchell, A. S., \& Chan, R. W. (1999). Relations among relationships: A family systems perspective. Monographs of the Society for Research in Child Development, 64, 150-183.

Kagan, J., Reznick, J. S., \& Snidman, N. (1988). Biological bases of childhood shyness. Science, 240, 167-171.

Kamptner, L., Wang, J., \& Cusick, L. (1997, April). Influences of the early parent-child relationship on subsequent sibling and peer relations in adult females. Poster presented at the biennial meeting of the Society for Research in Child Development, Washington, D.C. 
Kazdin, A. E., (1992). Research design in clinical psychology (2nd ed.). Boston, MA: Allyn \& Bacon.

Kiracofe, N. M., \& Kiracofe, H. N. (1990). Child-perceived parental favoritism and birth order. Individual Psychology, 46, 74-81.

Klonsky, B. G., Dutton, D. L., \& Liebel, C. L. (1990). Developmental antecedents of private self-consciousness, public self-consciousness, and social anxiety. Genetic, Social, and General Psychology Monographs, 116, 273-297.

Kowal, A., \& Kramer, L. (1997). Children's understanding of parental differential treatment. Child Development, 68, 113-126.

Leary, M. R. (1990). Responses to social exclusion: Social anxiety, jealousy, loneliness, depression, and low self-esteem. Journal of Social and Clinical Psychology, 9, 221-229.

Leary, M. R., \& Dobbins, S. E. (1983). Social anxiety, sexual behavior, and contraceptive use. Journal of Personality and Social Psychology, 45, 13471354.

Leary, M. R., \& Kowalski, R. M. (1995). Social anxiety. New York: Guilford Masia, C. L., \& Morris, T. L. (1998). Parental factors associated with social anxiety: Methodological limitations and suggestions for integrated behavioral research. Clinical Psychology: Science and Practice, 5, 211-228.

Massey, C. J. (1999). Familial influences on adolescent adjustment: The sibling relationship within the family system. Unpublished master's thesis, West Virginia University, Morgantown, West Virginia. 
McHale, S. M., Crouter, A. C., McGuire, S. A., \& Updegraff, K. A. (1995). Congruence between mothers' and fathers' differential treatment of siblings: Links with family relations and children's well-being. Child Development, 66, 116-128.

Mekos, D., Hetherington, E. M., \& Reiss, D. (1996). Sibling differences in problem behavior and parental treatment in nondivorced and remarried families. Child Development, 67, 2148-2165.

Minuchin, P. (1985). Families and individual development: Provocations from the field of family therapy. Child Development, 56, 289-302.

Moore, D., \& Schultz, Jr., N. R. (1983). Loneliness at adolescence: Correlates, attributions, and coping. Journal of Youth and Adolescence, 12, 95-100.

Morris, T. L. (in press). Social phobia. In M. W. Vasey \& M. R. Dadds (Eds.), The developmental psychopathology of anxiety. Oxford University Press.

Morris, T. L., \& Huffman, D. G. (1998, March). Parental influence and social anxiety: An etiological pathway. Paper presented at the annual meeting of the Anxiety Disorders Association of America, Boston, MA.

Neeman, J., Harter, S. (1986). Manual for the Self-Perception Profile for College Students. Denver, CO: University of Denver.

Neighbors, B., Forehand, R., \& McVicar, D. (1993). Resilient adolescents and interparental conflict. American Journal of Orthopsychiatry, 63, 462-471.

O'Connor, T. G., Hetherington, E. M., \& Reiss, D. (1998). Family systems and adolescent development: Shared and nonshared risk and protective factors in nondivorced and remarried families. Development and Psychopathology, 10 , 353-375. 
Osman, A., Kopper, B. A., Barrios, F. X., Osman, J. R., \& Wade, T. (1997). The Beck Anxiety Inventory: Reexamination of factor structure and psychometric properties. Journal of Clinical Psychology, 53, 7-14.

Parish, T. S., \& McCluskey, J. J. (1994). The relationship between parenting styles and young adults' self-concepts and evaluations of parents. Family Therapy, 21. 223-226

Parker, G. (1979a). Reported parental characteristics of agoraphobics and social phobics. British Journal of Psychiatry, 135, 555-560.

Parker, G. (1979b). Reported parental characteristics in relation to trait depression and anxiety levels in a non-clinical group. Australian and New Zealand Journal of Psychiatry, 13, 260-264.

Parker, G. (1983a). Parental affectionless control as an antecedent to adult depression. Archives of General Psychiatry, 40, 956-960.

Parker, G. (1983b). Parental overprotection: A risk factor in psychosocial development. New York: Grune \& Stratton.

Parker, G. (1986). Validating an experiential measure of parenting style: The use of a twin sample. Acta Psychiatrica Scandinavica, 73, 22-27.

Parker, G., \& Gladstone, G. L. (1996). Parental characteristics as influences on adjustment in adulthood. In G. R. Pierce, B. R. Sarason, \& I. G. Sarason (Eds.), Handbook of social support and the family (pp. 195-218). New York: Plenum.

Parker, G., Tupling, H., \& Brown, L. B. (1979). A parental bonding instrument. British Journal of Medical Psychology, 52, 1-10. 
Pilkonis, P. A. (1977). Shyness, public and private, and its relationship to other measures of social behavior. Journal of Personality, 45, 585-595.

Ponzetti, Jr., J. J., \& James, C. M. (1997). Loneliness and sibling relationships. Journal of Social Behavior and Personality, 12, 102-112.

Rice, K. G. (1990). Attachment in adolescence: A narrative and meta-analytic review. Journal of Youth and Adolescence, 19, 511-538.

Riskind, J. H., Beck, A. T., Brown, G., \& Steer, R. A. (1987). Taking the measure of anxiety and depression: Validity of reconstructed Hamilton scales. Journal of Nervous and Mental Disease, $175,474-479$.

Rosenberg, M. (1979). Which significant others? American Behavioral Scientist, 16. 829-860.

Rubin, K. H. (1993). The Waterloo Longitudinal Project: Correlates and consequences of social withdrawal from childhood to adolescence. In K. H. Rubin and J. B. Asendorpf (Eds.), Social withdrawal, inhibition, and shyness in childhood (pp. 291-314). Hillsdale, NJ: Lawrence Erlbaum.

Rutter, M. (1987). Psychosocial resilience and protective mechanisms. American Journal of Orthopsychiatry, 57, 316-331.

Schlenker, B. R., \& Leary, M. R. (1982). Social anxiety and self-presentation: A conceptualization and model. Psychological Bulletin, 92, 641-669.

Schmidt, L. A., \& Fox, N. A. (1995). Individual differences in young adults' shyness and sociability: Personality and health correlates. Personality and Individual Differences, $19,455-462$. 
Schuster, C. S., \& Ashburn, S. S. (1992). The process of human development: A holistic life-span approach ( $3^{\text {rd }}$ ed.). New York: Lippincott.

Schwarz, J. C., \& Zuroff, D. C. (1979). Family structure and depression in female college students: Effects of parental conflict, decision-making power, and inconsistency of love. Journal of Abnormal Psychology, 88, 398-406.

Seelig, K. J., \& Brandon, K. (1997, November). The relationship between parenting, gender, and depressive symptoms in adolescents. Poster presented at the annual meeting of the Association for the Advancement of Behavior Therapy, Miami, FL.

Sim, H., \& Vuchinich, S. (1996). The declining effects of family stressors on antisocial behavior from childhood to adolescence and early adulthood. Journal of Family Issues, $17,408-427$.

Springer, S. A., Gastfriend, D. R. (1995). A pilot study of factors associated with resilience to substance abuse in adolescent sons of alcoholic fathers. Journal of Addictive Diseases, 14, 53-66.

Sroufe, L. A., \& Fleeson, J. (1988). The coherence of family relationships. In R. A. Hinde \& J. Stevenson-Hinde (Eds.), Relationships within families (pp. 27-47). Oxford, Great Britain: Oxford University Press.

Stemberger, R. T., Turner, S. M., Beidel, D. C., \& Calhoun, K. S. (1995). Social phobia: An analysis of possible developmental factors. Journal of Abnormal Psychology, 104, 526-531. 
Steer, R. A., \& Clark, D. A. (1997). Psychometric characteristics of the Beck Depression Inventory - II with college students. Measurement and Evaluation in Counseling and Development, 30, 128-136.

Stocker, C. M. (1994). Children's perceptions of relationships with siblings, friends, and mothers: Compensatory processes and links with adjustment. Journal of Child Psychology and Psychiatry, 35, 1447-1459.

Stocker, C. M. (1995). Differences in mothers' and fathers' relationships with siblings: Links with children's behavior problems. Development and Psychopathology, 7. 499-513.

Stocker, C. M., Lanthier, R. P., \& Furman, W. (1997). Sibling relaitonships in early adulthood. Journal of Family Psychology, 11, 210-221.

Sullivan, H. S. (1953). The interpersonal theory of psychiatry. New York: Norton.

Turner, S. M., Beidel, D. C., Dancu, C. V., \& Stanley, M. A. (1989). An empirically derived inventory to measure social fears and anxiety: The Social Phobia and Anxiety Inventory. Psychological Assessment: A Journal of Consulting and Clinical Psychology, 1, 35-40.

Warren, S. L., Huston, L., Egeland, B., \& Sroufe, L. A. (1997). Child and adolescent anxiety disorders and early attachment. Journal of the American Academy of Child and Adolescent Psychiatry, 36, 637-644.

Zervas, L. J., \& Sherman, M. E. (1994). The relationship between perceived parental favoritism and self-esteem. The Journal of Genetic Psychology, 155, 25-33. 


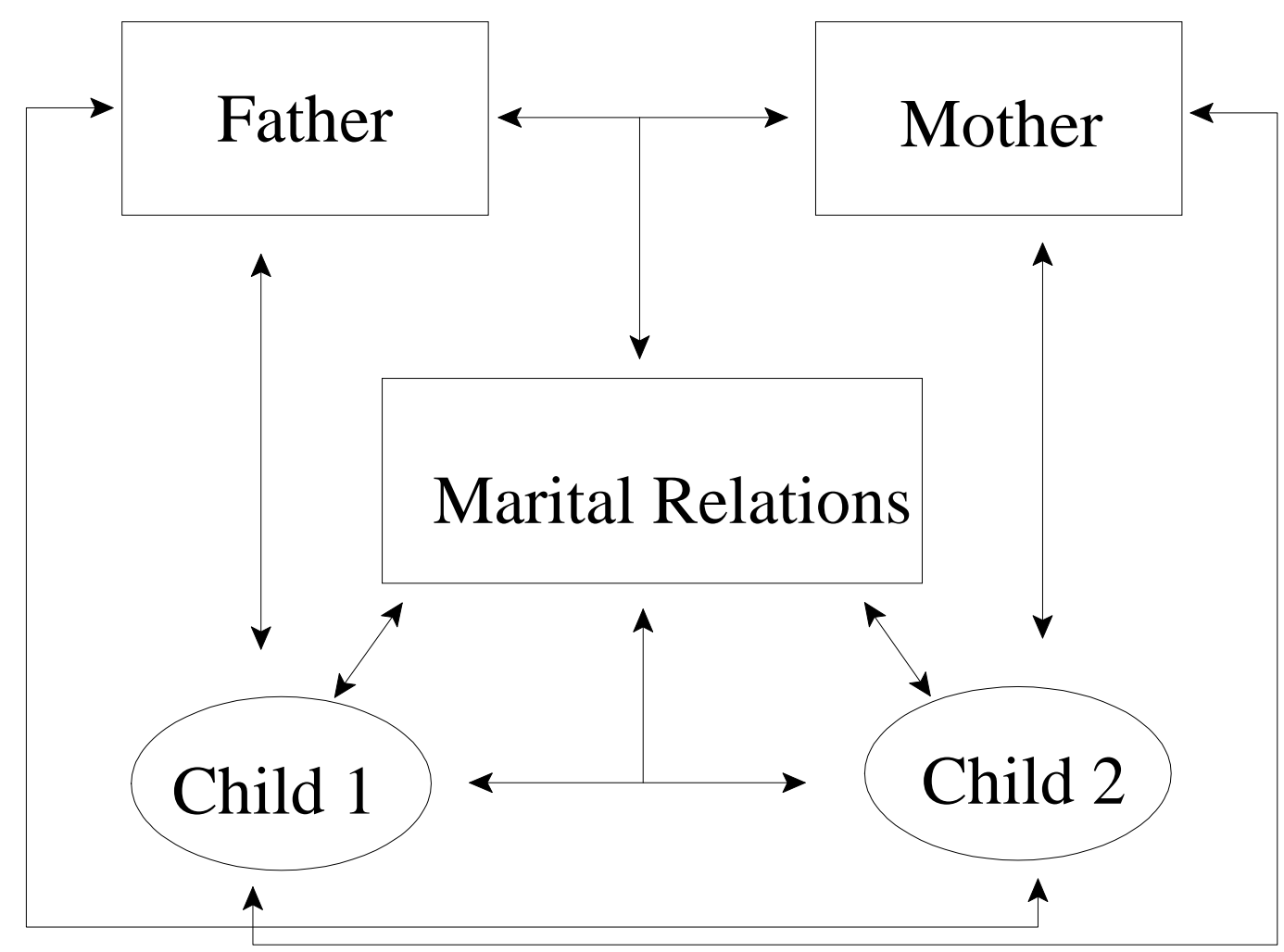

Figure 1. Interrelationships within the family system. 
Table 1

Descriptive Statistics for Additional Demographic Variables

\begin{tabular}{|c|c|c|c|c|}
\hline Variable & $\underline{N}$ & $\underline{M}$ & $\underline{\mathrm{SD}}$ & Range \\
\hline Number of Siblings & 515 & 1.65 & 1.13 & $0-7$ \\
\hline $\begin{array}{l}\text { Years Lived with Sibling Included } \\
\text { in the Study (One Sib.) }\end{array}$ & 227 & 15.33 & 3.17 & $3-20$ \\
\hline $\begin{array}{l}\text { Years Lived with Sibling Included } \\
\text { in the Study (Most Liked Sib.) }\end{array}$ & 223 & 14.60 & 3.83 & $2-20$ \\
\hline $\begin{array}{l}\text { Years Lived with Sibling Included } \\
\text { in the Study (Least Liked Sib.) }\end{array}$ & 221 & 13.77 & 4.07 & $2-20$ \\
\hline $\begin{array}{l}\text { Age of Sibling Included in Study } \\
\text { (One Sib.) }\end{array}$ & 227 & 18.70 & 4.66 & $5-34$ \\
\hline $\begin{array}{l}\text { Age of Sibling Included in Study } \\
\text { (Most Liked Sib.) }\end{array}$ & 223 & 18.67 & 5.58 & $2-30$ \\
\hline $\begin{array}{l}\text { Age of Sibling Included in Study } \\
\text { (Least Liked Sib.) }\end{array}$ & 222 & 18.16 & 5.96 & $6-48$ \\
\hline $\begin{array}{l}\text { Years Lived w/ Biological/Adoptive } \\
\text { Mother }\end{array}$ & 511 & 17.55 & 1.98 & $0-18$ \\
\hline $\begin{array}{l}\text { Years Lived w/Biological/Adoptive } \\
\text { Father }\end{array}$ & 501 & 15.59 & 5.04 & $0-18$ \\
\hline Years Lived w/Step-Mother & 29 & 3.59 & 4.97 & $0-17$ \\
\hline Years Lived w/Step-Father & 64 & 7.13 & 4.47 & $0-18$ \\
\hline
\end{tabular}

(table continues) 
Table 1 (continued)

\begin{tabular}{|c|c|c|c|c|}
\hline$\underline{\text { Variable }}$ & $\underline{\mathrm{N}}$ & $\underline{M}$ & $\underline{\mathrm{SD}}$ & Range \\
\hline Years Lived w/Female Guardian & 6 & 7.00 & 5.37 & $1-14$ \\
\hline Years Lived w/Male Guardian & 10 & 9.00 & 6.31 & $1-18$ \\
\hline Age of Biological/Adoptive Mother & 509 & 45.42 & 4.72 & $34-63$ \\
\hline Age of Biological/Adoptive Father & 494 & 47.65 & 5.34 & $34-67$ \\
\hline Age of Step-Mother & 29 & 42.90 & 6.76 & $25-54$ \\
\hline Age of Step-Father & 51 & 44.88 & 7.01 & $29-62$ \\
\hline Age of Female Guardian & 4 & 67.00 & 8.60 & $57-78$ \\
\hline Age of Male Guardian & 7 & 61.29 & 10.72 & $46-75$ \\
\hline
\end{tabular}


Table 2

Descriptive Statistics for Measured Variables

\begin{tabular}{|c|c|c|c|c|}
\hline Variables & $\underline{N}$ & $\underline{M}$ & $\underline{\mathrm{SD}}$ & Range \\
\hline \multicolumn{5}{|l|}{ Adjustment Outcomes } \\
\hline General Anxiety (BAI; Overall) & 515 & 11.00 & 8.52 & $0-51$ \\
\hline Males & 178 & 10.19 & 9.03 & $0-51$ \\
\hline Females & 337 & 11.43 & 8.23 & $0-41$ \\
\hline Depression (BDI-II; Overall) & 515 & 11.18 & 8.22 & $0-50$ \\
\hline Males & 178 & 10.33 & 7.96 & $0-37$ \\
\hline Females & 337 & 11.64 & 8.34 & $0-50$ \\
\hline $\begin{array}{l}\text { Social Phobia Total Score } \\
\quad \text { (SPAl; Overall) }\end{array}$ & 514 & 63.45 & 32.37 & $0-167.13$ \\
\hline Males & 177 & 61.09 & 28.99 & 4-144.68 \\
\hline Females & 337 & 63.45 & 33.99 & $0-167.13$ \\
\hline $\begin{array}{l}\text { Social Anxiety Subscale } \\
\text { (SPAI; Overall) }\end{array}$ & 514 & 43.99 & 27.39 & $-13.85-137.37$ \\
\hline Males & 177 & 44.09 & 24.41 & $-8.25-119.60$ \\
\hline Females & 337 & 43.94 & 28.87 & $-13.85-137.37$ \\
\hline
\end{tabular}


Table 2 (continued)

\begin{tabular}{|c|c|c|c|c|}
\hline Variables & $\underline{N}$ & $\underline{M}$ & $\underline{\mathrm{SD}}$ & Range \\
\hline $\begin{array}{l}\text { Agoraphobia Subscale } \\
\text { (SPAI; Overall) }\end{array}$ & 514 & 19.47 & 11.45 & $0-60$ \\
\hline Males & 177 & 17.03 & 9.97 & $0-51$ \\
\hline Females & 337 & 20.76 & 11.97 & $0-60$ \\
\hline Global Self-Worth (Overall) & 513 & 3.05 & 0.67 & $1-4$ \\
\hline Males & 176 & 3.08 & 0.70 & $1-4$ \\
\hline Females & 337 & 3.03 & 0.66 & $1-4$ \\
\hline Social Acceptance (Overall) & 513 & 3.00 & 0.74 & $1-4$ \\
\hline Males & 176 & 2.94 & 0.76 & $1-4$ \\
\hline Females & 337 & 3.03 & 0.73 & $1-4$ \\
\hline \multicolumn{5}{|l|}{ Relationships } \\
\hline Maternal Care (PBI; Overall) & 512 & 30.00 & 6.83 & $2-36$ \\
\hline Males & 177 & 29.16 & 7.08 & $2-36$ \\
\hline Females & 335 & 30.44 & 6.66 & 3-36 \\
\hline
\end{tabular}

(tables continues) 
Table 2 (continued)

\begin{tabular}{|c|c|c|c|c|}
\hline Variables & $\underline{N}$ & $\underline{M}$ & $\underline{\mathrm{SD}}$ & Range \\
\hline Paternal Care (PBI; Overall) & 507 & 26.73 & 8.13 & $0-36$ \\
\hline Males & 174 & 25.17 & 8.05 & $3-36$ \\
\hline Females & 333 & 27.55 & 8.06 & $0-36$ \\
\hline Maternal Control (PBI; Overall) & 508 & 12.83 & 7.00 & $0-36$ \\
\hline Males & 175 & 12.85 & 7.44 & $0-36$ \\
\hline Females & 333 & 12.82 & 6.77 & $1-36$ \\
\hline Paternal Control (PBI; Overall) & 504 & 11.45 & 6.26 & $0-34$ \\
\hline Males & 173 & 10.21 & 6.44 & $0-29$ \\
\hline Females & 331 & 12.70 & 6.06 & $1-34$ \\
\hline $\begin{array}{l}\text { Sibling Social Support (NRI; Overall) } \\
\quad \text { (One Sib.) }\end{array}$ & 227 & 3.26 & 0.83 & $1.13-5.00$ \\
\hline Males & 76 & 3.16 & 0.77 & $1.21-5.00$ \\
\hline Females & 151 & 3.32 & 0.86 & $1.13-4.83$ \\
\hline
\end{tabular}

(table continues) 
Table 2 (continued)

\begin{tabular}{|c|c|c|c|c|}
\hline Variables & $\underline{N}$ & $\underline{M}$ & $\underline{\mathrm{SD}}$ & Range \\
\hline $\begin{array}{l}\text { Sibling Social Support (NRI; Overall) } \\
\text { (Most Liked Sib.) }\end{array}$ & 219 & 3.63 & 0.64 & $1.79-5.00$ \\
\hline Males & 75 & 3.57 & 0.64 & $1.83-5.00$ \\
\hline Females & 144 & 3.66 & 0.65 & $1.79-4.83$ \\
\hline $\begin{array}{l}\text { Sibling Social Support (NRI; Overall) } \\
\text { (Least Liked Sib.) }\end{array}$ & 220 & 2.90 & 0.85 & $1.00-5.00$ \\
\hline Males & 75 & 2.81 & 0.89 & $1.13-5.00$ \\
\hline Females & 145 & 2.95 & 0.82 & $1.00-4.75$ \\
\hline $\begin{array}{l}\text { Sibling Negativity (NRI; Overall) } \\
\quad \text { (One Sib.) }\end{array}$ & 227 & 2.04 & 0.70 & $1.00-4.22$ \\
\hline Males & 77 & 2.12 & 0.68 & $1.00-4.22$ \\
\hline Females & 151 & 2.00 & 0.71 & $1.00-4.11$ \\
\hline $\begin{array}{l}\text { Sibling Negativity (NRI; Overall) } \\
\quad \text { (Most Liked Sib.) }\end{array}$ & 221 & 1.78 & 0.64 & $1.00-4.89$ \\
\hline Males & 77 & 1.91 & 0.65 & $1.00-3.78$ \\
\hline Females & 144 & 1.71 & 0.62 & $1.00-4.89$ \\
\hline
\end{tabular}

(table continues) 
Table 2 (continued)

\begin{tabular}{|c|c|c|c|c|}
\hline Variables & $\underline{N}$ & $\underline{M}$ & $\underline{S D}$ & Range \\
\hline $\begin{array}{l}\text { Sibling Negativity (NRI; Overall) } \\
\quad \text { (Least Liked Sib.) }\end{array}$ & 221 & 2.35 & 0.87 & $1.00-4.78$ \\
\hline Males & 76 & 2.35 & 0.92 & $1.00-4.11$ \\
\hline Females & 145 & 2.35 & 0.85 & $1.00-4.78$ \\
\hline \multicolumn{5}{|l|}{ Parental Differential Treatment } \\
\hline $\begin{array}{l}\text { Maternal Affection (SIDE-R; } \\
\text { Overall) (One Sib.) }\end{array}$ & 227 & -0.01 & 0.49 & $-2.60-1.40$ \\
\hline Males & 77 & -0.09 & 0.52 & $-2.60-.80$ \\
\hline Females & 150 & 0.03 & 0.47 & $-1.20-1.40$ \\
\hline $\begin{array}{l}\text { Paternal Affection (SIDE-R; Overall) } \\
\text { (One Sib) }\end{array}$ & 225 & 0.00 & 0.60 & $-2.20-1.80$ \\
\hline Males & 76 & -0.03 & 0.63 & $-2.00-1.60$ \\
\hline Females & 149 & 0.02 & 0.59 & $-2.20-1.80$ \\
\hline $\begin{array}{l}\text { Maternal Affection (SIDE-R; Overall) } \\
\text { (Most Liked Sib.) }\end{array}$ & 222 & -0.02 & 0.59 & $-2.20-1.80$ \\
\hline Males & 77 & 0.10 & 0.65 & $-1.80-1.80$ \\
\hline Females & 145 & -0.09 & 0.56 & $-2.20-1.20$ \\
\hline
\end{tabular}

(table continues) 
Table 2 (continued)

\begin{tabular}{|c|c|c|c|c|}
\hline Variables & $\underline{N}$ & $\underline{M}$ & $\underline{S D}$ & Range \\
\hline $\begin{array}{l}\text { Paternal Affection (SIDE-R; Overall) } \\
\text { (Most Liked Sib.) }\end{array}$ & 220 & -0.05 & 0.67 & $-2.20-1.80$ \\
\hline Males & 76 & 0.04 & 0.75 & $-2.00-1.80$ \\
\hline Females & 144 & -0.10 & 0.62 & $-2.20-1.80$ \\
\hline $\begin{array}{l}\text { Maternal Affection (SIDE-R; Overall) } \\
\text { (Least Liked Sib.) }\end{array}$ & 216 & -0.05 & 0.76 & $-2.60-2.20$ \\
\hline Males & 76 & -0.07 & 0.79 & $-2.60-2.00$ \\
\hline Females & 140 & -0.04 & 0.75 & $-2.40-2.20$ \\
\hline $\begin{array}{l}\text { Paternal Affection (SIDE-R; Overall) } \\
\text { (Least Liked Sib.) }\end{array}$ & 218 & -0.13 & 0.80 & $-2.60-1.80$ \\
\hline Males & 75 & -0.20 & 0.96 & $-2.60-1.80$ \\
\hline Females & 143 & -0.09 & 0.69 & $-2.60-1.60$ \\
\hline $\begin{array}{l}\text { Maternal Control (SIDE-R; Overall) } \\
\text { (One Sib.) }\end{array}$ & 227 & 0.05 & 0.57 & $-2.25-2.75$ \\
\hline Males & 77 & 0.10 & 0.57 & $-1.25-2.00$ \\
\hline Females & 150 & 0.02 & 0.56 & $-2.25-2.75$ \\
\hline
\end{tabular}

(table continues) 
Table 2 (continued)

\begin{tabular}{|c|c|c|c|c|}
\hline Variables & $\underline{N}$ & $\underline{M}$ & $\underline{S D}$ & Range \\
\hline $\begin{array}{l}\text { Paternal Control (SIDE-R; Overall) } \\
\text { (One Sib.) }\end{array}$ & 225 & -0.01 & 0.49 & $-1.50-2.00$ \\
\hline Males & 76 & 0.14 & 0.51 & $-1.00-1.75$ \\
\hline Females & 149 & -0.09 & 0.47 & $-1.50-2.00$ \\
\hline $\begin{array}{l}\text { Maternal Control (SIDE-R; Overall) } \\
\text { (Most Liked Sib.) }\end{array}$ & 222 & 0.07 & 0.63 & $-1.75-2.25$ \\
\hline Males & 77 & -0.02 & 0.69 & $-1.75-2.25$ \\
\hline Females & 145 & 0.11 & 0.59 & $-1.00-2.25$ \\
\hline $\begin{array}{l}\text { Paternal Control (SIDE-R; Overall) } \\
\text { (Most Liked Sib.) }\end{array}$ & 219 & 0.08 & 0.61 & $-1.50-2.25$ \\
\hline Males & 76 & 0.04 & 0.62 & $-1.50-2.00$ \\
\hline Females & 143 & 0.10 & 0.61 & $-1.25-2.25$ \\
\hline $\begin{array}{l}\text { Maternal Control (SIDE-R; Overall) } \\
\text { (Least Liked Sib.) }\end{array}$ & 217 & 0.10 & 0.72 & $-2.00-3.00$ \\
\hline Males & 76 & 0.14 & 0.76 & $-2.00-3.00$ \\
\hline Females & 141 & 0.07 & 0.70 & $-1.75-2.25$ \\
\hline
\end{tabular}

(table continues) 
Table 2 (continued)

\begin{tabular}{lcccc}
\hline Variables & $\underline{\mathrm{N}}$ & $\underline{\mathrm{M}}$ & $\underline{\mathrm{SD}}$ & Range \\
\hline $\begin{array}{l}\text { Paternal Control (SIDE-R; Overall) } \\
\text { (Least Liked Sib.) }\end{array}$ & 217 & 0.05 & 0.68 & $-1.75-2.25$ \\
$\quad$ Males & 75 & 0.06 & 0.66 & $-1.50-1.50$ \\
$\quad$ Females & 142 & 0.04 & 0.69 & $-1.75-2.25$ \\
\hline
\end{tabular}


Table 3

Descriptive Statistics for the Categorical Variables

\begin{tabular}{|c|c|c|c|c|}
\hline Variables & $\underline{N}$ & $\underline{M}$ & $\underline{\mathrm{SD}}$ & Range \\
\hline \multicolumn{5}{|c|}{ Parental Categories (PBI) } \\
\hline \multicolumn{5}{|l|}{ Optimal } \\
\hline Care (Overall) & 106 & 34.35 & 1.47 & $31-36$ \\
\hline Males & 33 & 33.80 & 1.57 & $31-36$ \\
\hline Females & 73 & 34.60 & 1.37 & $31.50-36.00$ \\
\hline Control (Overall) & 106 & 6.18 & 2.29 & $1.00-10.50$ \\
\hline Males & 33 & 5.88 & 2.15 & $1.00-9.50$ \\
\hline Females & 73 & 6.32 & 2.35 & $1.00-10.50$ \\
\hline \multicolumn{5}{|c|}{ Affectionate Constraint } \\
\hline Care (Overall) & 73 & 33.75 & 1.62 & $30.50-36.00$ \\
\hline Males & 12 & 33.00 & 1.49 & $30.50-36.00$ \\
\hline Females & 61 & 33.90 & 1.61 & $31-36$ \\
\hline Control (Overall) & 73 & 15.18 & 2.75 & $12.00-22.50$ \\
\hline Males & 12 & 15.42 & 1.82 & $13.00-18.50$ \\
\hline Females & 61 & 15.13 & 2.91 & $12.00-22.50$ \\
\hline
\end{tabular}


Table 3 (continued)

\begin{tabular}{|c|c|c|c|c|}
\hline Variables & $\underline{N}$ & $\underline{M}$ & $\underline{\mathrm{SD}}$ & Range \\
\hline \multicolumn{5}{|l|}{ Affectionless Control } \\
\hline Care (Overall) & 104 & 21.63 & 5.24 & $5.00-29.50$ \\
\hline Males & 36 & 21.85 & 4.51 & $10.50-28.50$ \\
\hline Females & 68 & 21.51 & 5.62 & $5.00-29.50$ \\
\hline Control (Overall) & 104 & 18.55 & 4.79 & $11.50-32.50$ \\
\hline Males & 36 & 18.25 & 4.91 & $11.50-32.50$ \\
\hline Females & 68 & 18.71 & 4.75 & $11.50-29.50$ \\
\hline \multicolumn{5}{|l|}{ Neglectful } \\
\hline Care (Overall) & 38 & 23.74 & 4.80 & $8.00-29.50$ \\
\hline Males & 19 & 23.08 & 5.24 & $8-29$ \\
\hline Females & 19 & 24.39 & 4.38 & $16.00-29.50$ \\
\hline Control (Overall) & 38 & 6.45 & 2.29 & $1.50-10.00$ \\
\hline Males & 19 & 6.39 & 2.31 & $2-9$ \\
\hline Females & 19 & 6.50 & 2.33 & $1.50-10.00$ \\
\hline
\end{tabular}

(table continues) 
Table 3 (continued)

\begin{tabular}{|c|c|c|c|c|}
\hline Variables & $\underline{N}$ & $\underline{M}$ & $\underline{\mathrm{SD}}$ & Range \\
\hline \multicolumn{5}{|c|}{ Maternal Parenting Styles (PBI) } \\
\hline \multicolumn{5}{|l|}{ Optimal } \\
\hline Care (Overall) & 155 & 34.78 & 1.38 & $32-36$ \\
\hline Males & 56 & 34.55 & 1.46 & $32-36$ \\
\hline Females & 99 & 34.91 & 1.33 & $32-36$ \\
\hline Control (Overall) & 155 & 6.50 & 2.92 & $0-11$ \\
\hline Males & 56 & 6.39 & 3.19 & $0-11$ \\
\hline Females & 99 & 6.57 & 2.77 & $1-11$ \\
\hline \multicolumn{5}{|c|}{ Affectionate Constraint } \\
\hline Care (Overall) & 121 & 34.25 & 1.47 & $32-36$ \\
\hline Males & 30 & 33.77 & 1.38 & $32-36$ \\
\hline Females & 91 & 34.41 & 1.48 & $32-36$ \\
\hline Control (Overall) & 121 & 15.54 & 3.33 & $12-27$ \\
\hline Males & 30 & 16.77 & 3.50 & $12-25$ \\
\hline Females & 91 & 15.13 & 3.19 & $12-27$ \\
\hline
\end{tabular}

(table continues) 
Table 3 (continued)

\begin{tabular}{|c|c|c|c|c|}
\hline Variables & $\underline{N}$ & $\underline{M}$ & $\underline{\mathrm{SD}}$ & Range \\
\hline \multicolumn{5}{|l|}{ Affectionless Control } \\
\hline Care (Overall) & 157 & 23.66 & 6.89 & $3-31$ \\
\hline Males & 60 & 23.42 & 6.66 & $3-31$ \\
\hline Females & 97 & 23.81 & 7.07 & $3-31$ \\
\hline Control (Overall) & 157 & 19.63 & 5.69 & $12-36$ \\
\hline Males & 60 & 19.58 & 5.97 & $12-36$ \\
\hline Females & 97 & 19.66 & 5.54 & $12-36$ \\
\hline \multicolumn{5}{|l|}{ Neglectful } \\
\hline Care (Overall) & 74 & 26.28 & 6.08 & $2-31$ \\
\hline Males & 29 & 25.69 & 7.08 & $2-31$ \\
\hline Females & 45 & 26.67 & 5.38 & $11-31$ \\
\hline Control (Overall) & 74 & 7.27 & 2.68 & $1-11$ \\
\hline Males & 29 & 7.31 & 2.77 & $2-11$ \\
\hline Females & 45 & 7.24 & 2.66 & $1-11$ \\
\hline
\end{tabular}

(table continues) 
Table 3 (continued)

\begin{tabular}{|c|c|c|c|c|}
\hline Variables & $\underline{N}$ & $\underline{\mathrm{M}}$ & $\underline{\mathrm{SD}}$ & Range \\
\hline \multicolumn{5}{|c|}{ Paternal Parenting Styles (PBI) } \\
\hline \multicolumn{5}{|l|}{ Optimal } \\
\hline Care (Overall) & 146 & 33.20 & 2.33 & 29-36 \\
\hline Males & 48 & 32.42 & 2.30 & $29-36$ \\
\hline Females & 98 & 33.58 & 2.27 & $29-36$ \\
\hline Control (Overall) & 146 & 6.17 & 2.44 & $0-10$ \\
\hline Males & 48 & 5.54 & 2.56 & $0-10$ \\
\hline Females & 98 & 6.48 & 2.34 & $1-10$ \\
\hline \multicolumn{5}{|c|}{ Affectionate Constraint } \\
\hline Care (Overall) & 116 & 32.47 & 2.29 & $29-36$ \\
\hline Males & 28 & 32.04 & 2.25 & $29-36$ \\
\hline Females & 88 & 32.61 & 2.30 & $29-36$ \\
\hline Control (Overall) & 116 & 14.89 & 3.46 & $11-25$ \\
\hline Males & 28 & 14.18 & 3.28 & $11-23$ \\
\hline Females & 88 & 15.11 & 3.50 & $11-25$ \\
\hline
\end{tabular}

(table continues) 
Table 3 (continued)

\begin{tabular}{|c|c|c|c|c|}
\hline Variables & $\underline{N}$ & $\underline{M}$ & $\underline{\mathrm{SD}}$ & Range \\
\hline \multicolumn{5}{|l|}{ Affectionless Control } \\
\hline Care (Overall) & 156 & 19.74 & 6.79 & $0-28$ \\
\hline Males & 50 & 19.48 & 6.44 & $3-28$ \\
\hline Females & 106 & 19.87 & 6.97 & $0-28$ \\
\hline Control (Overall) & 156 & 16.88 & 5.11 & $11-34$ \\
\hline Males & 50 & 16.98 & 4.95 & $11-29$ \\
\hline Females & 106 & 16.84 & 5.20 & $11-34$ \\
\hline \multicolumn{5}{|l|}{ Neglectful } \\
\hline Care (Overall) & 85 & 20.82 & 6.82 & $0-28$ \\
\hline Males & 47 & 20.02 & 6.44 & $5-28$ \\
\hline Females & 38 & 21.82 & 7.23 & $0-28$ \\
\hline Control (Overall) & 85 & 5.89 & 2.94 & $0-10$ \\
\hline Males & 47 & 5.40 & 3.22 & $0-10$ \\
\hline Females & 38 & 6.50 & 2.45 & $1-10$ \\
\hline
\end{tabular}

(table continues) 
Table 3 (continued)

\begin{tabular}{|c|c|c|c|c|}
\hline Variables & $\underline{N}$ & $\underline{M}$ & $\underline{\mathrm{SD}}$ & Range \\
\hline \multicolumn{5}{|c|}{ Sibling Relationship Categories (NRI) } \\
\hline \multicolumn{5}{|c|}{ High Social Support/Low Negativity } \\
\hline Social Support (Overall) & 132 & 3.94 & .43 & $3.25-5.00$ \\
\hline Males & 33 & 4.00 & .44 & $3.29-5.00$ \\
\hline Females & 99 & 3.92 & .42 & $3.25-4.83$ \\
\hline Negativity (Overall) & 132 & 1.50 & .28 & $1.00-1.94$ \\
\hline Males & 33 & 1.49 & .30 & $1.00-1.94$ \\
\hline Females & 99 & 1.50 & .28 & $1.00-1.94$ \\
\hline \multicolumn{5}{|c|}{ High Social Support/High Negativity } \\
\hline Social Support (Overall) & 86 & 3.77 & .34 & $3.25-4.71$ \\
\hline Males & 27 & 3.71 & .31 & $3.29-4.48$ \\
\hline Females & 59 & 3.79 & .36 & $3.25-4.71$ \\
\hline Negativity (Overall) & 86 & 2.45 & .42 & $2.00-3.78$ \\
\hline Males & 27 & 2.50 & .47 & $2.00-3.44$ \\
\hline Females & 59 & 2.43 & .40 & $2.00-3.78$ \\
\hline
\end{tabular}

(table continues) 
Table 3 (continued)

\begin{tabular}{|c|c|c|c|c|}
\hline Variables & $\underline{N}$ & $\underline{M}$ & $\underline{\mathrm{SD}}$ & Range \\
\hline \multicolumn{5}{|c|}{ Low Social Support/High Negativity } \\
\hline Social Support (Overall) & 137 & 2.63 & .50 & $1.21-3.38$ \\
\hline Males & 54 & 2.68 & .50 & $1.21-3.38$ \\
\hline Females & 83 & 2.59 & .50 & $1.46-3.38$ \\
\hline Negativity (Overall) & 137 & 2.63 & .50 & $2.00-4.28$ \\
\hline Males & 54 & 2.67 & .49 & $2.00-4.22$ \\
\hline Females & 83 & 2.61 & .51 & $2.00-4.28$ \\
\hline \multicolumn{5}{|c|}{ Low Social Support/Low Negativity } \\
\hline Social Support (Overall) & 89 & 2.78 & .44 & $1.13-3.38$ \\
\hline Males & 36 & 2.76 & .37 & $1.96-3.38$ \\
\hline Females & 53 & 2.80 & .49 & $1.13-3.38$ \\
\hline Negativity (Overall) & 89 & 1.60 & .26 & $1.00-1.94$ \\
\hline Males & 36 & 1.62 & .20 & $1.17-1.89$ \\
\hline Females & 53 & 1.59 & .29 & $1.00-1.94$ \\
\hline
\end{tabular}

(table continues) 
Table 3 (continued)

\begin{tabular}{|c|c|c|c|c|}
\hline Variables & $\underline{N}$ & $\underline{M}$ & $\underline{\mathrm{SD}}$ & Range \\
\hline \multicolumn{5}{|c|}{$\begin{array}{l}\text { Parental Favoritism (SIDE-R; Both } \\
\text { Parents) }\end{array}$} \\
\hline \multicolumn{5}{|l|}{ No Favoritism } \\
\hline Affection (Overall) & 17 & .00 & .00 & $0-0$ \\
\hline Males & 4 & .00 & .00 & $0-0$ \\
\hline Females & 13 & .00 & .00 & $0-0$ \\
\hline Control (Overall) & 17 & .00 & .00 & $0-0$ \\
\hline Males & 4 & .00 & .00 & $0-0$ \\
\hline Females & 13 & .00 & .00 & $0-0$ \\
\hline \multicolumn{5}{|l|}{ Favored } \\
\hline Affection (Overall) & 30 & .49 & .29 & $.20-1.55$ \\
\hline Males & 5 & .61 & .55 & $.20-1.55$ \\
\hline Females & 25 & .46 & .22 & $.20-.80$ \\
\hline Control (Overall) & 30 & -.41 & .44 & $-1.88-.00$ \\
\hline Males & 5 & -.54 & .38 & $-1.00-.00$ \\
\hline Females & 25 & -.39 & .45 & $-1.88-.00$ \\
\hline
\end{tabular}

(table continues) 
Table 3 (continued)

\begin{tabular}{|c|c|c|c|c|}
\hline Variables & $\underline{N}$ & $\underline{M}$ & $\underline{\mathrm{SD}}$ & Range \\
\hline \multicolumn{5}{|c|}{$\begin{array}{l}\text { Favored by One Parent/Unfavored } \\
\text { by Other Parent }\end{array}$} \\
\hline Affection (Overall) & 32 & -.03 & .30 & $-.50-.60$ \\
\hline Males & 12 & -.03 & .32 & $-.50-.60$ \\
\hline Females & 20 & -.05 & .29 & $-.50-.50$ \\
\hline Control (Overall) & 32 & .05 & .30 & $-.63-.94$ \\
\hline Males & 12 & .10 & .24 & $-.25-.63$ \\
\hline Females & 20 & .03 & .33 & $-.63-.94$ \\
\hline \multicolumn{5}{|l|}{ Unfavored } \\
\hline Affection (Overall) & 27 & -.74 & .34 & $-1.40-(-.20)$ \\
\hline Males & 11 & -.79 & .33 & $-1.40-(-.30)$ \\
\hline Females & 16 & -.71 & .35 & $-1.30-(-.20)$ \\
\hline Control (Overall) & 27 & .53 & .42 & $.00-1.69$ \\
\hline Males & 11 & .56 & .39 & $.13-1.25$ \\
\hline Females & 16 & .52 & .45 & $.00-1.69$ \\
\hline
\end{tabular}

(table 3 continues) 
Table 3 (continued)

\begin{tabular}{|c|c|c|c|c|}
\hline Variables & $\underline{N}$ & $\underline{M}$ & $\underline{\mathrm{SD}}$ & Range \\
\hline \multicolumn{5}{|c|}{ Maternal Favoritism (SIDE-R) } \\
\hline \multicolumn{5}{|l|}{ No Favoritism } \\
\hline Affection (Overall) & 38 & .00 & .00 & $0-0$ \\
\hline Males & 14 & .00 & .00 & $0-0$ \\
\hline Females & 24 & .00 & .00 & $0-0$ \\
\hline Control (Overall) & 38 & .00 & .00 & $0-0$ \\
\hline Males & 14 & .00 & .00 & $0-0$ \\
\hline Females & 24 & .00 & .00 & $0-0$ \\
\hline \multicolumn{5}{|l|}{ Favored } \\
\hline Affection (Overall) & 86 & .50 & .31 & $.20-1.40$ \\
\hline Males & 29 & .47 & .28 & $.20-1.30$ \\
\hline Females & 57 & .52 & .33 & $.20-1.40$ \\
\hline Control (Overall) & 86 & -.35 & .39 & $-2.25-.00$ \\
\hline Males & 29 & -.31 & .32 & $-1.25-.00$ \\
\hline Females & 57 & -.37 & .42 & $-2.25-.00$ \\
\hline
\end{tabular}

(table continues) 
Table 3 (continued)

\begin{tabular}{|c|c|c|c|c|}
\hline Variables & $\underline{N}$ & $\underline{\mathrm{M}}$ & $\underline{\mathrm{SD}}$ & Range \\
\hline \multicolumn{5}{|l|}{ Unfavored } \\
\hline Affection (Overall) & 98 & -.68 & .50 & $-2.60-(-.20)$ \\
\hline Males & 31 & -.72 & .61 & $-2.60-(-.20)$ \\
\hline Females & 67 & -.66 & .45 & $-2.00-(-.20)$ \\
\hline Control (Overall) & 98 & .57 & .58 & $.00-2.75$ \\
\hline Males & 31 & .59 & .58 & $.00-2.00$ \\
\hline Females & 67 & .56 & .58 & $.00-2.75$ \\
\hline \multicolumn{5}{|c|}{ Paternal Favoritism (SIDE-R) } \\
\hline \multicolumn{5}{|l|}{ No Favoritism } \\
\hline Affection (Overall) & 51 & .00 & .00 & $.00-.00$ \\
\hline Males & 13 & .00 & .00 & $.00-.00$ \\
\hline Females & 38 & .00 & .00 & $.00-.00$ \\
\hline Control (Overall) & 51 & .00 & .00 & $.00-.00$ \\
\hline Males & 13 & .00 & .00 & $.00-.00$ \\
\hline Females & 38 & .00 & .00 & $.00-.00$ \\
\hline
\end{tabular}

(table contirnues) 
Table 3 (continued)

\begin{tabular}{|c|c|c|c|c|}
\hline Variables & $\underline{N}$ & $\underline{M}$ & $\underline{\mathrm{SD}}$ & Range \\
\hline \multicolumn{5}{|l|}{ Favored } \\
\hline Affection (Overall) & 93 & .57 & .41 & $.20-1.80$ \\
\hline Males & 24 & .74 & .53 & $.20-1.80$ \\
\hline Females & 69 & .51 & .34 & $.20-1.80$ \\
\hline Control (Overall) & 93 & -.40 & .42 & $-1.50-.00$ \\
\hline Males & 24 & -.38 & .42 & $-1.50-.00$ \\
\hline Females & 69 & -.41 & .43 & $-1.50-.00$ \\
\hline \multicolumn{5}{|l|}{ Unfavored } \\
\hline Affection (Overall) & 91 & -.75 & .51 & $-2.20-(-.20)$ \\
\hline Males & 37 & -.74 & .52 & $-2.20-(-.20)$ \\
\hline Females & 54 & -.76 & .51 & $-2.20-(-.20)$ \\
\hline Control (Overall) & 91 & .44 & .49 & $.00-1.88$ \\
\hline Males & 37 & .47 & .51 & $.00-1.75$ \\
\hline Females & 54 & .42 & .47 & $.00-1.88$ \\
\hline
\end{tabular}


Table 4

Intercorrelations for the Measured Variables for Only Children

\begin{tabular}{|c|c|c|c|c|c|c|c|c|c|c|c|c|c|}
\hline Variable & 1 & 2 & 3 & 4 & 5 & 6 & 7 & 8 & 9 & 10 & 11 & 12 & 13 \\
\hline 1. Depression-Mom & & & & & & & & & & & & & \\
\hline 2. Shyness - Mom & $.27^{*}$ & & & & & & & & & & & & \\
\hline 3. Anxiety - Mom & .18 & .04 & & & & & & & & & & & \\
\hline 4. Self-esteem - Mom & $.52^{* *}$ & .08 & .07 & & & & & & & & & & \\
\hline 5. Depression - Dad & $.39^{* *}$ & .06 & .23 & $.39^{* *}$ & & & & & & & & & \\
\hline 6. Shyness - Dad & -.09 & .24 & -.01 & .15 & .10 & & & & & & & & \\
\hline 7. Anxiety - Dad & $.35^{\star \star}$ & $.28^{*}$ & $.31^{*}$ & .11 & $.31^{*}$ & .03 & & & & & & & \\
\hline 8. Self-esteem - Dad & .08 & -.08 & .16 & .08 & $.35^{\star *}$ & -.07 & $-.35^{\star}$ & & & & & & \\
\hline 9. General Anxiety & -.24 & .07 & .07 & -.22 & -.24 & .10 & $-.26^{*}$ & $-.36^{\star *}$ & & & & & \\
\hline 10. Depression & -.03 & .17 & .01 & -.03 & -.01 & .04 & -.09 & $-.30^{*}$ & $.61^{* *}$ & & & & \\
\hline $\begin{array}{l}\text { 11. Social Phobia } \\
\text { Total Score }\end{array}$ & -.15 & .12 & .23 & -.09 & -.06 & -.10 & .06 & -.19 & .22 & $.46^{\star *}$ & & & \\
\hline 12. Agoraphobia & $-.32^{*}$ & -.04 & .08 & -.15 & -.01 & -.02 & -.10 & -.16 & $.45^{\star \star}$ & $.40^{* *}$ & $.60^{\star *}$ & & \\
\hline 13. Social Anxiety & -.05 & .16 & -.01 & -.04 & -.06 & -.11 & .11 & -.16 & .09 & $.39^{* *}$ & $-.95^{\star *}$ & $.32^{*}$ & \\
\hline
\end{tabular}

${ }^{*} \underline{p}<.05 ;{ }^{* *} \underline{p}<.01 ; \underline{N}=63$

(table continues) 
Table 4 (continued)

\begin{tabular}{lccccccc}
\hline \multicolumn{1}{c}{ Variable } & 14 & 15 & 16 & 17 & 18 & 19 & 20 \\
\hline 1. Depression-Mom & .01 & .03 & -.11 & .05 & .24 & -.19 & -.17 \\
2. Shyness - Mom & .01 & -.07 & .01 & -.06 & .15 & -.17 & -.23 \\
3. Anxiety - Mom & .12 & -.07 & .07 & .01 & .23 & .08 & -.09 \\
4. Self-esteem - Mom & .04 & .18 & .12 & .04 & .26 & -.04 & -.06 \\
5. Depression - Dad & .24 & .09 & .16 & .12 & $.59^{\star *}$ & -.20 & .11 \\
6. Shyness - Dad & -.06 & .05 & .23 & .14 & .25 & .13 & .13 \\
7. Anxiety - Dad & .15 & -.03 & -.05 & .13 & .15 & -.17 & .12 \\
8. Self-esteem - Dad & $.45^{\star *}$ & $.35^{\star *}$ & -.13 & -.08 & .21 & -.28 & .01 \\
9. General Anxiety & $-.32^{*}$ & $-.34^{* *}$ & .14 & .12 & .06 & .15 & .01 \\
10. Depression & $-.60^{* *}$ & $-.53^{* *}$ & -.09 & $.53^{* *}$ & .08 & $.35^{\star *}$ & .07 \\
11. Social Phobia & $-.36^{* *}$ & $-.64^{* *}$ & -.05 & $.34^{* *}$ & -.08 & $.30^{*}$ & .20 \\
$\quad$ Total Score & & & & & & & \\
12. Agoraphobia & -.19 & $-.34^{\star *}$ & .13 & .23 & .04 & .21 & .19 \\
13. Social Anxiety & $-.35^{* *}$ & $-.63^{\star *}$ & -.11 & $.31^{*}$ & -.12 & $.27^{*}$ & .16 \\
\hline
\end{tabular}

${ }^{*} \underline{p}<.05 ;{ }^{* *} \underline{p}<.01$

(table continues) 
Table 4 (continued)

\begin{tabular}{lccccccc}
\hline \multicolumn{1}{c}{ Variable } & 14 & 15 & 16 & 17 & 18 & 19 & 20 \\
\hline 14. Global Self-worth & & & & & & & \\
15. Social Acceptance & $.70^{* *}$ & & & & & & \\
16. Maternal Care & .23 & .14 & & & & & \\
17. Maternal Control & $-.40^{* *}$ & $-.34^{* *}$ & $-.31^{*}$ & & & \\
18. Paternal Care & .19 & .14 & $.46^{*}$ & .11 & & \\
19. Paternal Control & $-.38^{* *}$ & $-.26^{*}$ & -.10 & $.63^{* *}$ & -.20 & & \\
20. Gender of Adol. ${ }^{*}$ & -.02 & .02 & .18 & $.34^{* *}$ & .12 & $.48^{* *}$ & \\
\hline
\end{tabular}

${ }^{*} \mathrm{p}<.05 ;{ }^{* *} \mathrm{p}<.01 ;{ }^{\#}$ Gender of Adolescent was coded as $1=$ male and $2=$ female. 
Table 5

Intercorrelations for the Measured Variables for Adolescents with Sibling(s)

\begin{tabular}{|c|c|c|c|c|c|c|c|c|c|c|c|c|c|}
\hline Variable & 1 & 2 & 3 & 4 & 5 & 6 & 7 & 8 & 9 & 10 & 11 & 12 & 13 \\
\hline \multicolumn{14}{|l|}{ 1. Depression-Mom } \\
\hline 2. Shyness - Mom & $.11^{*}$ & & & & & & & & & & & & \\
\hline 3. Anxiety - Mom & $.38^{\star \star}$ & $.10^{*}$ & & & & & & & & & & & \\
\hline 4. Self-esteem - Mom & $.31^{\star *}$ & $.24^{* *}$ & $.23^{\star \star}$ & & & & & & & & & & \\
\hline 5. Depression - Dad & $.19^{\star *}$ & -.01 & .08 & $.10^{\star}$ & & & & & & & & & \\
\hline 6. Shyness - Dad & $.17^{\star \star}$ & $.15^{\star \star}$ & $.28^{\star \star}$ & $.19^{\star \star}$ & .02 & & & & & & & & \\
\hline 7. Anxiety - Dad & $.17^{\star \star}$ & .02 & $.36^{\star *}$ & $.17^{* \star}$ & $.16^{\star \star}$ & -.03 & & & & & & & \\
\hline 8. Self-esteem - Dad & $.17^{\star \star}$ & $.12^{*}$ & .07 & $.15^{\star \star}$ & $.31^{\star \star}$ & $.19^{* \star}$ & .09 & & & & & & \\
\hline 9. General Anxiety & $-.14^{\star *}$ & -.07 & $-.25^{\star *}$ & $-.20^{\star *}$ & -.06 & -.08 & $-.13^{\star *}$ & $-.10^{\star}$ & & & & & \\
\hline 10. Depression & $-.22^{\star \star}$ & -.07 & $-.25^{\star \star}$ & $-.23^{\star \star}$ & -.05 & -.07 & $-.16^{\star \star}$ & -.07 & $.59^{\star \star}$ & & & & \\
\hline $\begin{array}{l}\text { 11. Social Phobia } \\
\text { Total Score }\end{array}$ & $-.18^{\star *}$ & $-.11^{*}$ & $-.16^{\star \star}$ & $-.17^{\star *}$ & -.08 & -.08 & $-.13^{\star \star}$ & -.06 & $.33^{\star \star}$ & $.43^{* *}$ & & & \\
\hline 12. Agoraphobia & $-.15^{\star *}$ & -.07 & $-.21^{\star *}$ & $-.11^{*}$ & $-.12^{*}$ & -.05 & $-.18^{\star \star}$ & -.07 & $.40^{* *}$ & $.35^{\star \star}$ & $.58^{* \star}$ & & \\
\hline 13. Social Anxiety & $-.15^{\star \star}$ & $-.10^{*}$ & $-.10^{*}$ & $-.15^{\star \star}$ & -.05 & -.08 & -.07 & -.04 & $.22^{\star *}$ & $.35^{\star \star}$ & $.94^{\star *}$ & $.26^{\star \star}$ & \\
\hline
\end{tabular}

${ }^{*} \underline{p}<.05 ;{ }^{* *} \underline{p}<.01 ; N=452$

(table continues) 
Table 5 (continued)

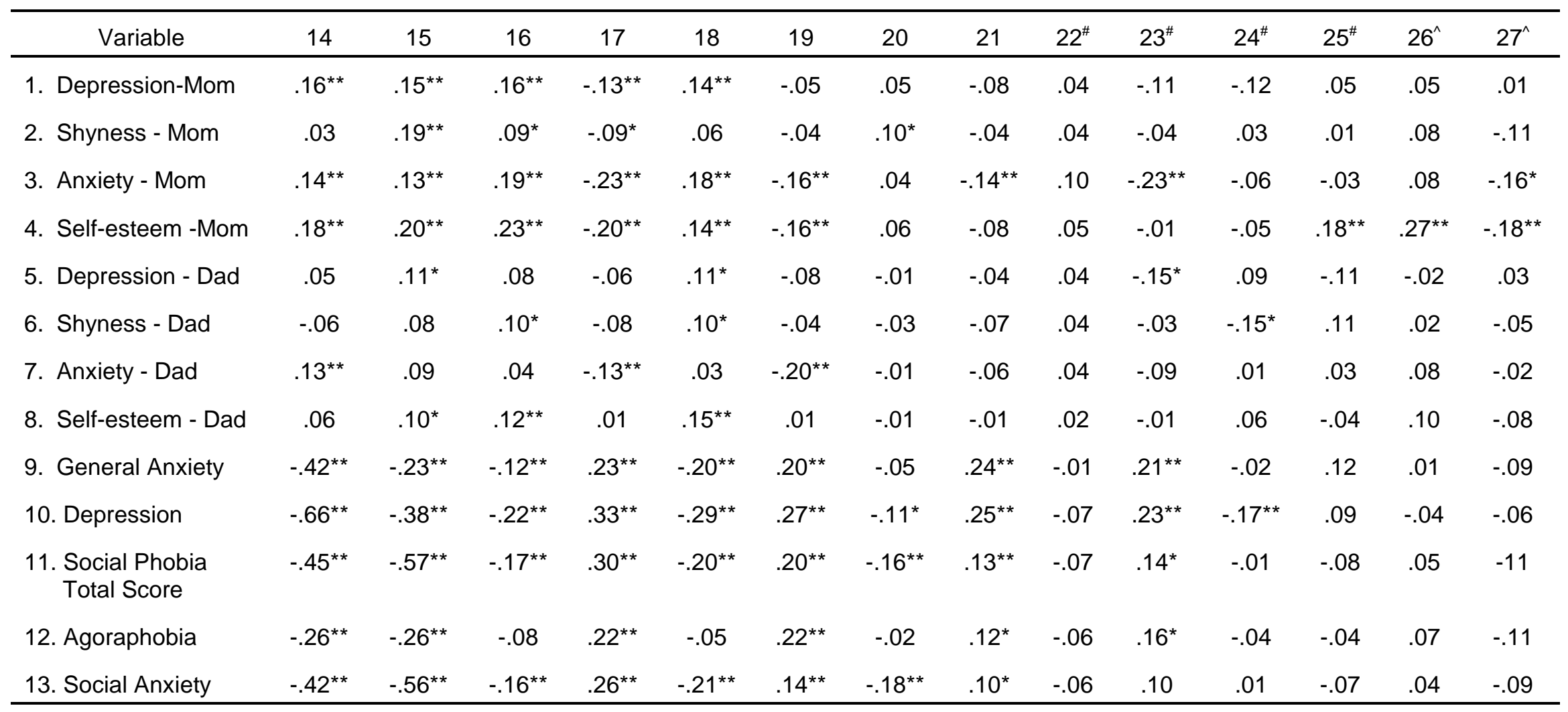

${ }^{*} \underline{p}<.05 ;{ }^{* *} \underline{p}<.01 ; N=452 ;{ }^{*} n=227 ;{ }^{\wedge}=225$

(table continues) 
Table 5 (continued)

\begin{tabular}{|c|c|c|c|c|c|c|c|c|c|c|c|c|c|c|}
\hline Variable & $28^{\wedge}$ & $29^{\wedge}$ & $30^{\wedge}$ & $31^{\wedge}$ & $32^{\wedge}$ & $33^{\wedge}$ & $34^{\#}$ & $35^{\#}$ & $36^{\wedge}$ & $37^{\wedge}$ & $38^{\wedge}$ & $39^{\wedge}$ & 40 & 41 \\
\hline 2. Shyness - Mom & -.02 & -.12 & .03 & .01 & .06 & -.09 & $-.21^{* *}$ & -.10 & -.01 & .06 & -.12 & .02 & -.01 & -.04 \\
\hline 3. Anxiety - Mom & .07 & -.12 & .04 & $-.14^{*}$ & .01 & $-.15^{\star}$ & -.07 & .11 & -.02 & .01 & -.01 & -.07 & -.01 & -.02 \\
\hline 4. Self-esteem -Mom & -.07 & -.02 & $.27^{\star *}$ & -.11 & .11 & -.12 & -.02 & -.09 & -.12 & .02 & -.02 & .09 & -.06 & $-.14^{\star \star}$ \\
\hline 7. Anxiety - Dad & -.12 & -.05 & .05 & -.02 & -.05 & -.06 & .12 & .12 & -.03 & .07 & .12 & -.05 & .03 & .01 \\
\hline 8. Self-esteem - Dad & -.03 & -.01 & .12 & .02 & .01 & -.06 & -.09 & .09 & .01 & -.04 & .02 & .01 & -.01 & -.04 \\
\hline 9. General Anxiety & -.09 & $.14^{*}$ & -.03 & -.04 & -.12 & $.25^{\star *}$ & $-.14^{\star}$ & -.10 & .08 & $.15^{\star}$ & .09 & -.06 & -.04 & .08 \\
\hline 13. Social Anxiety & -.05 & .01 & $.14^{*}$ & -.07 & -.01 & .08 & $-.17^{\star \star}$ & .05 & .01 & .04 & .03 & .04 & .05 & -.03 \\
\hline
\end{tabular}

${ }^{*} \underline{p}<.05 ;{ }^{* *} \underline{p}<.01 ; N=452 ;{ }^{*} n=227 ;{ }^{\wedge}=225$

(table continues) 
Table 5 (continued)

\begin{tabular}{|c|c|c|c|c|c|c|c|c|c|c|c|c|c|}
\hline Variable & 14 & 15 & 16 & 17 & 18 & 19 & 20 & 21 & $22^{\#}$ & $23^{\#}$ & $24^{\#}$ & $25^{\#}$ & 26 \\
\hline \multicolumn{14}{|l|}{ 14. Global Self-Worth } \\
\hline 15. Social Acceptance & $.56^{\star *}$ & & & & & & & & & & & & \\
\hline 16. PBI Care - Mom & $.24^{\star *}$ & $.21^{\star *}$ & & & & & & & & & & & \\
\hline 17. PBI Control - Mom & $-.33^{\star *}$ & $-.27^{\star *}$ & $-.43^{\star *}$ & & & & & & & & & & \\
\hline 18. PBI Care - Dad & $.29^{\star \star}$ & $.28^{\star \star}$ & $.47^{\star \star}$ & $-.28^{\star \star}$ & & & & & & & & & \\
\hline 19. PBI Control - Dad & $-.25^{\star *}$ & $-.21^{* *}$ & $-.27^{\star *}$ & $.65^{\star *}$ & $-.33^{\star *}$ & & & & & & & & \\
\hline $\begin{array}{l}\text { 20. NRI Social } \\
\text { Support - Sibings }\end{array}$ & $.13^{* *}$ & .02 & $.30^{\star *}$ & $-.19^{\star \star}$ & $.32^{\star \star}$ & $-.18^{\star *}$ & & & & & & & \\
\hline $\begin{array}{l}\text { 21. NRI Negativity - } \\
\text { Siblings }\end{array}$ & $-.17^{\star \star}$ & $.12^{*}$ & $-.23^{\star \star}$ & $.25^{\star *}$ & $-.19^{* *}$ & $.23^{\star *}$ & $-.36^{\star *}$ & & & & & & \\
\hline $\begin{array}{l}\text { 22. Maternal Affection" } \\
\text { (One Sib; SIDE-R) }\end{array}$ & -.04 & -.07 & $.39^{* *}$ & $-.16^{*}$ & .12 & $-.21^{* *}$ & .12 & -.10 & & & & & \\
\hline $\begin{array}{l}\text { 23. Maternal Control }{ }^{\#} \\
\text { (One Sib; SIDE-R) }\end{array}$ & -.11 & -.07 & $-.31^{\star *}$ & $.30^{* *}$ & $-.22^{\star *}$ & $.21^{\star *}$ & $-.18^{\star *}$ & $-.23^{\star \star}$ & $-.41^{* *}$ & & & & \\
\hline $\begin{array}{l}\text { 24. Paternal Affection }{ }^{\#} \\
\text { (One Sib; SIDE-R) }\end{array}$ & $.15^{\star}$ & $-.11^{*}$ & -.02 & -.10 & $.29^{\star *}$ & $-.21^{\star \star}$ & -.07 & .10 & -.01 & -.07 & & & \\
\hline $\begin{array}{l}\text { 25. Paternal Control }{ }^{\#} \\
\text { (One Sib; SIDE-R) }\end{array}$ & -.08 & -.07 & -.06 & -.02 & $-.20^{* *}$ & $.17^{*}$ & -.10 & .07 & $-.23^{* *}$ & $.42^{\star *}$ & $-.33^{\star \star}$ & & \\
\hline $\begin{array}{l}\text { 26. Maternal Affection } \\
\text { (Least Liked Sib; } \\
\text { SIDE-R) }\end{array}$ & $-.16^{*}$ & $-.10^{*}$ & $.57^{\star *}$ & $-.33^{\star \star}$ & -.02 & -.13 & .12 & -.06 & ---- & ---- & ---- & ---- & \\
\hline
\end{tabular}

${ }^{*} \underline{\underline{p}}<.05 ;{ }^{* *} \underline{\underline{p}}<.01 ; N=452 ;{ }^{*} \mathrm{n}=227 ;{ }^{\wedge} \mathrm{n}=225$

(table continues) 
Table 5 (continued)

\begin{tabular}{|c|c|c|c|c|c|c|c|c|c|c|c|c|}
\hline Variable & $27^{\wedge}$ & $28^{\wedge}$ & $29^{\wedge}$ & $30^{\wedge}$ & $31^{\wedge}$ & $32^{\wedge}$ & $33^{\wedge}$ & $34^{\#}$ & $35^{\#}$ & $36^{\wedge}$ & $37^{\wedge}$ & $38^{\wedge}$ \\
\hline 14. Global Self-Worth & -.01 & $.22^{* *}$ & -.09 & .11 & -.03 & $.20^{* *}$ & $-.14^{*}$ & $.19^{* *}$ & -.06 & -.08 & -.07 & -.10 \\
\hline 15. Social Acceptance & -.02 & .11 & .03 & -.06 & .07 & .07 & -.05 & .01 & -.03 & -.07 & -.08 & -.04 \\
\hline 16. PBI Care - Mom & $-.39^{\star *}$ & -.06 & -.06 & $.46^{* *}$ & $-.25^{\star \star}$ & -.04 & -.06 & -.04 & -.01 & -.09 & .07 & -.03 \\
\hline 17. PBI Control - Mom & $.27^{\star *}$ & -.05 & .10 & $-.30^{\star *}$ & $.27^{\star *}$ & -.12 & $.24^{* *}$ & -.10 & .07 & .06 & -.04 & -.03 \\
\hline 18. PBI Care - Dad & -.09 & $.40^{* *}$ & $-.27^{\star *}$ & .05 & -.05 & $.32^{* *}$ & $-.28^{* *}$ & .03 & -.11 & -.05 & -.01 & .06 \\
\hline 19. PBI Control - Dad & .11 & -.05 & $.20^{* *}$ & $-.25^{\star \star}$ & $.19^{* *}$ & $-.15^{*}$ & $.34^{* *}$ & -.12 & $.16^{*}$ & $.14^{*}$ & -.04 & -.06 \\
\hline $\begin{array}{l}\text { 20. NRI Social } \\
\text { Support - Sibings }\end{array}$ & $-.17^{*}$ & -.02 & -.06 & $.17^{*}$ & $-.18^{\star *}$ & .09 & $-.20^{* *}$ & -.01 & -.09 & -.12 & -.12 & -.02 \\
\hline $\begin{array}{l}\text { 21. NRI Negativity - } \\
\text { Siblings }\end{array}$ & .05 & .05 & $.15^{*}$ & -.08 & .13 & -.07 & $.23^{* *}$ & .07 & -.10 & .07 & .10 & .06 \\
\hline $\begin{array}{l}\text { 22. Maternal Affection" } \\
\text { (One Sib; SIDE-R) }\end{array}$ & ---- & ---- & ---- & ---- & ---- & ---- & ---- & -.12 & -.07 & ---- & ---- & ---- \\
\hline $\begin{array}{l}\text { 23. Maternal Control } \\
\text { (One Sib; SIDE-R) }\end{array}$ & ---- & ---- & ---- & ---- & ---- & ---- & ---- & .01 & .05 & ---- & ---- & ---- \\
\hline $\begin{array}{l}\text { 24. Paternal Affection\# }{ }^{\#} \text { (One Sib; SIDE-R) }\end{array}$ & ---- & ---- & ---- & ---- & ---- & ---- & ---- & -.08 & -.12 & ---- & ---- & ---- \\
\hline $\begin{array}{l}\text { 25. Paternal Control }{ }^{\#} \\
\text { (One Sib; SIDE-R) }\end{array}$ & ---- & ---- & ---- & ---- & ---- & ---- & ---- & .06 & .03 & ---- & ---- & ---- \\
\hline $\begin{array}{l}\text { 26. Maternal Affection } \\
\text { (Least Liked Sib; } \\
\text { SIDE-R) }\end{array}$ & $-.52^{\star *}$ & .01 & $-.16^{*}$ & $.58^{\star *}$ & $-.23^{\star *}$ & -.04 & .05 & ---- & ---- & -.04 & .09 & $-.15^{\star}$ \\
\hline
\end{tabular}

${ }^{*} \underline{p}<.05 ;{ }^{* *} \underline{p}<.01 ; N=452 ;{ }^{*} n=227 ;{ }^{\wedge}=225$

(table continues) 
Table 5 (continued)

\begin{tabular}{lccc}
\hline \multicolumn{1}{c}{ Variable } & $39^{\wedge}$ & 40 & 41 \\
\hline 14. Global Self-Worth & -.04 & -.05 & -.04 \\
15. Social Acceptance & $-.14^{\star}$ & -.04 & .06 \\
16. PBI Care - Mom & .10 & $-.09^{\star}$ & .08 \\
17. PBI Control - Mom & -.08 & .01 & -.04 \\
18. PBI Care - Dad & -.04 & $-.16^{\star \star}$ & $.14^{\star \star}$ \\
19. PBI Control - Dad & -.01 & .04 & $.10^{\star}$ \\
20. NRI Social Support - Sibings & -.04 & -.07 & .09 \\
21. NRI Negativity - Siblings & .01 & -.04 & -.08 \\
22. Maternal Affection\# (One Sib; SIDE-R) & ---- & -.04 & .11 \\
23. Maternal Control ${ }^{\#}$ (One Sib; SIDE-R) & ---- & -.08 & -.07 \\
24. Paternal Affection ${ }^{\#}$ (One Sib; SIDE-R) & ---- & .10 & .04 \\
25. Paternal Control\# (One Sib; SIDE-R) & ---- & .02 & $-.22^{\star \star}$ \\
26. Maternal Affection ${ }^{\wedge}$ (Least Liked Sib; & .10 & .08 & .02 \\
SIDE-R)
\end{tabular}

${ }^{*} \underline{p}<.05 ;{ }^{* *} \underline{p}<.01 ; N=452 ;{ }^{*} n=227 ;{ }^{\wedge} n=225$

(table continues) 
Table 5 (continued)

\begin{tabular}{|c|c|c|c|c|c|c|c|c|c|c|}
\hline Variable & $27^{\wedge}$ & $28^{\wedge}$ & $29^{\wedge}$ & $30^{\wedge}$ & $31^{\wedge}$ & $32^{\wedge}$ & $33^{\wedge}$ & $34^{\#}$ & $35^{\#}$ & $36^{\wedge}$ \\
\hline \multicolumn{11}{|l|}{$\begin{array}{l}\text { 27. Maternal Control^ (Least Liked Sib; } \\
\text { SIDE-R) }\end{array}$} \\
\hline $\begin{array}{l}\text { 28. Paternal Affection` (Least Liked Sib; } \\
\text { SIDE-R) }\end{array}$ & -.09 & & & & & & & & & \\
\hline $\begin{array}{l}\text { 29. Paternal Control }{ }^{\wedge} \text { (Least Liked Sib; } \\
\text { SIDE-R) }\end{array}$ & $.48^{* *}$ & $-.32^{\star \star}$ & & & & & & & & \\
\hline $\begin{array}{l}\text { 30. Maternal Affection (Most Liked Sib; } \\
\text { SIDE-R) }\end{array}$ & $-.30^{* *}$ & -.06 & -.07 & & & & & & & \\
\hline $\begin{array}{l}\text { 31. Maternal Control }{ }^{\wedge} \text { (Most Liked Sib; } \\
\text { SIDE-R) }\end{array}$ & $.43^{\star *}$ & .01 & $.19^{* *}$ & $-.46^{\star *}$ & & & & & & \\
\hline $\begin{array}{l}\text { 32. Paternal Affection^ (Most Liked Sib; } \\
\text { SIDE-R) }\end{array}$ & -.07 & $.59^{\star *}$ & $-.28^{\star *}$ & $.15^{\star}$ & $-.20^{* *}$ & & & & & \\
\hline $\begin{array}{l}\text { 33. Paternal Control }{ }^{\wedge} \text { (Most Liked Sib; } \\
\text { SIDE-R) }\end{array}$ & .05 & $-.16^{*}$ & $.40^{\star *}$ & $-.17^{*}$ & $.36^{\star \star}$ & $-.32^{* \star}$ & & & & \\
\hline 34. Age Difference Adol./One Sib.\# & ---- & ---- & ---- & ---- & ---- & ---- & ---- & & & \\
\hline 35. Gender Adol./One Sib. ${ }^{\# \&}$ & ---- & ---- & --- & ---- & ---- & ---- & ---- & .01 & & \\
\hline $\begin{array}{l}\text { 36. Age Difference Adol./Most Liked } \\
\text { Sib }^{\wedge}\end{array}$ & .01 & -.04 & -.04 & $-.20^{* *}$ & $.20^{* *}$ & $-.24^{* *}$ & .12 & ---- & ---- & \\
\hline
\end{tabular}

${ }^{*} \underline{\mathrm{p}}<.05 ;{ }^{* *} \underline{\mathrm{p}}<.01 ; \mathrm{N}=452 ;{ }^{*} \mathrm{n}=227 ;{ }^{n} \mathrm{n}=225 ;$

(table continues)

${ }^{\&}$ Gender of Adolescent and Sibling coded as 1 = same gender and $2=$ opposite gender . 
Table 5 (continued)

\begin{tabular}{|c|c|c|c|c|c|}
\hline Variable & $37^{\wedge}$ & $38^{\wedge}$ & $39^{\wedge}$ & 40 & 41 \\
\hline $\begin{array}{l}\text { 27. Maternal Control` (Least Liked Sib; } \\
\text { SIDE-R) }\end{array}$ & $-.15^{*}$ & .11 & $-.18^{* *}$ & .02 & -.05 \\
\hline $\begin{array}{l}\text { 28. Paternal Affection` (Least Liked Sib; } \\
\text { SIDE-R) }\end{array}$ & -.01 & $-.14^{*}$ & -.09 & -.13 & .07 \\
\hline $\begin{array}{l}\text { 29. Paternal Control }{ }^{\wedge} \text { (Least Liked Sib; } \\
\text { SIDE-R) }\end{array}$ & -.03 & .02 & -.09 & $.14^{*}$ & -.02 \\
\hline $\begin{array}{l}\text { 30. Maternal Affection (Most Liked Sib; } \\
\text { SIDE-R) }\end{array}$ & .08 & -.08 & .11 & -.01 & $-.15^{\star}$ \\
\hline $\begin{array}{l}\text { 31. Maternal Control }{ }^{\wedge} \text { (Most Liked Sib; } \\
\text { SIDE-R) }\end{array}$ & -.10 & .11 & -.12 & -.01 & .10 \\
\hline $\begin{array}{l}\text { 32. Paternal Affection^ (Most Liked Sib; } \\
\text { SIDE-R) }\end{array}$ & -.13 & -.08 & .06 & -.11 & -.10 \\
\hline $\begin{array}{l}\text { 33. Paternal Control }{ }^{\wedge} \text { (Most Liked Sib; } \\
\text { SIDE-R) }\end{array}$ & .06 & .03 & -.04 & .12 & .04 \\
\hline 34. Age Difference Adol./One Sib.\# & ---- & ---- & ---- & $-.14^{*}$ & -.09 \\
\hline 35. Gender Adol./One Sib.\#\& & ---- & ---- & ---- & .12 & .06 \\
\hline $\begin{array}{l}\text { 36. Age Difference Adol./Most Liked } \\
\text { Sib }^{\wedge}\end{array}$ & -.03 & $.39^{* *}$ & .01 & .02 & .12 \\
\hline
\end{tabular}

${ }^{*} \underline{\mathrm{p}}<.05 ;{ }^{* *} \underline{\mathrm{p}}<.01 ; \mathrm{N}=452 ;{ }^{*} \mathrm{n}=227 ;{ }^{\wedge} \mathrm{n}=225$

(table continues)

${ }^{\&}$ Gender of Adolescent and Sibling coded as 1 = same gender and 2 = opposite gender . 
Table 5 (continued)

\begin{tabular}{lccccc}
\hline \multicolumn{1}{c}{ Variable } & $37^{\wedge}$ & $38^{\wedge}$ & $39^{\wedge}$ & 40 & 41 \\
\hline 37. Gender Adol./Most Liked Sib. ${ }^{\wedge}$ & & & & & \\
38. Age Difference Adol./Least Liked Sib. & -.05 & & & & \\
39. Gender Adol./Least Liked Sib. ${ }^{\wedge}$ & .01 & .05 & & & \\
40. Age of Adolescent & -.01 & $-.14^{\star}$ & -.02 & & \\
41. Gender of Adolescent\% & -.01 & .09 & -.03 & -.02 & \\
\hline
\end{tabular}

${ }^{*} \underline{p}<.05 ;{ }^{* *} \underline{p}<.01 ; N=452 ;{ }^{*} n=227 ;{ }^{\wedge}=225$

$\%$ Gender of Adolescent was coded as $1=$ male and $2=$ female.

${ }^{\&}$ Gender of Adolescent and Sibling coded as $1=$ same gender and $2=$ opposite gender . 
Table 6

Means and Standard Deviations for Late Adolescent Adjustment Outcomes

by Maternal Parenting Styles

\begin{tabular}{|c|c|c|c|c|c|c|c|c|c|}
\hline \multirow[b]{3}{*}{ Adjustment Outcomes } & \multicolumn{4}{|c|}{ Maternal } & \multicolumn{4}{|c|}{ Parenting Styles } & \multirow[b]{3}{*}{$\eta^{2}$} \\
\hline & \multicolumn{2}{|c|}{ Optimal } & \multicolumn{2}{|c|}{$\begin{array}{c}\text { Affectionate } \\
\text { Constraint }\end{array}$} & \multicolumn{2}{|c|}{$\begin{array}{l}\text { Affectionless } \\
\text { Control }\end{array}$} & \multicolumn{2}{|c|}{$\underline{\text { Neglectful }}$} & \\
\hline & $\underline{M}$ & $\underline{\mathrm{SD}}$ & $\underline{M}$ & $\underline{\mathrm{SD}}$ & $\underline{M}$ & $\underline{\mathrm{SD}}$ & $\underline{M}$ & $\underline{\mathrm{SD}}$ & \\
\hline Agoraphobia & 17.44 & 11.09 & 19.98 & 11.56 & 22.04 & 11.96 & 17.45 & 10.02 & .01 \\
\hline Social Anxiety & $32.24 a$ & 24.21 & $44.32_{b}$ & 27.50 & $54.20_{b}$ & 27.73 & 42.05 & 25.43 & .06 \\
\hline General Anxiety & $9.30_{a}$ & 8.66 & 11.23 & 8.07 & $13.22_{b}$ & 8.98 & 9.47 & 6.69 & .02 \\
\hline Global Self-Worth & $3.38_{a}$ & .58 & $3.01_{b}$ & .62 & $2.75_{b}$ & .68 & $3.06_{b}$ & .60 & .06 \\
\hline Social Acceptance & $3.24_{a}$ & .68 & $3.01_{b}$ & .70 & $2.71_{b}$ & .77 & 3.04 & .71 & .02 \\
\hline
\end{tabular}

Note: Means with different subscripts significantly differ from each other, $p<.01$.

Only parenting styles that are significantly different from the optimal parenting style are annotated. 


\section{Table 7}

Means and Standard Deviations for Late Adolescent Adjustment Outcomes

\section{by Parenting Styles}

\begin{tabular}{|c|c|c|c|c|c|c|c|c|c|}
\hline \multirow[b]{3}{*}{ Adjustment Outcomes } & \multicolumn{4}{|c|}{ Parenting } & \multicolumn{4}{|c|}{ Styles } & \multirow[b]{3}{*}{$\eta^{2}$} \\
\hline & \multicolumn{2}{|c|}{ Optimal } & \multicolumn{2}{|c|}{$\begin{array}{c}\text { Affectionate } \\
\text { Constraint }\end{array}$} & \multicolumn{2}{|c|}{$\begin{array}{l}\text { Affectionless } \\
\text { Control }\end{array}$} & \multicolumn{2}{|c|}{$\underline{\text { Neglectful }}$} & \\
\hline & $\underline{M}$ & $\underline{\mathrm{SD}}$ & $\underline{M}$ & $\underline{\mathrm{SD}}$ & $\underline{M}$ & $\underline{\mathrm{SD}}$ & $\underline{M}$ & $\underline{\mathrm{SD}}$ & \\
\hline Agoraphobia & $17.10_{a}$ & 10.96 & 19.79 & 12.76 & $22.15_{b}$ & 11.57 & 17.73 & 9.82 & .04 \\
\hline Social Anxiety & $33.35 a$ & 25.55 & 41.00 & 25.15 & $54.11_{b}$ & 28.26 & 41.70 & 24.61 & .10 \\
\hline General Anxiety & $8.86_{a}$ & 8.21 & 11.03 & 8.54 & $13.80_{b}$ & 9.09 & 10.24 & 7.12 & .05 \\
\hline Global Self-Worth & $3.46_{a}$ & .55 & $3.07_{b}$ & .60 & $2.72_{b}$ & .69 & $3.05_{b}$ & .57 & .19 \\
\hline Social Acceptance & $3.32_{a}$ & .65 & $3.01_{b}$ & .72 & $2.63_{b}$ & .74 & 2.99 & .76 & .14 \\
\hline
\end{tabular}

Note: Means with different subscripts significantly differ from each other, $\mathrm{p}<.05$.

Only parenting styles that are significantly different from the optimal parenting style are annotated. 


\section{Table 8}

Means and Standard Deviations for Late Adolescent Adjustment Outcomes

by Sibling Relationship Categories

Sibling Relationship Categories

\begin{tabular}{cccc}
\hline $\begin{array}{c}\text { High Social Support/ } \\
\text { Low Negativity }\end{array}$ & $\begin{array}{c}\text { High Social Support/ } \\
\text { High Negativity }\end{array}$ & $\begin{array}{c}\text { Low Social Support/ } \\
\text { High Negativity }\end{array}$ & $\begin{array}{c}\text { Low Social Support/ } \\
\text { Low Negativity }\end{array}$
\end{tabular}

\begin{tabular}{|c|c|c|c|c|c|c|c|c|c|}
\hline Adjustment Outcomes & $\underline{M}$ & $\underline{\mathrm{SD}}$ & $\underline{M}$ & $\underline{\mathrm{SD}}$ & $\underline{M}$ & $\underline{\mathrm{SD}}$ & $\underline{M}$ & $\underline{\mathrm{SD}}$ & $\eta^{2}$ \\
\hline Agoraphobia & $18.09_{a}$ & 10.52 & $22.93_{b}$ & 11.94 & 20.64 & 12.35 & 17.90 & 9.64 & .02 \\
\hline Social Anxiety & $36.88_{a}$ & 26.92 & 45.32 & 27.69 & $46.37_{b}$ & 25.23 & $46.86_{b}$ & 28.27 & .02 \\
\hline General Anxiety & 10.27 & 8.18 & 11.63 & 8.57 & $12.48_{a}$ & 9.21 & $9.11_{b}$ & 6.60 & .02 \\
\hline Depression & $9.33_{a}$ & 7.09 & $12.44_{b}$ & 8.21 & $12.81_{b}$ & 9.02 & 9.70 & 7.17 & .03 \\
\hline Global Self-Worth & $3.20_{a}$ & .60 & $2.96_{b}$ & .66 & $2.97_{b}$ & .71 & 3.06 & .66 & .02 \\
\hline Social Acceptance & $3.21_{\mathrm{a}}$ & .68 & 2.97 & .75 & $2.90_{b}$ & .74 & $2.91_{b}$ & .74 & .03 \\
\hline
\end{tabular}

Note: Means with different subscripts significantly differ from each other, $p<.05$.

With the exception of general anxiety, only sibling relationship categories that are

significantly different from the high social support/low negativity sibling relationship category are annotated. 
Table 9

Means and Standard Deviations for Late Adolescent Adjustment Outcomes

by Parental Favoritism Categories

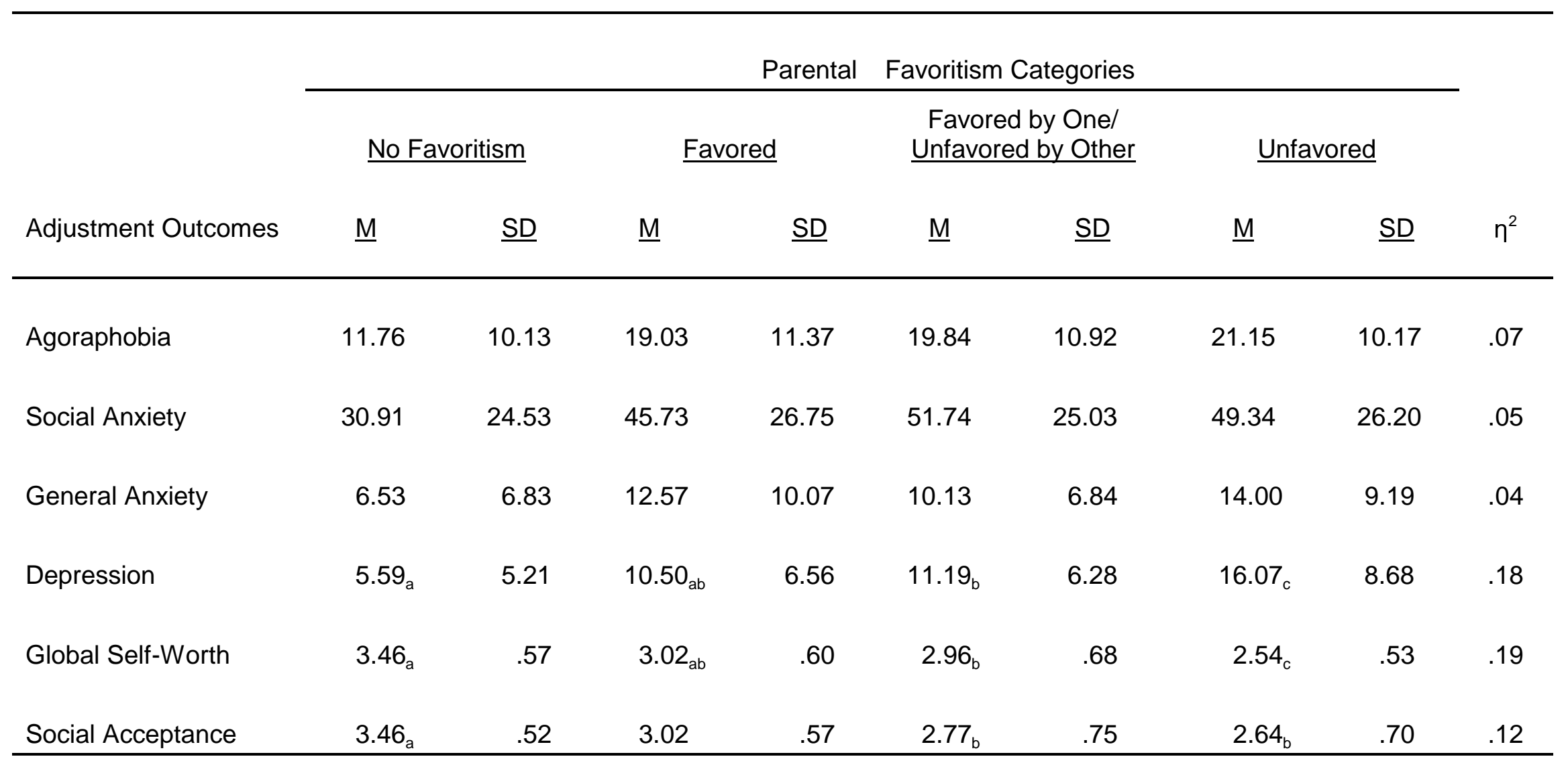

Note: Means with different subscripts significantly differ from each other, $p<.05$. 
Table 10

Means and Standard Deviations for Late Adolescent Adjustment Outcomes

by Family Relationship Variables

\begin{tabular}{|c|c|}
\hline Family & Relationship Variables \\
\hline At Least & \\
\hline One Present & None Present \\
\hline
\end{tabular}

\begin{tabular}{lccccc} 
Adjustment Outcomes & $\underline{\mathrm{M}}$ & $\underline{\mathrm{SD}}$ & $\underline{\mathrm{M}}$ & $\underline{\text { SD }}$ & $\eta^{2}$ \\
\hline Agoraphobia & 14.81 & 11.49 & 19.68 & 11.38 & .06 \\
Social Anxiety & $35.48_{\mathrm{a}}$ & 25.21 & $53.75_{\mathrm{b}}$ & 23.71 & .17 \\
General Anxiety & 8.66 & 7.23 & 13.44 & 9.17 & .05 \\
Depression & $7.94_{\mathrm{a}}$ & 7.67 & $14.28_{\mathrm{b}}$ & 8.49 & .12 \\
Global Self-Worth & $3.27_{\mathrm{a}}$ & .66 & $2.65_{\mathrm{b}}$ & .52 & .24 \\
Social Acceptance & $3.23_{\mathrm{a}}$ & .62 & $2.67_{\mathrm{b}}$ & .69 & .25 \\
\hline
\end{tabular}

Note: Means with different subscripts significantly differ from each other, $p<.01$. 
Appendix

Please answer the following questions about yourself.

1. Age:

2. Gender (check one): Male Female

3. What is your student classification (check one)?

Fr. Soph. Jr. Sr.

4. What is your ethnic group (check one)? Caucasian African-American Asian Hispanic American Indian Other

5. Relationship Status (check one): Single Living with Romantic Partner

Married

6. Please answer the following information on your sibling(s), if applicable:

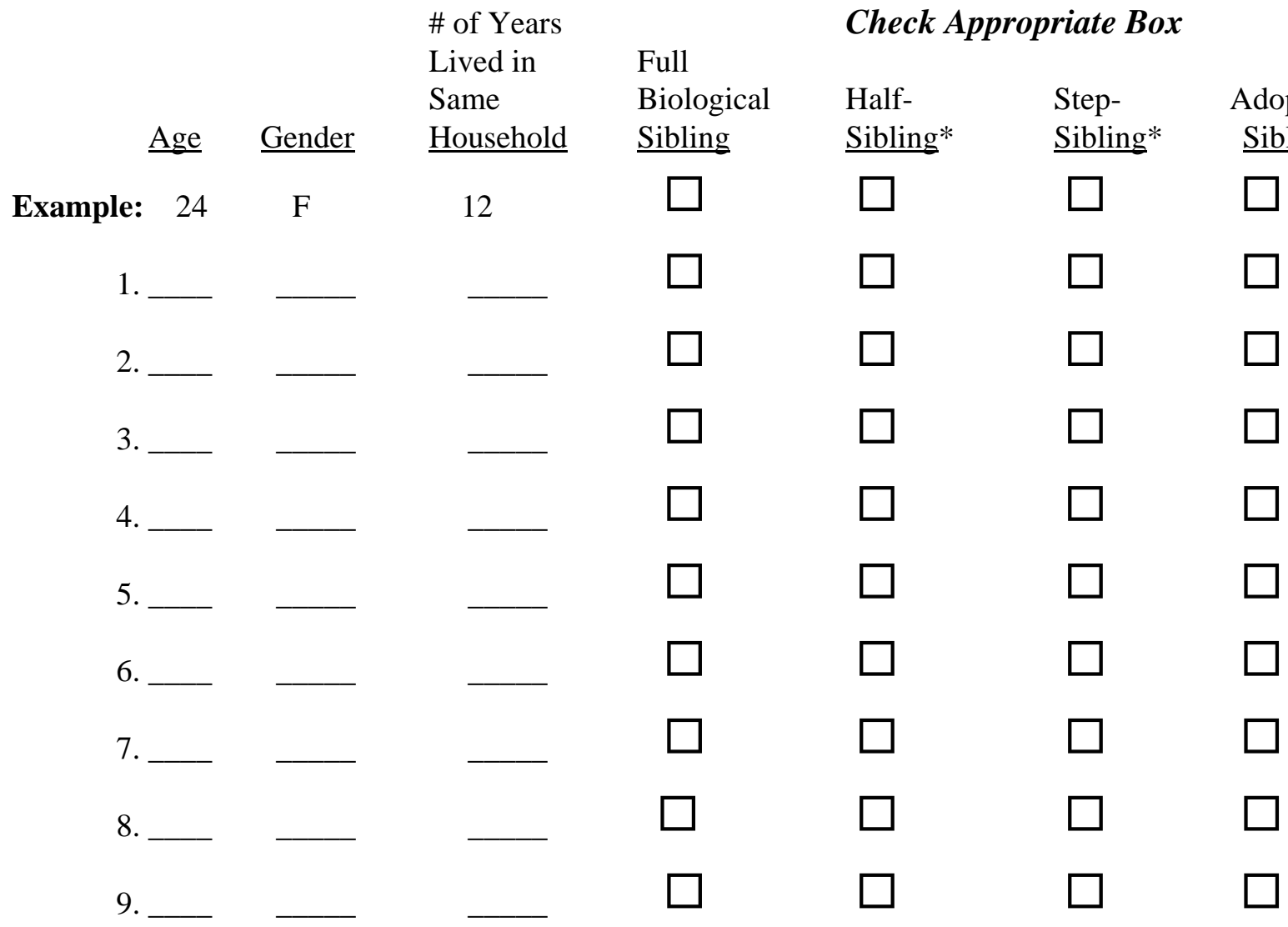

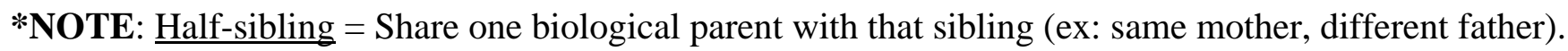

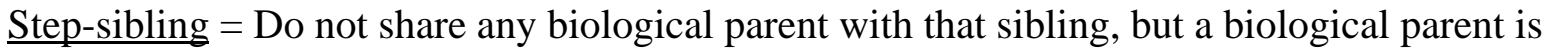
married to that sibling's mother or father. 
7. Your biological/adoptive parents were (check one):

Never Married
Still Married to One Another
Divorced

8. Did you live with a step-parent while you were growing up (circle one)?

Yes No

9. How many years (from birth to age 18) did you live in the same household with your:

Biological/Adoptive Mother
Biological/Adoptive Father
Step-Mother (if applicable)
Step-Father (if applicable)
Female Guardian (Please specify: ___
Male Guardian (Please specify: __

10. What is the age of your:

Biological/Adoptive Mother

Biological/Adoptive Father

Step-Mother (if applicable)

Step-Father (if applicable)

Female Guardian (Please specify:

Male Guardian (Please specify: 
Answer the following questions on the female and male parent figure you lived with the longest.

I will answer the following question on my (please circle one):

$$
\text { Biological/Adoptive Mother Step-Mother } \quad \text { Female Guardian }
$$

11. During your childhood and adolescence, did your female parent figure express any concerns about herself on these mental health issues: (please check all that apply)

Depression

Shyness

Anxiety and excessive worry

Low self-esteem or confidence

I will answer the following question on my (please circle one):

$$
\text { Biological/Adoptive Father Step-Father Male Guardian }
$$

12. During your childhood and adolescence, did your male parent figure express any concerns about himself on these mental health issues: (please check all that apply)

Depression

Shyness

Anxiety and excessive worry

Low self-esteem or confidence 